Everton Luiz Kotarski

Variações glacial - interglacial nos últimos $\mathbf{8 0 0}$ mil anos inferidas a partir da deposição de sedimentos da fração fina (Sortable Silt) em um testemunho da bacia de santos

Dissertação apresentada ao Instituto Oceanográfico da Universidade de São Paulo, como parte dos requisitos para obtenção do titulo de Mestre em Ciências, Programa de Oceanografia, área de Oceanografia Geológica.

Orientador: Prof. Dr. Felipe Antonio de Lima Toledo

São Paulo 
Universidade de São Paulo

Instituto Oceanográfico

\section{VARIAÇÕES GLACIAL - INTERGLACIAL NOS ULTIMOS 800 MIL ANOS INFERIDAS APARTIR DA DEPOSIÇÃO DE SEDIMENTOS DA FRAÇÃO FINA (Sortable Silt) EM UM TESTEMUNHO DA BACIA DE SANTOS}

\section{Everton Luiz Kotarski}

Dissertação apresentada ao Instituto Oceanográfico da Universidade de São Paulo, como parte dos requisitos para obtenção do título de Mestre em Ciências, área de Oceanografia Geológica.

Julgada em

Conceito

$\operatorname{Prof}(\mathrm{a}) . \operatorname{Dr}(\mathrm{a})$.

Conceito

Prof(a). Dr(a).

Conceito

Prof(a). Dr(a). 


\section{Agradecimentos}

Aos Profs., Dr. Felipe Toledo e Dr. ${ }^{a}$ Karen Costa pela incrível orientação, por toda sua dedicação e pela amizade ao longo de todos esses anos de trabalho além é claro, dos inúmeros auxílios, broncas e incentivos não somente na conclusão desse trabalho. Agradeço profundamente todos os ensinamentos sobre tudo dentro e fora da vida acadêmica. Sou incrivelmente sortudo por ter tido a oportunidade de encontrar pessoas tão maravilhosas e positivas em meu caminho, ainda mais por não deixarem que estereótipos afetassem seus julgamentos. Poderia escrever inúmeras páginas do quão sensacional você são, mas me restrinjo a apenas a agradecer por enxergarem em mim um potencial que muitas vezes eu mesmo ignoro.

Aos meus pais e minha irmã por todos os incentivos, e por todas as vezes em que fizeram cara de interessados mesmo não compreendendo o que eu faço no intuito de me apoiar. Aos meus pais, que sonhavam com o filho vindo para São Paulo e se tornando doutor, terão que sem contentar por hora com um mestre.

Agradeço também a toda equipe do LaPAS, tanto pela ajuda durante a elaboração da dissertação, quanto pela descontração e pelas conversas. Em especial, um agradecimento ao "Burns" por todas as vezes que mandou mensagem lembrando de entregar algo, a Mari que sempre foi muito solícita a qualquer pedido de ajuda e a Juliana por toda a sua preocupação e interesse ao longo da dissertação.

Ao Prof. Dr. Michel Michaelovitch de Mahiques por permitir o uso do malvern e por toda a disposição apresentada para tirar minhas dúvidas quanto as analises, que infelizmente o tempo não permitiu, mas mesmo assim muito obrigado.

Agradeço a CAPES pelo apoio financeiro.

Agradecer especialmente ao pessoal do SEREIAS, que por mais que não estejam atualmente competindo ativamente no circuito universitário, esse grupo de pessoas singulares, peculiares, exóticas, extraordinárias e de bom coração, oferecereu seu apoio incondicional sem questionar meu afastamento, sempre dispostos a ajudar e oferecer uma espetacular conversa, sempre fornecendo seu total apoio. 
A Mayza, que sempre esteve disposta a me ouvir independentemente do assunto e da hora, solucionando ou me guiando para várias resoluções emocionais.

A minha esposa, melhor amiga, maior revisora e maior leitora deste trabalho, Nara Nami V. Kotarski. Sem seus inúmeros incentivos e sua inigualável empatia por minhas frustrações, fazendo até com que eu eu esquecesse que as frustrações eram minhas. Obrigado por não ficar brava todas as vezes que eu te acordava as $3 \mathrm{~h}$ da manhã para querer te explicar algo, simplesmente para ver se fazia sentido ou porque precisava conversar com alguém, muito obrigado mesmo por aturar tantas oscilações de humor. E por, inacreditavelmente, conseguir falar Sortable Silt de um modo sexy.

E a todos aqueles que esqueci de citar aqui, façam mais da próxima vez. 


\section{Resumo}

Neste estudo, o tamanho médio do Sortable Silt da fração $<63$ micra dos sedimentos terrígenos foi medido em um testemunho para os últimos 800 ka na Bacia de Santos. Os estágios isotópicos marinhos (MIS) foram identificados até MIS o 19. Investigamos as variações oceanográficas passadas para obter uma melhor compreensão sobre a intensidade do fluxo de corrente de fundo durante os períodos glaciais / interglaciais. Os registros contínuos do Sortable Silt, isótopos de oxigênio e carbono, susceptibilidade magnética, taxa de sedimentação, fluxos de massa e conteúdo de carbonato foram obtidos e mostraram uma forte modulação com a intensidade do fluxo de corrente de fundo em resposta a ciclos glaciais e interglaciais. Em geral, para os períodos glaciais, foi possível observar uma dominância do deslocamento da água do fundo em direção ao norte. Uma comparação entre diferentes métodos de análise granulométrica (laser e técnica de pipetagem), revelou que ambos caracterizam os períodos interglacial e glacial. As análises espectrais mostraram um forte sinal no Sortable Silt para os ciclos da excentricidade ( $100 \mathrm{ka}$ ), o que foi confirmado pelos isótopos de oxigênio e susceptibilidade magnética, que apresentaram um sinal similar. Variações concomitantes no Sortable Silt e nos diferentes traçadores confirmam o potencial do primeiro como um proxy para a intensidade do fluxo de corrente de fundo.

Palavras-chave: Sortable Silt, Bacia de Santos, correntes de fundo. 


\section{Abstract}

In this study, the Sortable Silt mean size of the $<63$ micra terrigenous sediment fraction were measured in a core for the last 800kyrs in Santos Basin. Marine Isotopic Stages (MIS) down to MIS 19 were identified. We investigate the past oceanographic variations to obtain a better understanding about bottom-current flow intensity during glacial/interglacial periods. Continuous records of Sortable Silt, oxygen and carbon isotopes, magnetic susceptibility, sedimentation rate, mass fluxes and carbonate content were obtained and show a strong modulation of bottom-current flux intensity in response to glacial and interglacial cycles. In general, for glacial periods it was possible to observe a dominance of northward bottom water. A comparison between different methods of grain-size analysis (laser and the pipetting technique), revealed that both characterize the interglacial and glacial periods. The spectral analyzes showed a strong signal in the Sortable Silt for the cycles of the eccentricity ( 100 ka), which was confirmed by the oxygen isotopes and magnetic susceptibility, which presented a similar signal. Concomitant variations in the Sortable Silt and in the different tracers confirms the potential of the first as a proxy for bottom-current flow intensity. 
Sumário

Agradecimentos i

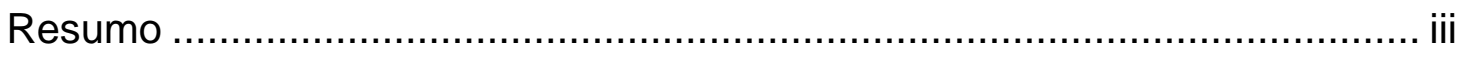

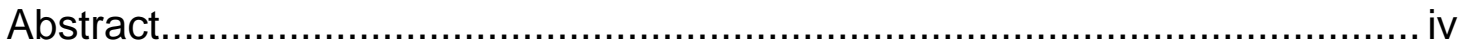

Lista de Figuras ............................................................................... vii

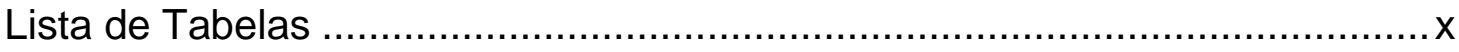

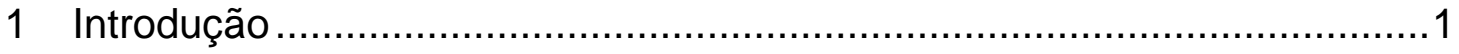

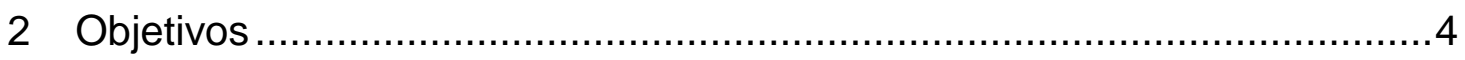

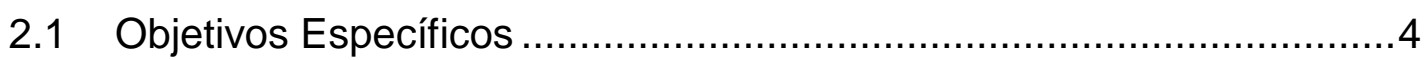

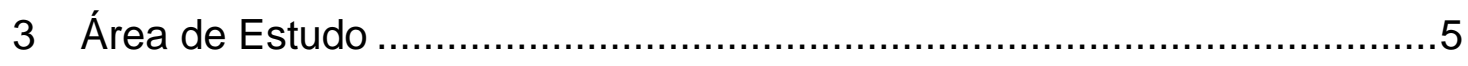

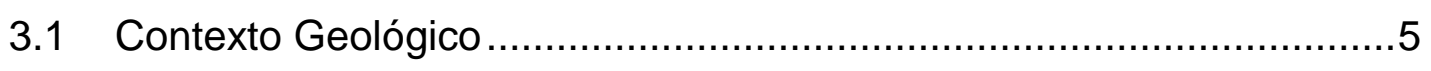

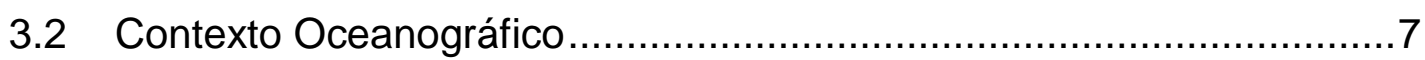

4 Materiais e Métodos ............................................................... 13

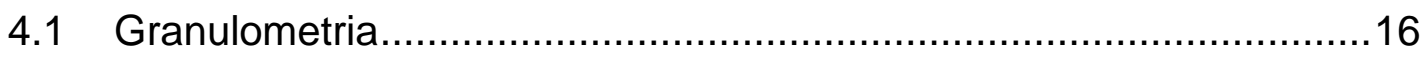

4.1.1 Análise Granulométrica a Laser .........................................17

4.1.2 Análise Granulométrica através do princípio da velocidade de sedimentação, técnica da pipetagem .................................................. 18

4.2 Análise Espectral...................................................................21

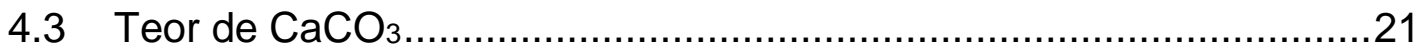

4.4 Susceptibilidade Magnética ..................................................22

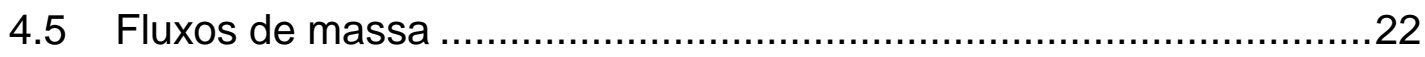

4.6 Isótopos de Oxigênio e de Carbono...........................................25

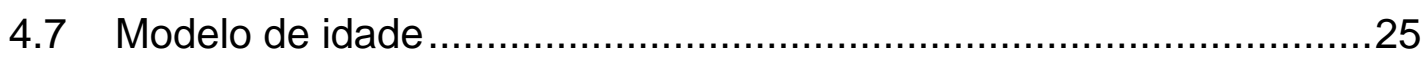

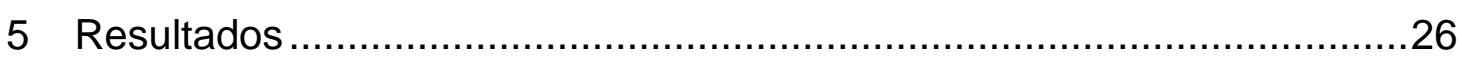

5.1 Isótopos de Oxigênio e Estratigrafia Isotópica .............................26 
5.2.1 Laser

5.2.2 Análise Granulométrica através do princípio da velocidade de sedimentação, técnica da pipetagem .36

5.2.3 Comparação do Sortable Silt. 41

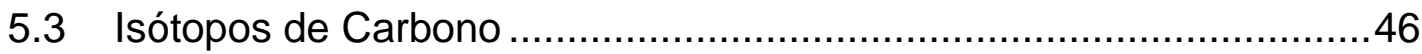

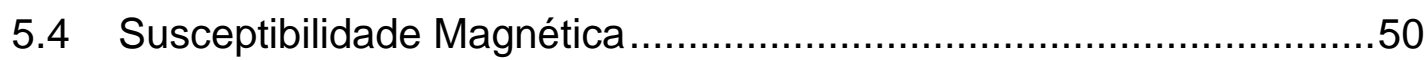

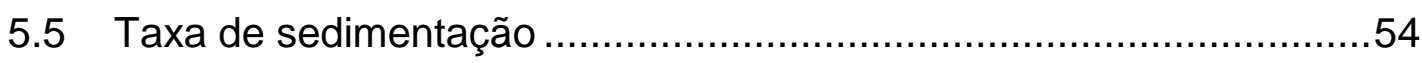

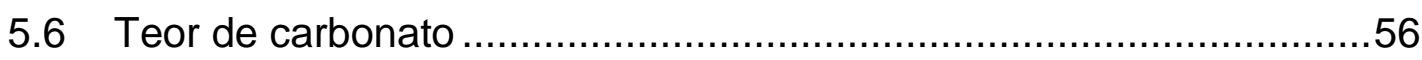

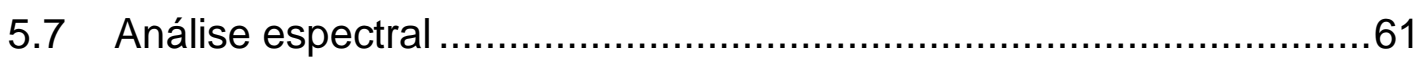

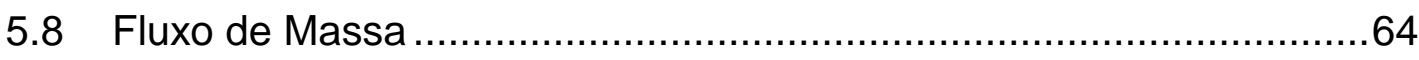

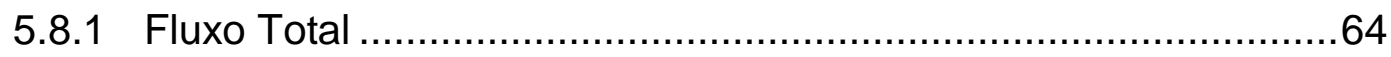

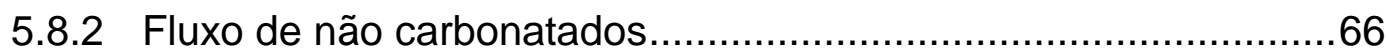

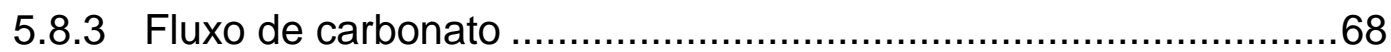

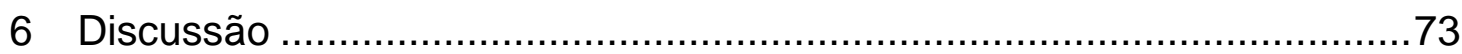

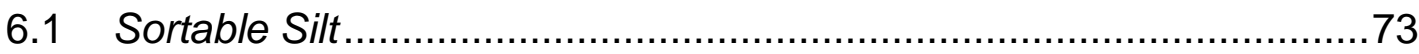

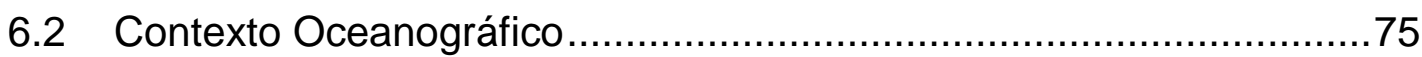

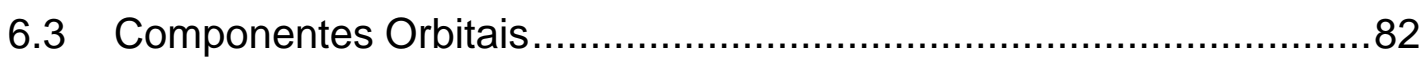

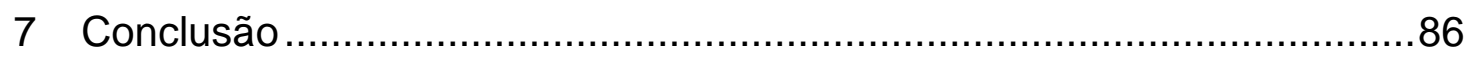

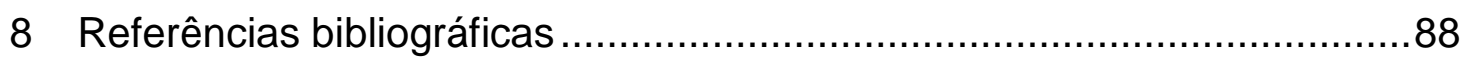




\section{Lista de Figuras}

Figura 1: Caracterização de massas d'água do Atlântico Sul na região de localização dos testemunhos deste estudo (modificado de Matsuura, 1986)

Figura 2: Modelo geral do transporte de calor nos oceanos.

Figura 3: Modelo geral da circulação termohalina, proposta por Broecker (1995)...11

Figura 4: Localização do testemunho KF-18 na margem continental sudeste brasileira, porção oeste do Atlântico Sul.

Figura 5: Estruturas e litologia do testemunho KF-18.

Figura 6: Curva da razão isotópica do oxigênio em foraminíferos bentônicos do testemunho KF-18. Assinalado em cinza estão os estágios isotópicos interglaciais. 26

Figura 7: Índice de Sortable Silt a partir da análise a laser. Assinalado em cinza estão os estágios isotópicos interglaciais.

Figura 8: Sortable Silt a partir da análise com o princípio da velocidade de sedimentação, técnica da pipetagem. Assinalado em cinza estão os estágios isotópicos interglaciais.

Figura 9: Comparação entre o índice de Sortable Silt a (a) laser e a (b) partir do princípio da velocidade de sedimentação.

Figura 10:Média por período do Sortable Silt entre os métodos, onde SS_M é a análise realizada no Malvern e SS_P é a análise realizada pela técnica da pipetagem.

Figura 11: Curva da razão isotópica do carbono em foraminíferos bentônicos do testemunho KF-18. Assinalado em cinza estão os estágios isotópicos interglaciais. 47 Figura 12: Susceptibilidade magnética ao longo do período. Assinalado em cinza estão os estágios isotópicos interglaciais

Figura 13: Taxa de sedimentação linear. Assinalado em cinza estão os estágios isotópicos interglaciais. .55 
Figura 14: Teor de Carbonato. Assinalado em cinza estão os estágios isotópicos interglaciais.

Figura 15: (a) Curva da razão isotopica do oxigeno e (b) susceptibilidade magnetica. Assinalado em cinza estão os estágios isotópicos interglaciais

Figura 16: Frequência dos isotopos de oxigênio. 63

Figura 17: Frequência da susceptibilidade magnética. .63

Figura 18: Frequência do Sortable Silt a laser.

Figura 19: Fluxo de massa total. Assinalado em cinza estão os estágios isotópicos interglaciais.

Figura 20: Fluxo de sedimento terrigeno em g/cm2/ka.Assinalado em cinza estão os estágios isotópicos interglaciais.

Figura 21: Fluxo de carbonato em $\mathrm{g} / \mathrm{cm}^{2} / \mathrm{ka}$.Assinalado em cinza estão os estágios isotópicos interglaciais.

Figura 22: Índice para a potência das correntes a partir do sedimento fino desenvolvido por Ledbetter em 1986, relacionando a velocidade das correntes de fundo com o Sortable Silt nas escalas (esquerda) phi $(\Phi)$ e (direita) $\mu \mathrm{m}$ .74

Figura 23: (a) Fluxo de não carbonatados; (b) Susceptibilidade Magnética;(c) teor de carbonato; (d) Sortable Silt a laser. Assinalado em cinza estão os estágios isotópicos interglaciais. A linha numerada identifica os intervalos indicados no texto. .77

Figura 24: Relação entre Isotopos de Oxigênio em foraminiferos bentonicos e a variação relativa do nivel do mar obtida por WAELBROECK et al.( 2002). .78

Figura 25: Comparação entre a (a) isótopos de oxigênio e o (b) Sortable Silt a laser. Assinalado em cinza estão os estágios isotópicos interglaciais

Figura 26: Comparação entre a (a) razão dos isótopos de carbono com o (b) Sortable Silt a laser. Assinalado em cinza estão os estágios isotópicos interglaciais.

Figura 27: Curva do (a) Teor de carbonato e (b) do Sortable Silt. Assinalado em cinza estão os estágios isotópicos interglaciais. .82 
Figura 28: Análise de frequências para: (a) Susceptibilidade magnética, (b) isótopos de oxigênio e (c) Sortable Silt a laser. Os períodos marcados em cinza correspondem a 100, 41 e 23 mil anos da esquerda para a direita. ............................................. 84 


\section{Lista de Tabelas}

Tabela 1: Relação entre o tempo e a profundidade da coleta das alíquotas durante a técnica da pipetagem, a sequência de coleta esta representada abaixo dos intervalos.

Tabela 2: Parâmetros estatísticos extraídos da razão isotópica de oxigênio em foraminíferos bentônicos.

Tabela 3: Parâmetros estatísticos extraídos do Sortable Silt a laser. .36

Tabela 4: Parâmetros estatísticos extraídos do Sortable Silt a com o princípio da velocidade de sedimentação, técnica da pipetagem.

Tabela 5: Parâmetros estatísticos extraídos da comparação entre os índices de Sortable Silt ponto a ponto e em relação a média, onde SS_M é a análise realizada no Malvern e SS_P é a análise realizada pela técnica da pipetagem.

Tabela 6: Percetis extraídos do Sortable Silt a laser e com o princípio da velocidade de deposição, onde SS_M é a análise realizada no Malvern e SS_P é a análise realizada pela técnica da pipetagem.

Tabela 7: Categorização da média por período. .45

Tabela 8: Parâmetros estatísticos extraídos da razão isotópica do carbono em foraminíferos bentônicos. .50

Tabela 9: Parâmetros estatísticos extraídos da susceptibilidade magnética. 54

Tabela 10: Taxa de sedimentação linear em cm/ka. .56

Tabela 11: Parâmetros estatísticos extraídos do teor de carbonato. .61

Tabela 12: Fluxo total médio em $\mathrm{g} / \mathrm{cm} 1 / \mathrm{ka}$. .66

Tabela 13: Fluxo médio de não carbonatados (terrígeno). .68

Tabela 14: Parâmetros estatísticos extraídos do fluxo de carbonato. 72 


\section{Introdução}

Nos últimos anos as variações climáticas tem sido alvo de inúmeros estudos, que ganham mais evidência após eventos catastróficos como inundações, derretimento de geleiras, variações no nível do mar ou alterações nas temperaturas médias globais. As causas e mecanismos de funcionamento dessas variações muitas vezes são desconhecidos ou erroneamente interpretados. Sabe-se, no entanto, que, essas alterações no clima ocorreram durante todo o período geológico desde a formação da Terra. Nos últimos 2,5 milhões de anos, é possível constatar que a Terra vem sofrendo variações cíclicas marcadas por períodos glaciais e interglaciais (URIARTE, 2010). O estudo dessas variações cíclicas é de fundamental importância para o entendimento da formação e alteração do clima do planeta e de sua atual distribuição geográfica.

Os estudos de Paleoceanografia fornecem subsídios importantes para um melhor entendimento entre a interação do oceano e atmosfera, que é essencial para a geração e manutenção das circulações atmosféricas e oceânicas que influenciam na distribuição de calor. Esses mecanismos de distribuição de calor são eficinêntes devido a irregularidade da incidência de radiação solar (ocasionada pela esfericidade do planeta), sendo a incidência de radiação máxima no equador e decrescente em direção aos polos (WALLACE \& HOBBS, 2006).

A partir de estudos em testemunhos de gelo, foi possível constatar que durante os últimos 800 mil anos o planeta sofreu oito períodos glaciais e interglaciais, com variação na intensidade de formação das massas de águas profundas (LÜTHI et al., 2008). No Atlântico, ocorreram variações na intensidade das massas de água, como o enfraquecimento da APAN (Água Profunda do Atlântico Norte) durante o último máximo glacial, sendo esta diminuição compensada, em grande parte, pela intensificação de outros fluxos na coluna de água, como a intensificação de massas de água intermediarias (HENDERSON; ANDERSON, 2003). As alterações nas propriedades físicas das águas superficiais nas regiões de formação de massas de água refletem no mecanismo de funcionamento da termohalina, podendo intensificar 
ou enfraquecer a sua formação, afetando o fluxo de calor, refletindo em variações na temperatura média global (PIOLA et al., 2003).

Na Bacia de Santos, os últimos eventos registrados de variação no nível médio do mar que foram influenciados pelos seguintes eventos glaciais e interglaciais: $A$ Transgressão de Cananeia, denominada como o evento de elevação relativa do nível do mar em cerca de 8 metros acima do atual, que ocorreu há aproximadamente 120 mil anos. (SUGUIO \& MARTIN, 1978). A seguir ocorreu uma diminuição do nível do mar, em torno de 130 metros, expondo grande parte da plataforma costeira. O último evento marcante de variação do nível do mar ocorreu Há 5.600 anos, denominado Transgressão Santos, com uma elevação de 5 metros acima do atual, desde então ocorreu uma regressão marinha até o nível do mar atual (SUGUIO \& MARTIN, 1987).

A plataforma continental da Bacia de Santos é constituída de províncias fisiográficas submersas de baixa declividade, que se estendem da região costeira até a quebra do talude. Esta região está mais propicia a sofrer alterações devido aos eventos de variação do nível do mar, tornando-a parcialmente ou totalmente exposta (TEIXEIRA et al., 2000).

A margem continental sudeste brasileira, compreendida entre as coordenadas geográficas $24^{\circ}-S$ e $27^{\circ}-S$ (englobando a Bacia de Santos), demonstra uma transição entre a dominância da Corrente do Brasil (CB) e a Corrente Costeira do Brasil (CCB). A CB fornece para a plataforma continental minerais argilosos de regiões equatoriais, enquanto a CCB fornece os sedimentos finos provenientes do Rio da Prata (NAGAI et al., 2014) que, ocasionalmente, são transportados para fora da plataforma por meandros provenientes da CB, ocasionando assim a deposição em oceano profundo de sedimentos provenientes dos Pampas argentinos, disponibilizados pela pluma do Rio da Prata (RAZIK et al., 2015).

Os estudos sedimentares realizados na região apontam para dois padrões sedimentares distintos, sugerindo uma separação entre o norte e o sul da ilha de São Sebastião: o setor norte apresenta um padrão mais complexo, com matéria orgânica mista, indicando condições oligotróficas (devido à ausência de descargas fluviais significativas), sendo assim a sedimentação é dominada pela dinâmica das massas de água e pela circulação na plataforma; no setor sul, a dominância é de sedimentos 
finos, associados a descarga do Rio da Prata, sendo a presença de matéria orgânica em tal setor de origem pelágica (MAHIQUES et al., 2008).

A variação na intensidade da corrente gerada afeta diretamente o tamanho do grão depositado. Em regiões onde as correntes possuem menores intensidades, os sedimentos tendem a ser mais finos, quando comparados a sedimentos de regiões com correntes mais intensas (CARVALHO, 2002). O fortalecimento ou enfraquecimento dessas correntes em uma mesma região afetam diretamente a deposição dos sedimentos, registrando assim tais alterações.

Em 2003, HALL e colaboradores analisaram os registros geoquímicos e sedimentológicos do Oceano Pacifico e observaram variações nas correntes de fundo durante os períodos glaciais dos últimos 1,2 milhões de anos. Essas alterações foram inferidas a partir das variações significativas no tamanho do grão de silte, comparando-os com os registros das análises dos isótopos de oxigênio, possibilitando correlacionar estas observações com as alterações nos padrões de velocidade das correntes entre períodos glaciais e interglaciais

A análise da dimensão do grão de silte, denominado como "Sortable Silt", tem sido utilizado com sucesso em estudos de paleocorrentes, pois a variação do tamanho dos grãos se dá em função do comportamento hidrodinâmico da época da deposição, possibilitando assim inferir mudanças relativas na velocidade das correntes (MOLYNEUX et al., 2007). Como as correntes de fundo oceânicas raramente podem mover sedimentos maiores que o diâmetro de $0,063 \mathrm{~mm}$, isso define o intervalo superior sob qual deve ser analisado o sedimento para se obter informações sobre as variações das correntes no passado. Porém, as partículas mais finas, como o silte muito fino e a argila, comportam-se de forma coesa. Deste modo, seu transporte e deposição ocorrem em forma de agregados e não em grãos individuais, estabelecendo assim o limite inferior. Considerar o intervalo entre 0,010 mm e 0,063 $\mathrm{mm}$ para o estudo sobre tamanho de grãos possibilita assim a reconstituição das correntes de fundo. 


\section{Objetivos}

O objetivo deste estudo foi comparar o padrão de deposição da fração fina do sedimento menor que $63 \mu \mathrm{m}$ no talude da Bacia de Santos (com o auxilio do traçador Sortable Silt) com os indicadores de correntes de fundo nas variações entre os períodos glaciais e interglaciais ao longo dos últimos 800 mil.

Sendo assim, o presente estudo poderá auxiliar em uma maior compreensão das mudanças paleoceanograficas na região e inferir a respeito dos fatores que controlam ou influenciam na intensidade das correntes de fundo. Além disso, pretende-se avaliar, a representatividade do traçador do Sortbable Silt como um proxy para paleocorrentes, até então um parâmetro pouco utilizado nesta porção do oceano. Acredita-se que este traçador tenha muito potencial para contribuir nos estudos paleoceanográficos e paleoclimáticos desta região.

\subsection{Objetivos Específicos}

O presente estudo visa realizar uma análise qualitativa e quantitativa do Sortable Silt, além de responder as seguintes questões:

- As variações nas intensidades de corrente entre os períodos glaciais e interglaciais está evidente e apresentam um comportamento cíclico?

- E possível observar diferenças de velocidade entre as correntes que transportam as massas de água provenientes de Norte e Sul?

- Qual a sensibilidade do método de análise pelo princípio da velocidade de sedimentação, utilizando a técnica da pipetagem?

- Qual a sensibilidade do Sortable Silt para as variações de menor amplitude?

- O proxy se encontra perfeitamente calibrado? Quais são suas possíveis fontes de interferência na região?

- Há relação do Sortable Silt com os demais traçadores?

- É possível identificar as influências astronômicas na região? 


\section{3 Área de Estudo}

\subsection{Contexto Geológico}

A Bacia de Santos está localizada na margem continental sul brasileira, como limite ao sul a Bacia de Pelotas no Alto de Cabo Frio e a Bacia de Campos ao Norte no Alto de Florianópolis. A localização do testemunho, segundo a classificação geomorfológica, pertence ao Embaiamento de São Paulo.

A plataforma continental apresenta-se consideravelmente ampla na Bacia de Santos, tendo de forma geral um relevo suave com os contornos batimétricos, acompanhando as configurações da costa. O ponto de máxima largura com $230 \mathrm{~km}$ de extensão, encontra-se aproximadamente na região de Santos, pertencendo justamente ao setor do Embaiamento de São de Paulo. Este setor apresenta a quebra da plataforma entre 120 e $180 \mathrm{~m}$ de profundidade, com um talude de largura entre 59 e $122 \mathrm{~km}$ e uma declividade entre $1^{\circ} \mathrm{e} 1^{\circ} 45^{\prime}$, sedo que o talude superior é mais abrupto e estreito do que o inferior (Zembruscki,1979).

A planície costeira na Bacia de Santos é muito estreita, especialmente área central compreendida entre o Rio de Janeiro e Santos, sendo que a costa apresenta um aspecto sinuoso formando uma serie de grandes baias e ilhas associadas ao afloramento do embasamento Pré-Cambriano (DUARTE; VIANA, 2007). Os aportes atuais de sedimentos terrígenos para a plataforma continental estão reduzidos devido a presença da Serra do Mar, que impede o acesso de grandes fluxos da drenagem continental e os redireciona para oeste. Os aportes que atingem o oceano possuem representatividade diminuta (CONTI; FURTADO, 2006).

O aporte sedimentar na região da Bacia de Santos foi maior durante os períodos glaciais, devido a baixa no nível médio do mar, expondo a plataforma continental e facilitando a chegada dos sedimentos (KOWSMANN; COSTA, 1979). A esses períodos estão associado a maioria das variações no aporte sedimentar de terrígeno na área durante o Quaternário, devido as variações no nível do 
mar(MILLIMAN, 1978) sendo que, com a progressiva elevação do nível do mar, houve uma diminuição da sedimentação terrígena (MAHIQUES et al., 2002)

Os padrões de sedimentação da região compreendida entre 20 e $50^{\circ} S$ da plataforma externa até as profundidades abissais, são atribuídos principalmente a variações nas condições climáticas (intemperismo), localização geográfica (presença de rios) e a produção marinha, que é alterada pelos padrões de circulação. A região mais ao norte é caracterizada por menores granulometrias e um maior teor de carbonato, enquanto a sul a granulometria é mais grossa e com baixos teores de carbonato.

A região de transição entre ambas as regiões é definida pela Confluência das Correntes do Brasil e Malvinas (FRENZ et al., 2004). Na região da confluência os sedimentos são caracterizados por elevadas concentrações de carbono orgânico e baixos teores de carbonato. No Embaiamento de São Paulo as condições climáticas são mais homogêneas e o perfil de sedimentação entre a plataforma externa e o talude superior sugere um ambiente em resposta a combinação da morfologia de fundo, fluxo lateral (perpendicular as isóbatas) devido ao meandramento da Corrente do Brasil e ao transporte da água costeira em direção ao mar aberto (MAHIQUES et al., 2002). O Embaiamento de São Paulo apresenta distinções nas composições de seus depósitos, tanto na fração orgânica como inorgânica. A região na plataforma e talude superior da llha de São Sebastiao marca o limite entre essas zonas de sedimentação (MAHIQUES et al., 2004)

A sazonalidade da penetração da pluma da descarga fluvial do Rio da Prata, de baixa salinidade e temperatura, interagindo com os meandros da Corrente do Brasil favorecem a produtividade, aumentando o teor de matéria orgânica nos sedimentos. Através da razão de isótopos de neodímio sugere-se uma contribuição de sedimentos alóctones, reforçando a influência da pluma oriunda do Rio da Prata sobre a região (MAHIQUES et al., 2002, 2004).

Na região a norte da llha de São Sebastião os sedimentos apresentam uma relativa heterogeneidade, sugerindo uma complexa hidrodinâmica, apresentando setores com baixas taxas de deposição associados ao fluxo principal da Corrente do 
Brasil, que impediria a deposição, e setores na plataforma interna com distribuição da fração orgânica relacionada a ressurgência costeira (MAHIQUES et al., 2004)

\subsection{Contexto Oceanográfico}

A composição da estrutura da coluna de água do Atlântico Sul em um plano vertical demonstra um alto nível de estratificação bem definido, sendo possível identificar facilmente as massas d'água (Figura 1), que apresentam características físicas únicas. Estas características são adquiridas no processo de formação das massas d'água, representando as condições regionais, à medida que essas massas d'água vão se deslocando sofrem modificações em sua composição através processos de mistura e ação biológica, porém ainda é possível utilizar essas características para identifica-las mesmo estando a quilômetros de distância da sua origem (KRISSEK, 1993). 


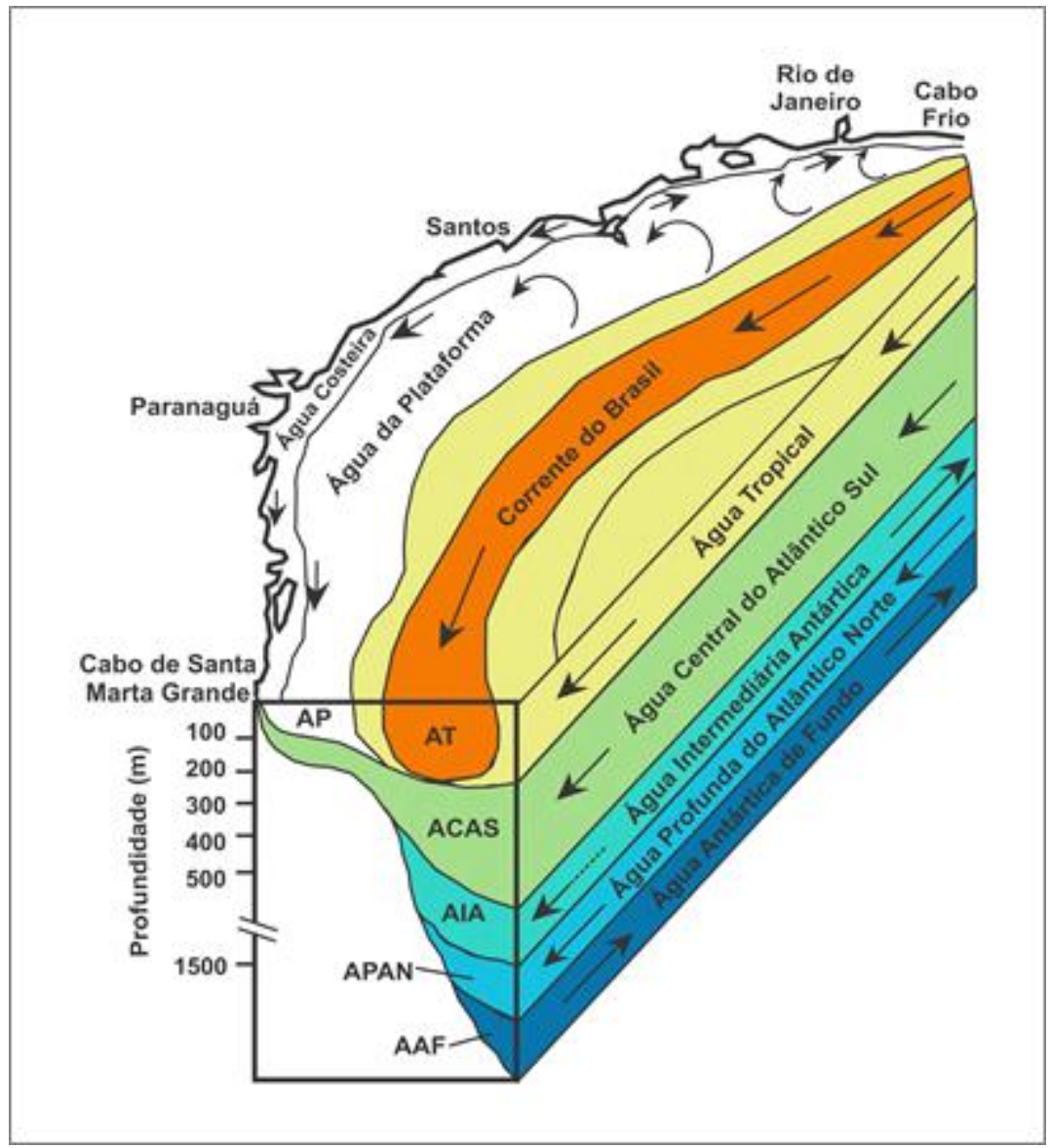

Figura 1: Caracterização de massas d'água do Atlântico Sul na região de localização dos testemunhos deste estudo (modificado de Matsuura, 1986).

Na plataforma continental ocorre a Água de Plataforma, que é composta pela mistura de águas oceânicas com as provenientes da drenagem continental (Figura 1). A região de estudo possui em sua costa adjacente pequenos estuários influenciandoa. A influência maior ocorre eventualmente quando as águas frias $\left(14-17^{\circ} \mathrm{C}\right)$ e com baixa salinidade (33-34) do Rio da Prata atingem a plataforma continental do Embaiamento de São Paulo (CAMPOS et al., 1999). Essa intrusão é regida pela componente da tensão de cisalhamento do vento perpendicular à costa, sendo que pouca influência tem o volume da vazão do rio neste processo, segundo dados históricos e estudos de modelagem (PIMENTA et al., 2005; PIOLA et al., 2005).

A Corrente do Brasil (CB) afeta a superfície transportando a Água Tropical (AT, em inglês Tropical Water, TW) que possui uma temperatura elevada $\left(>18^{\mathrm{a}} \mathrm{C}\right)$ e alta salinidade (>36). Na região da picnoclina ocorre o transporte da Água Central do 
Atlântico Sul (ACAS, em inglês South Atlantic Central Water, SACW), apresentando temperatura entre 6-20ㄷ e salinidade entre 34,6-36 (SILVEIRA et al., 2000). A CB flui em direção ao sul e corresponde a corrente de contorno oeste do giro subtropical, sendo um desmembramento da Corrente Sul Equatorial (CSE), originando também a Corrente Norte do Brasil (CNB). A latitude de origem não é exata mas, em nível superficial, está mais localizada a norte (9-15ㅇ), enquanto com aumento da profundidade desloca para sul (25으), ao nível da SACW (CIRANO et al., 2006).

Em comparação com as demais correntes de contorno oeste, a CB é a que apresenta menor intensidade, devido a sua origem no desmembramento da CSE e pela interação com as contracorrentes equatoriais (STRAMMA; IKEDA; PETERSON, 1990). Contudo, a partir dos $24^{\circ}-S$, a CB sofre uma intensificação de $5 \%$ a cada 100 $\mathrm{km}$, devido a sua interação com uma célula de recirculação (STRAMMA, 1989; PETERSON; STRAMMA, 1991).

A CB flui próxima à costa e somente se afasta em uma interação com a Corrente das Malvinas e um ramo da Circumpolar Antártica que flui para norte, denominada de Confluência Brasil-Malvinas. Dessa interação, águas superficiais sofrem subducção e contribuem amplamente para a formação da SACW, a contribuição do Oceano Indico é através dos anéis da Corrente das Agulhas, representando uma importante intrusão de energia e massa no Oceano Atlântico (TOMCZAK; GODFREY, 2005; DUARTE; VIANA, 2007). A Corrente de Benguela (CBe), a oeste, e a Corrente do Atlântico Sul (CAS), a sul, completam o giro subtropical.

A CBe constitui a corrente de contorno leste, que tem origem na latitude do Cabo de Boa Esperança, fluindo para norte e, aos $30^{\circ} \mathrm{S}$, se afasta do continente africano fluindo para noroeste, com ventos predominantes de $S$ e SE na região da Cbe, onde a ressurgência é favorecida. A CAS flui separadamente da Corrente Circumpolar Antártica para leste, separadas pela frente subtropical, e ambas alimentam a CBe (PETERSON; STRAMMA, 1991).

As alterações nas condições de temperatura superficial do mar, salinidade e intensidade do vento influenciam na circulação das águas profundas ocasionando em variações, pois as águas profundas são formadas pelo afundamento destas águas 
superficiais (BROECKER; TAKAHASHI; TAKAHASHI, 1985). A oscilação na formação de águas profundas é observada na variação do volume nas principais calotas de gelo no planeta (BROECKER; DENTON, 1990), isso porque, a circulação termohalina tem um papel fundamental no transporte de calor (GORDON, 1986).

O transporte de calor pela termohalina, no modelo geral, tem sua distribuição de calor dos trópicos em direção aos pólos, porém, no Atlântico Sul, ocorre o contrário das demais bacias oceânicas, nas quais o fluxo é dirigido dos polos para o equador (Figura 2), ocasionando em uma perda de calor do Atlântico Sul para o Atlântico Norte, associado à ausência de uma corrente intensa em direção aos pólos (RINTOUL, 1991). A CB tem um início fraco e aumenta sua intensidade através das recirculações internas da bacia ao longo de sua trajetoria, enquanto a $\mathrm{CBe}$ é mais intensa, proporcionando um maior transporte de energia proveniente da radiação solar em direção ao Atlântico Norte (PETERSON; STRAMMA, 1991).

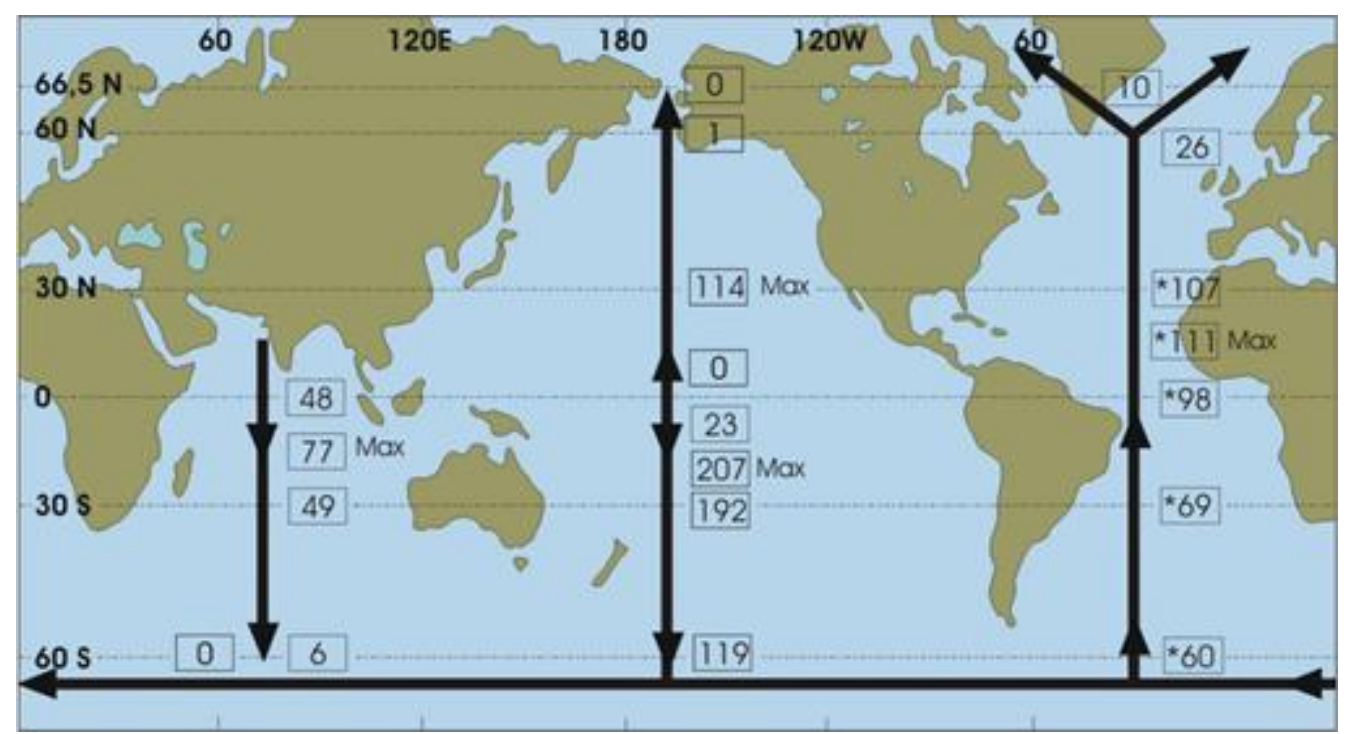

Figura 2: Modelo geral do transporte de calor nos oceanos.

O transporte de calor oceânico no Atlântico, comumente conhecido como circulação termohalina, é geralmente apresentado como um modelo de transporte altamente simplificado (Figura 3), que consiste unicamente em componentes 
meridionais, apesar de existirem numerosos núcleos de recirculação multidimensionais, sendo extremamente complexo (BROECKER, 1995).

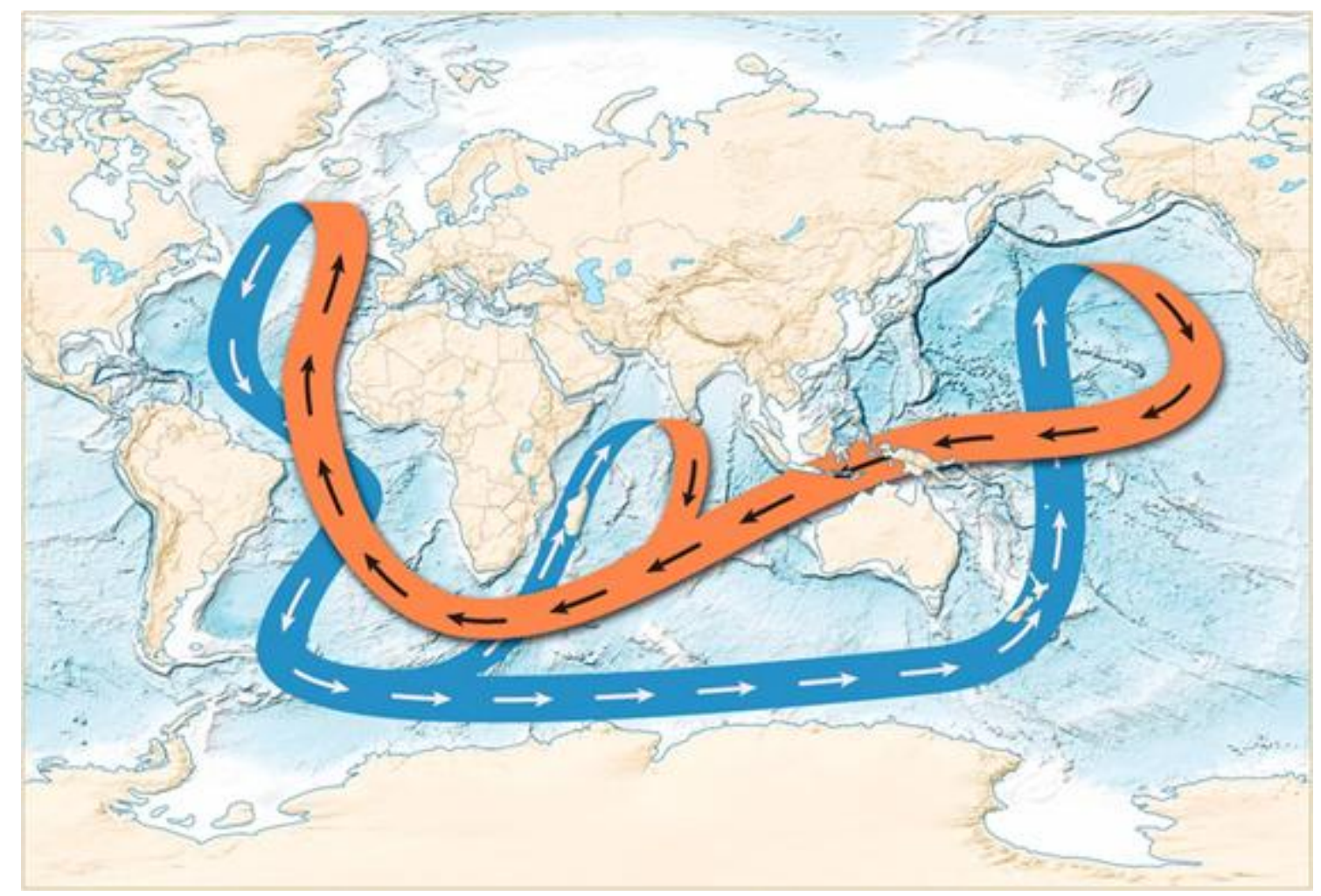

Figura 3: Modelo geral da circulação termohalina, proposta por Broecker (1995).

A circulação termohalina demonstra uma relação cíclica entre os períodos glaciais e interglaciais relacionada com a AMOC (sigla em inglês para Atlantic Meridional Overturning Circulation). Durante eventos glaciais há um enfraquecimento culminando em um avanço prolongado da cobertura de gelo em altas latitudes, conduzindo as temperaturas atmosféricas mais frias ocasionando na compressão das regiões tropicais devido ao aumento da influência das recorrentes frentes frias. $O$ enfraquecimento da AMOC afeta a intensidade da Corrente Norte do Brasil, apresentando menor intensidade, diminuindo o transporte de sal e calor para o Atlântico Norte, tornando a porção oeste do Atlântico Sul em um reservatório de sal e calor durantes os eventos glaciais. Tais eventos extremos da AMOC podem ser caracterizados pelas menores contribuições da NADW.

Do outro lado, a componente sul é representada pela Água de Fundo Antártica (em inglês Antarctic Bottom Water - $A A B W$ ), uma das principais massas de águas 
geradas no Oceano Austral. Sendo formada em grande parte dentro do mar de Weddell, sendo que o mar de Ross e a costa de Adélia tem contribuição significativa (REID et al., 1977).

Atualmente durante o inverno as águas que ressurgem na Corrente Antártica Circumpolar, nas proximidades da costa da Antártica, são rapidamente resfriadas pelas trocas de calor com a atmosfera e com a interação com gelo marinho. Tal interação com o gelo marinho torna-a mais salina, aumentando sua densidade e ocasionando em um rápido afundamento, contribuindo assim para uma mistura vertical eficiente. 


\section{Materiais e Métodos}

O testemunho KF-18, que foi utilizado para análise, foi coletado na Bacia de Santos com a coordenada geográfica $25^{\circ} 12^{\prime} 14^{\prime \prime}$ S e 42 $37^{\prime} 19^{\prime \prime}$ W, a 2.220 metros de profundidade, onde a orientação da plataforma assume a direção E-W e apresenta um talude mais largo e pouco inclinado (Figura 4). O testemunho possui $2.038 \mathrm{~cm}$ de sedimentos, principalmente lamosos provenientes de uma sedimentação francamente pelágica com fração mais grossa composta principalmente por partículas carbonáticas. A classificação litológica quanto ao teor de carbonato indicou que a litologia varia entre marga (entre 30 e $60 \%$ de carbonato), lama rica em carbonato (entre 18 e $30 \%$ de carbonato) e lama levemente carbonática (entre 5 e $18 \%$ de carbonato). Na Figura 5 é apresentado um esquema da litologia e estruturas encontradas ao longo do testemunho. 


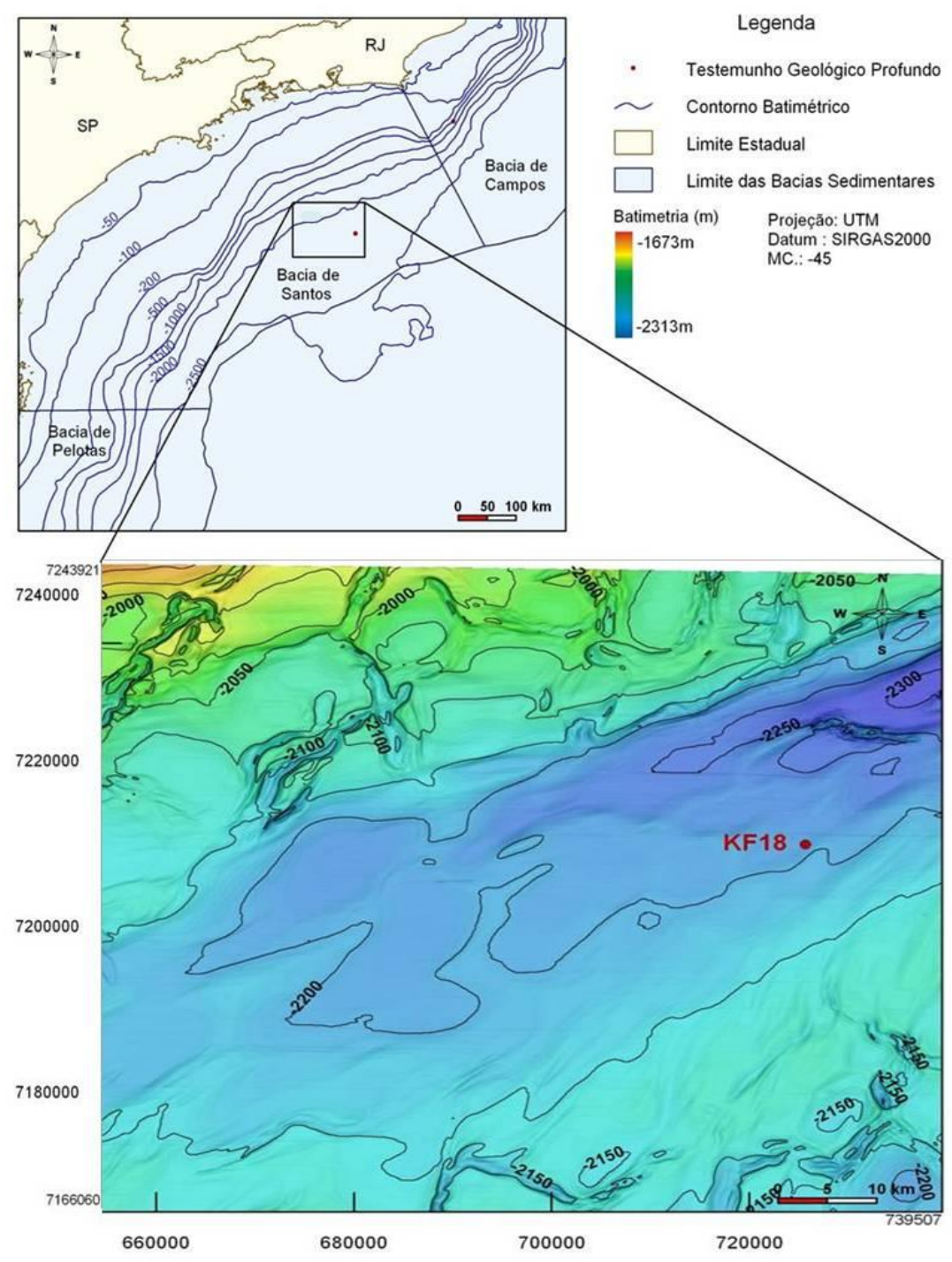

Figura 4: Localização do testemunho KF-18 na margem continental sudeste brasileira, porção oeste do Atlântico Sul. 


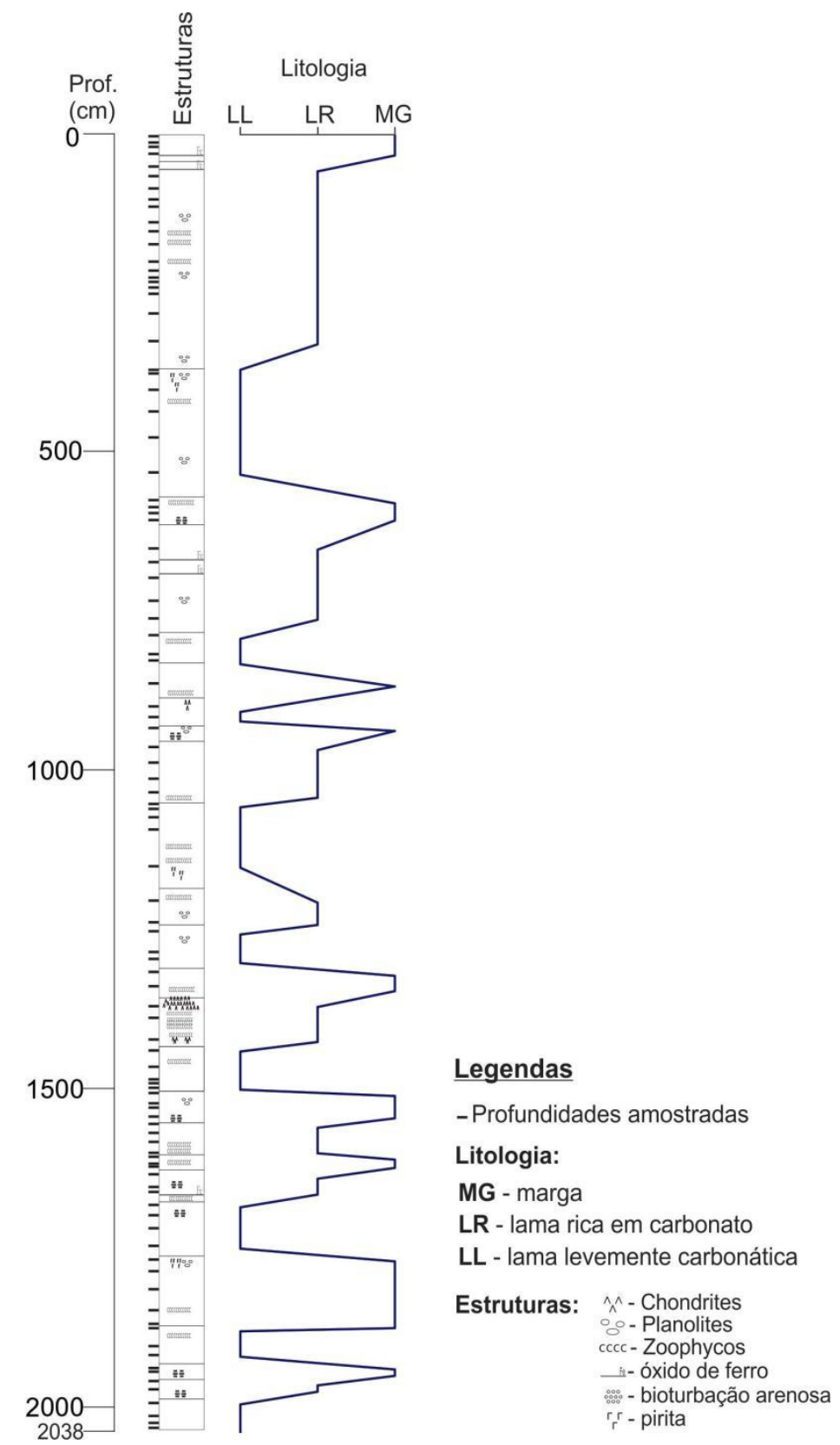

Figura 5: Estruturas e litologia do testemunho KF-18.

As amostras foram processadas através da lavagem em peneiras de malha com abertura de $0,063 \mathrm{~mm}$ para a separação entre as frações grossa e fina, com a preservação de ambas. No presente trabalho foi utilizada somente a fração fina, que sofre alteração em sua granulometria devido a modificações na deposição associadas as correntes de fundo. 


\subsection{Granulometria}

As amostras foram tomadas em média a cada $5 \mathrm{~cm}$ uma da outra ao longo do testemunho, totalizando 407 amostras de sedimento. Foram selecionadas seguindo 0 objetivo de caracterizar os períodos glaciais e interglaciais e coincidindo com as amostras utilizadas para a análise isotópica. As amostras foram submetidas a peneiras com malha de $63 \mathrm{~mm}$, separando cerca de 16 gramas dessa fração para os procedimentos seguintes.

Para este tipo de análise é recomendado eliminar os componentes biogênicos (que apresentam comportamento hidrodinâmico diferente, afetando assim o resultado). Deste modo, foi utilizado ácido clorídrico para eliminar o carbonato, adicionando lentamente na amostra até a reação cessar, sendo observada por alguns instantes para confirmação do termino da reação. Para as amostras que ocasionalmente apresentavam uma reação mais energética e transbordavam o Becker foi adotado o protocolo de descarte de tal amostra e todo o processo era reiniciado a partir da amostra bruta.

Como medida de segurança foi acrescentado ácido clorídrico em excesso e mantida a amostra em imersão por um período de 24 horas. Após esse período as amostras foram lavadas durante uma semana, uma vez por dia, com água destilada, a fim de não ocorrer contaminação devido a partículas presentes na água canalizada.

Depois de todo o tratamento para retirada do carbonato as amostras seguiram para o passo seguinte, a eliminação da matéria orgânica, na qual permaneceram em imersão em uma solução de peróxido de oxigênio, que foi adicionado lentamente para evitar reações bruscas a uma temperatura de aproximadamente $50^{\circ} \mathrm{C}$, controlada com o auxilio de uma chapa aquecedora embaixo das amostras.

Em todas as amostras foi acrescentada solução em excesso e observadas atentamente pelas primeiras horas, para que não ocorresse a reação rapidamente $e$ viesse a "ferver". Nos casos que isso ocorreu foi acrescentado álcool 70\% para interromper a reação. Tais amostras que apresentaram uma reação muito rápida e transbordaram o Becker foram descartadas e refeitas desde o processo de retirada do carbonato. 
O período de retirada da matéria orgânica foi variado de uma amostra para outra, extendendo-se de 1 dia a 1 semana. As amostras foram retiradas da solução aquecida quando não apresentavam mais a presença de matéria orgânica, sendo encaminhadas para a lavagem final.

Todas as amostras foram abundantemente lavadas após as etapas anteriores, para garantir que resíduos das soluções de peroxido de oxigênio e do ácido clorídrico não interferissem nas análises seguintes.

Durante todo o processo de retirada do carbonato e da matéria orgânica, inclusive durante as lavagens, caso fosse observado uma possível perda de material todo, o processamento das amostras era reiniciado. Tais medidas foram adotadas para impedir que ocorresse uma pré-seleção do tamanho do grão.

Após o tratamento do sedimento, retirando as possíveis interferências, as amostras foram homogeneizadas e separadas para análise através de dois diferentes métodos: (1) a análise baseada na medição a laser, utilizando cerca de 1 grama juntamente com uma solução de oxalato de sódio (antifloculante) para cada análise de amostra, determinando assim o tamanho médio dos grãos e (2) a análise pelo princípio da velocidade de sedimentação através do uso de pipetas, utilizando cerca de 15 gramas do sedimento para cada análise de amostra.

\subsubsection{Análise Granulométrica a Laser}

Para a análise granulométrica a laser foi utilizado o equipamento Malvern Hydro 2000. Este método consiste na difração a laser, no qual as partículas passam a frente do feixe de luz e são difratadas em um ângulo especifico conforme o tamanho, sendo a variação do tamanho da partícula o inverso ao tamanho do ângulo (SHILLABEER; HART; RIDDLE, 1992).

Esse método fornece a distribuição do diâmetro médio dos grãos por volume, baseado no princípio físico que considera a Aproximação de Fraunhofer ou a Teoria de Mie para o cálculo do modelo de difração. Para a escolha da construção do modelo foram considerados o comprimento de onda utilizado e a proximidade com o tamanho 
das partículas, definindo assim o melhor princípio físico para uma maior precisão, que é ajustado automaticamente pelo equipamento (RAWLE et al., 2003).

As amostras foram inseridas no equipamento para análise mediante a agitação e homogeneização da solução de oxalato de sódio com o sedimento, evitando que ocorresse floculação do material, fornecendo assim uma resposta superestimada do tamanho do grão.

Os resultados são fornecidos em porcentagem na notação phi $(\Phi)$, que foram convertidos em micrometros posteriormente, utilizando a seguinte equação:

$$
\Phi=-\log _{2} d
$$

onde, d é o diâmetro médio do grão em micrometros.

A notação em micrometros foi escolhida para a composição do índice de Sortable Silt, pois apresenta um comportamento linear proporcional às velocidades expressas por ele.

\subsubsection{Análise Granulométrica através do princípio da velocidade de sedimentação, técnica da pipetagem}

Para a análise da granulometria das frações menores que $0,063 \mathrm{~mm}$ foi utilizada a técnica da pipetagem. Esta técnica é baseada na velocidade de sedimentação gravitacional definida pela Lei de Stokes, que determina a velocidade da partícula em um campo uniforme de forças, em um meio fluido qualquer, apresentando a velocidade de queda constante que está relacionada às características morfológicas dessa partícula (LIMA \& LUZ, 2001).

A análise através da pipeta é baseada nas mudanças de concentração das partículas de sedimento em uma mistura entre água destilada e sedimento, em 
provetas de 1 litro de volume acrescidos de 1 grama de oxalato de sódio, que são retiradas em intervalos de tempo pré-estabelecidos em profundidade igualmente préestabelecida, correspondendo a uma determinada classe. Devido a diferença na velocidade de deposição dos grãos, é possível separa-los em classes de tamanho a partir da diferença de concentração, coletando-se uma alíquota de 20 mililitros a uma profundidade de $20 \mathrm{~cm}$ da superfície da mistura água e sedimento após 58 segundos do cessar da agitação para homogeneização da mistura na proveta, posteriormente acondicionado em um Becker previamente pesado.

Esse período inicial corresponde a dissipação da energia empregada para a homogeneização, tornando-se a base para o início do cálculo das variações nas concentrações em função da velocidade de deposição.

A próxima alíquota é retirada no intervalo de 3 minutos e 52 segundos a uma profundidade de $20 \mathrm{~cm}$, nos intervalos de 7 minutos e 44 segundos, 31 minutos e 2 horas e 3 minutos, sendo as alíquotas retiradas a uma profundidade de $10 \mathrm{~cm}$. A diferença nas profundidades de retirada das alíquotas é para otimização do tempo de análise, uma vez que esse é o intervalo de tempo necessário para o grão de uma determinada classe percorrer a coluna de água em direção ao fundo. Foram realizadas 6 amostras por vez em um intervalo de tempo de 2 horas e 30 minutos, intercalando os tempos de coleta entre as amostras como demonstrado na

Tabela 1. 
Tabela 1: Relação entre o tempo e a profundidade da coleta das alíquotas durante a técnica da pipetagem, a sequência de coleta esta representada abaixo dos intervalos.

\begin{tabular}{|c|c|c|c|c|c|c|}
\hline Amostra & 1 & 2 & 3 & 4 & 5 & 6 \\
\hline $\begin{array}{c}P \\
R \\
O \\
F \\
(\mathrm{~cm})\end{array}$ & $0^{\prime}$ & $5^{\prime}$ & $10^{\prime}$ & $15^{\prime}$ & $20^{\prime}$ & $25^{\prime}$ \\
\hline 20 & $\begin{array}{c}58^{\prime \prime} \\
1 \\
1\end{array}$ & $\begin{array}{c}5^{\prime} 58^{\prime \prime} \\
3\end{array}$ & $\begin{array}{c}10^{\prime} 58^{\prime \prime} \\
6\end{array}$ & $\begin{array}{c}15^{\prime} 58^{\prime \prime} \\
9\end{array}$ & $\begin{array}{c}20^{\prime} 58^{\prime \prime} \\
12\end{array}$ & $\begin{array}{c}25^{\prime} 58^{\prime \prime} \\
15\end{array}$ \\
\hline 20 & $\begin{array}{c}3^{\prime} 52^{\prime \prime} \\
2 \\
2\end{array}$ & $\begin{array}{c}8^{\prime} 52^{\prime \prime} \\
5\end{array}$ & $\begin{array}{c}13^{\prime} 52^{\prime \prime} \\
8\end{array}$ & $\begin{array}{c}18^{\prime} 52^{\prime \prime} \\
11\end{array}$ & $\begin{array}{c}23^{\prime} 52^{\prime \prime} \\
14 \\
\end{array}$ & $\begin{array}{c}28^{\prime} 52^{\prime \prime} \\
17\end{array}$ \\
\hline 10 & $\begin{array}{c}7^{\prime} 44^{\prime \prime} \\
4\end{array}$ & $\begin{array}{c}12^{\prime} 44^{\prime \prime} \\
7\end{array}$ & $\begin{array}{c}17^{\prime} 44^{\prime \prime} \\
10\end{array}$ & $\begin{array}{c}22^{\prime} 44^{\prime \prime} \\
13\end{array}$ & $\begin{array}{c}27^{\prime} 44^{\prime \prime} \\
16\end{array}$ & $\begin{array}{c}32^{\prime} 44^{\prime \prime} \\
19\end{array}$ \\
\hline 10 & $\begin{array}{l}31^{\prime} \\
18\end{array}$ & $36^{\prime}$ & $41^{\prime}$ & $46^{\prime}$ & $\begin{array}{l}51^{\prime} \\
23\end{array}$ & $\begin{array}{l}56^{\prime} \\
24\end{array}$ \\
\hline 10 & $\begin{array}{c}2 \mathrm{H}^{\prime} \\
25 \\
25\end{array}$ & $\begin{array}{c}2 \mathrm{H} 8^{\prime} \\
26\end{array}$ & $\begin{array}{c}2 \mathrm{H} 13^{\prime} \\
27\end{array}$ & $\begin{array}{c}2 \mathrm{H} 18^{\prime} \\
28\end{array}$ & $\begin{array}{c}2 \mathrm{H} 23^{\prime} \\
29 \\
29\end{array}$ & $\begin{array}{c}2 \mathrm{H} 28^{\prime} \\
30\end{array}$ \\
\hline
\end{tabular}

Devido a esse movimento vertical e lento dos grãos é necessária muita cautela na retirada da alíquota, pois qualquer movimento que perturbe a mistura comprometerá a análise, assim como a retirada nos intervalos e profundidades préestabelecidas. Durante a análise todas as amostras que não seguiram os padrões acima descritos foram refeitas. 
A determinação das concentrações em cada classe granulométrica é aferida pelo peso do resíduo seco da pipetagem. A concentração de cada classe é corrigida pelo volume coletado descontado-se o peso do oxalato de sódio colocado no início da análise (SUGUIO, 1973).

\subsection{Análise Espectral}

Para as análises espectrais foi necessário realizar uma interpolação dos dados a fim de se obter um intervalo regular na distribuição dos dados no tempo. Para essa interpolação foi escolhida a técnica do spline cubico, que promove a menor perda das periodicidadedes contidas no registro original (SCHULZ; STATTEGGER, 1997). A interpolação foi feita usando intervalos de tempo de 1 mil anos.

Para a análise espectral foi utilizado o método do periodograma, que é uma estimativa da densidade espectral de um sinal (GHIL, 2002). As análises de espectro foram concluídas com o uso do softaware R (3.2.3).

\subsection{Teor de $\mathrm{CaCO}_{3}$}

O teor de carbonato foi estimado utilizando 407 amostras ao longo do testemunho, em intervalos aproximadamente equidistantes. Foi utilizado aproximadamente $1 \mathrm{~g}$ de amostra, submetido a uma solução de $\mathrm{HCl} 10 \%$, com o objetivo de eliminar o $\mathrm{CaCO}_{3}$ conforme a equação a seguir:

$$
\mathrm{CaCO}_{3}+2 \mathrm{HCl} \rightarrow \mathrm{CaCl}_{2}+\mathrm{H}_{2} \mathrm{O}+\mathrm{CO}_{2}
$$

Após o ataque ácido o resíduo foi colocado para secagem em estufa a uma temperatura abaixo de $60^{\circ} \mathrm{C}$, para que não fosse alterada a composição mineralógica. Esse resíduo representa a quantidade de material livre de $\mathrm{CaCO}_{3}$ presente na 
amostra, utilizando o peso inicial e final para calcular o teor de $\mathrm{CaCO}_{3}$, como descrito na equação abaixo:

$$
\% \mathrm{CaCO}_{3}=\frac{\text { Peso }_{\text {inicial }}-\text { Peso }_{\text {final }}}{P_{\text {inicial }}} * 100
$$

\subsection{Susceptibilidade Magnética}

Os dados de susceptibilidade magnética foram fornecidos pela Petrobrás, que utilizou o equipamento MSCL Geotek 7.9, equipamento que realiza teste não destrutivos, fornecendo assim a susceptibilidade magnética em SIX10-5.

\subsection{Fluxos de massa}

Para determinar os fluxos de massa dos sedimentos carbonáticos e terrígenos foi utilizada a metodologia descrita por AUFFRET et al. (2002). Inicialmente é necessário o cálculo da densidade de massa úmida, a qual pode ser relacionada com a densidade de raios gama, como demonstrado abaixo:

$$
D_{u}=\left(0,8247 * D_{\gamma}\right)+0,0948
$$

Onde:

Du: Densidade de massa úmida $\left(\mathrm{g} \mathrm{cm}^{-3}\right)$

$D_{\mathrm{y}}$ : Densidade de raios gama $\left(\mathrm{g} \mathrm{cm}^{-3}\right)$

Os dados de densidade de raios gamas $(\mathrm{g} \mathrm{cm}-3)$ foram fornecidos pela Petrobras, que utilizou o equipamento MSCL Geotek 7.9. 
A densidade de massa seca é definida como:

$$
D_{s}=D_{g} * \frac{D_{i}-D_{u}}{D_{i}-D_{g}}
$$

Onde:

Ds: Densidade de massa seca $\left(\mathrm{g} \mathrm{cm}^{-3}\right)$

Dg: Densidade média dos grãos $\left(\mathrm{g} \mathrm{cm}^{-3}\right)$

$D_{i:}$ Densidade média da água intersticial $\left(\mathrm{g} \mathrm{cm}^{-3}\right)$

Du: Densidade de massa úmida $\left(\mathrm{g} \mathrm{cm}^{-3}\right)$

Porém, para determinar a densidade de massa seca, é necessário fazer algumas considerações: para possibilitar e otimizar os cálculos, foi assumido que a densidade média dos grãos na amostra é de $2,65 \mathrm{~g} \mathrm{~cm}^{-3}$ e que a densidade média da água intersticial é de $1,024 \mathrm{gcm}^{-3}$ (AUFFRET et al., 2002)

$$
D_{s}=2,65 * \frac{1,024-D_{u}}{1,024-2,65}
$$

Onde:

Ds: Densidade de massa seca $\left(\mathrm{g} \mathrm{cm}^{-3}\right)$

Du: Densidade de massa úmida $\left(\mathrm{g} \mathrm{cm}^{-3}\right)$

As taxas de acumulo de sedimento expressas em massa, indicando o fluxo total de massa na região são descritas como: 


$$
F_{t}=T L S-D_{S}
$$

Onde:

$F_{t}$ Taxa de acumulo de sedimento em massa, fluxo total $\left(\mathrm{g} \mathrm{cm}^{-2} \mathrm{ka}^{-1}\right)$

TLS: taxa linear de sedimentação $\left(\mathrm{cm} \mathrm{ka}^{-1}\right)$

$D_{s}$ : Densidade de massa seca $\left(\mathrm{g} \mathrm{cm}^{-3}\right)$

Considerando que a sílica opalina é muito rara e não existem evidências de uma neoformação digenética, a componente não carbonática pode ser considerada na totalidade como sendo de origem terrígena, descrita como:

$$
F_{r}=F_{t}(1-T C)
$$

Onde:

Fr: Taxa de acumulo de não carbonatos, fluxo de terrígenos $\left(\mathrm{g} \mathrm{cm}^{-2} \mathrm{ka}^{-1}\right)$

$F_{t}$ Taxa de acumulo de sedimento em massa, fluxo total $\left(\mathrm{g} \mathrm{cm}^{-2} \mathrm{ka}^{-1}\right)$

TC: Teor de carbonato total (\%)

A taxa de acumulo de carbonatos (fluxo de carbonato) é descrito como:

$$
F_{c}=F_{t}-F_{r}
$$

Onde: 

$F_{c}$ : Taxa de acumulo de carbonatos, fluxo de carbonatos $\left(\mathrm{g} \mathrm{cm}^{-2} \mathrm{ka}^{-1}\right)$
Fr: Taxa de acumulo de não carbonatos, fluxo de terrígenos $\left(\mathrm{g} \mathrm{cm}^{-2} \mathrm{ka}^{-1}\right)$
$F_{t}$ : Taxa de acumulo de sedimento em massa, fluxo total $\left(\mathrm{g} \mathrm{cm}^{-2} \mathrm{ka}^{-1}\right)$

\subsection{Isótopos de Oxigênio e de Carbono.}

Para este estudo, foram utilizadas análises isotópicas de oxigênio e carbono em testa de foraminíferos bentônicos da espécie Cibicidoides wuellerstorfi que foram selecionadas pela equipe do LaPAS-IOUSP. A partir dos dados de isótopos de oxigênio foram determinados os períodos glaciais e interglaciais de acordo com TOLEDO e colaboradores (2016).

\subsection{Modelo de idade}

O modelo de idade foi concebido pela equipe do Laboratório de Paleoceanografia do Atlântico Sul (LAPAS) utilizando como base a curva isotópica do oxigênio $\left(\delta^{18} \mathrm{O}\right)$, obtida a partir de foraminíferos bentônicos. Para a determinação do modelo foi utilizada a correlação com a curva LR04 (LISIECKI; RAYMO, 2005).

A curva LR04 é constituída a partir da curva isotópica de oxigênio de foraminíferos bentônicos em escala global, obtida a partir de dados globais interligados orbitalmente por 57 pontos. O programa Analyseries foi utilizado para a identificação dos pontos correspondentes e interpolação dos dados para obtenção do modelo de idade.

O modelo de idade deste testemunho esta reportado em DE ALMEIDA et al., 2015; TOLEDO et al., 2016; GONZALES et al., 2017. 


\section{Resultados}

\subsection{Isótopos de Oxigênio e Estratigrafia Isotópica}

A partir da curva da razão isotópica do oxigênio (Figura 6) que abrange os últimos 800 mil anos, foi possível identificar 19 estágios isotópicos marinhos (Marine Isotope Stages, MIS), sendo que o testemunho apresenta 7 ciclos completos de glaciação. Os estágios encontrados com numeração impar representam as condições interglaciais (excluindo-se o MIS 3), enquanto pares descrevem as condições glaciais.

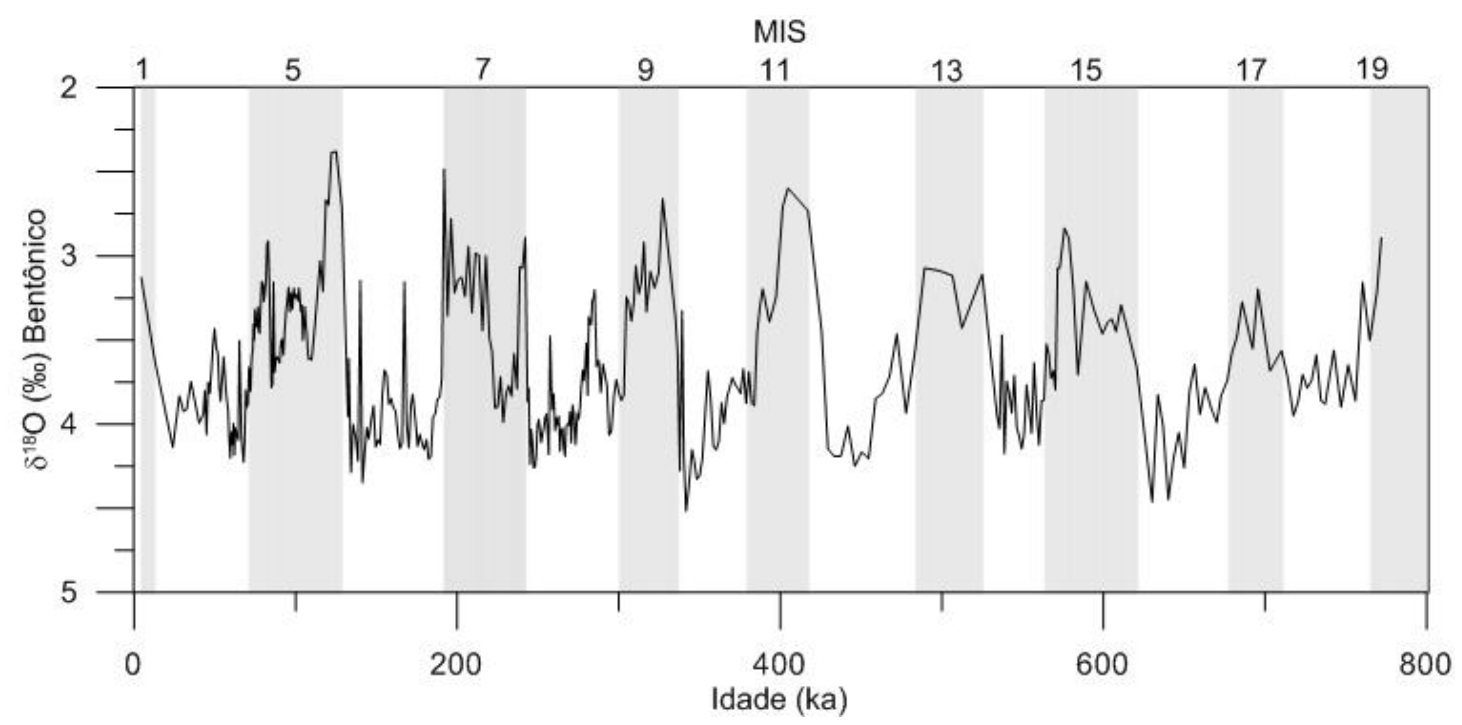

Figura 6: Curva da razão isotópica do oxigênio em foraminíferos bentônicos do testemunho KF-18. Assinalado em cinza estão os estágios isotópicos interglaciais.

Para o MIS 19, representando o intervalo interglacial basal, o mesmo se encontra incompleto com idade da base estimada EM $~ 800$ k.a. sendo inferior ao limite entre o MIS 20-19. Este período corresponde a $8 \mathrm{~cm}(2038-2030 \mathrm{~cm})$ do testemunho e foi representado por 3 amostras. As análises de isótopos de oxigênio apresentaram mediana de 3,22\%, sendo a variância de 0,09\%, com um máximo de 3,5\% e um mínimo de 2,89\% para esse período. 
O MIS 18 foi definido como período glacial compreendido entre 760,4 e 713 k.a., correspondendo a 65CM de sedimento no intervalo entre $2025-1960 \mathrm{~cm}$ e está representado por 14 amostras. As análises de isótopos de apresentaram a mediana de 3,76\%, uma variância de $0,04 \%$, com um máximo de 3,95\% e um mínimo de $3,16 \%$ para esse período.

O MIS 17 foi definido como período interglacial, compreendido entre 710,2 e 676,6 k.a., correspondendo a $39 \mathrm{~cm}$ de sedimentos no intervalo entre 1955-1916CM e está representado por 9 amostras. As análises de isótopos de oxigênio apresentaram a mediana de 3,55\%, uma variância de 0,03\%o, com um máximo de $3,74 \%$ e um mínimo de $3,2 \%$ para esse período, apresentando o maior valor para a mediana dentre os períodos interglaciais analisados.

O MIS 16 foi definido como período glacial compreendido entre 672,7 e 630,2 k.a., correspondendo a 65 de sedimentos no intervalo entre $1910-1988 \mathrm{~cm}$ e está representado por 14 amostras. As análises de isótopos de oxigênio apresentaram a mediana de 3,97\%, uma variância de 0,06\%, com um máximo de 4,46\% e um mínimo de $3,64 \%$ para esse período.

O MIS 15 foi definido como período interglacial compreendido entre 620,6 e 563,2 k.a., correspondendo a $100 \mathrm{~cm}$ de sedimentos no intervalo entre $1840-1740 \mathrm{~cm}$ e está representado por 21 amostras. As análises de isótopos de oxigênio apresentaram a mediana de 3,39\%, uma variância de 0,09\%, com um máximo de $3,86 \%$ e um mínimo de $2,83 \%$ para esse período.

O MIS 14 foi definido como período glacial compreendido entre 561,3 e 534,1 k.a., correspondendo a $90 \mathrm{~cm}$ de sedimentos no intervalo entre1735-1645 cm e está representado por 19 amostras. As análises de isótopos de oxigênio apresentaram a mediana de 3,93\%, uma variância de 0,04\%, com um máximo de 4,18\%o e um mínimo de $3,47 \%$ para esse período.

O MIS 13 foi definido como período interglacial compreendido entre 524,9 e 483,5 k.a., correspondendo a $30 \mathrm{~cm}$ de sedimentos no intervalo entre $1640-1610 \mathrm{~cm}$ e está representado por 7 amostras. As análises de isótopos de oxigênio apresentaram a mediana de $3,11 \%$, uma variância de $0,04 \%$, com um máximo de $3,55 \%$ e um mínimo de 3,07\% para esse período. 
O MIS 12 foi definido como período glacial compreendido entre 477,8 e 425,6 k.a., correspondendo a $60 \mathrm{~cm}$ de sedimentos no intervalo entre $1605-1545 \mathrm{~cm}$ e está representado por 13 amostras. As análises de isótopos de oxigênio apresentaram a mediana de 4,01\%, uma variância de $0,08 \%$, com um máximo de 4,25\% e um mínimo de $3,45 \%$ para esse período.

O MIS 11 foi definido como período interglacial compreendido entre 425 e 378,8 k.a., correspondendo a $55 \mathrm{~cm}$ de sedimentos no intervalo entre1540-1485 cm e está representado por 12 amostras. As análises de isótopos de oxigênio apresentaram a mediana de 3,35\%, uma variância de $0,21 \%$, com um máximo de 3,89\% e um mínimo de $2,6 \%$ para esse período, apresentou a maior variância ao longo do testemunho.

O MIS 10 foi definido como período glacial compreendido entre 377,1 e 337,8 k.a., correspondendo a $119 \mathrm{~cm}$ de sedimentos no intervalo entre1480-1361 cm e está representado por 25 amostras. As análises de isótopos de oxigênio apresentaram a mediana de 4,00\%, uma variância de $0,08 \%$, com um máximo de 4,52\%o e um mínimo de $3,33 \%$ para esse período, apresentando o maior valor de razão isotópica do testemunho e a maior variância entre os períodos glaciais.

O MIS 9 foi definido como período interglacial compreendido entre 337,8 e 300 k.a., correspondendo a $85 \mathrm{~cm}$ de sedimentos no intervalo entre1356-1271 cm e está representado por 18 amostras. As análises de isótopos de oxigênio apresentaram a mediana de $3,26 \%$, uma variância de $0,10 \%$, com um máximo de 3,86\% e um mínimo de 2,66\% para esse período.

O MIS 8 foi definido como período glacial compreendido entre 298,5 e 243,5 k.a., correspondendo a $320 \mathrm{~cm}$ de sedimentos no intervalo entre 1266-946 cm e está representado por 65 amostras. As análises de isótopos de oxigênio apresentaram a mediana de 3,95\%, uma variância de 0,06\%, com um máximo de 4,26\% e um mínimo de $3,20 \%$ para esse período.

O MIS 7 foi definido como período interglacial compreendido entre 242,1 e 191,9 k.a., correspondendo a $130 \mathrm{~cm}$ de sedimentos no intervalo entre $941-811 \mathrm{~cm}$ e está representado por 27 amostras. As análises de isótopos de oxigênio apresentaram a mediana de 3,34\%, uma variância de 0,16\%, com um máximo de 3,99\%o e um 
mínimo de 2,48\% para esse período, apresentando a maior razão isotópica dentre os períodos interglaciais.

O MIS 6 foi definido como período glacial compreendido entre 190,5 e 131 k.a., correspondendo a $218 \mathrm{~cm}$ de sedimentos no intervalo entre 806-588 cm e está representado por 45 amostras. As análises de isótopos de oxigênio apresentaram a mediana de 3,99\%, uma variância de 0,06\%, com um máximo de 4,35\%o e um mínimo de 3,15\% para esse período e apresentando o menor valor para a razão isotópica dentre os períodos glaciais.

O MIS 5 foi definido como período interglacial compreendido entre 128,7 e 71,1 k.a., correspondendo a $345 \mathrm{~cm}$ de sedimentos no intervalo entre $583-238 \mathrm{~cm}$ e está representado por 69 amostras. As análises de isótopos de oxigênio apresentaram a mediana de 3,33\%o, uma variância de 0,09\%o, com um máximo de 3,8\%o e um mínimo de $2,38 \%$ para esse período, apresentando o menor valor para a razão isotópica do testemunho.

O MIS 4 foi definido como período glacial compreendido entre 70,5 e 57,5 k.a., correspondendo a $97 \mathrm{~cm}$ de sedimentos no intervalo entre $233-136 \mathrm{~cm}$ e está representado por 21 amostras. As análises de isótopos de oxigênio apresentaram a mediana de 4,06\%o, uma variância de 0,03\%o, com um máximo de 4,23\% e um mínimo de $3,5 \%$ para esse período, apresentando o maior valor para a mediana para todo o testemunho.

Apesar do MIS 3 receber a designação de um número ímpar e de um período considerado interglacial, o mesmo não é tido como. Devido aos valores isotópicos não tão reduzidos como os demais períodos interglaciais, estudos o consideram como de ampla diversidade de fases climáticas quentes durante o último máximo glacial, associando-o a ocorrência de eventos Dansgaard-Oeschger (DO) (Van Meerbeecket al., 2009; Houmark-Nielsen, 2010). Sendo considerado um período misto que apresenta inúmeras incursões de calor dentro de um período glacial (Lisiecki \& Raymo (2005)).

O MIS 3 compreendido entre 56,9 e 30,6 k.a., correspondendo a $104 \mathrm{~cm}$ de sedimento no intervalo entre $131-27 \mathrm{~cm}$ e está representado por 21 amostras. As 
análises de isótopos de oxigênio apresentaram a mediana de 3,76\%, uma variância de $0,03 \%$, com um máximo de 4,06\% e um mínimo de 3,43\%o para esse período.

O MIS 2 foi definido como período glacial, sendo o último máximo glacial, compreendido entre 28 e 23,9 k.a., correspondendo a $8 \mathrm{~cm}$ de sedimento no intervalo entre 22-14 cm e está representado por apenas 2 amostras. As análises de isótopos de oxigênio apresentaram a mediana de 3,98\%o, uma variância de $0,05 \%$, com um máximo de $4,14 \%$ e um mínimo de 3,83\% para esse período.

O MIS 1 foi definido como período interglacial atual compreendido entre 12,8 e 4,4 k.a., correspondendo a $6 \mathrm{~cm}$ de sedimentos no intervalo entre 0-6 cm e está representado por apenas 2 amostras. As análises de isótopos de oxigênio apresentaram a mediana de 3,37\%, uma variância de $0,12 \%$, com um máximo de 3,62\% e um mínimo de 3,13\% para esse período.

Os períodos observados e seus respectivos limites temporais estão resumidos naTabela 2, abaixo: 
Tabela 2: Parâmetros estatísticos extraídos da razão isotópica de oxigênio em foraminíferos bentônicos.

\begin{tabular}{|cccccc|}
\hline MIS & Máximo & Mínimo & Mediana & Variância & media \\
1 & 3,62 & 3,13 & 3,37 & 0,12 & 3,37 \\
2 & 4,14 & 3,83 & 3,98 & 0,05 & 3,98 \\
3 & 4,06 & 3,43 & 3,76 & 0,03 & 3,76 \\
4 & 4,23 & 3,50 & 4,06 & 0,03 & 4,00 \\
5 & 3,80 & 2,38 & 3,33 & 0,09 & 3,34 \\
6 & 4,35 & 3,15 & 3,99 & 0,06 & 3,95 \\
7 & 3,99 & 2,48 & 3,34 & 0,16 & 3,35 \\
8 & 4,26 & 3,20 & 3,95 & 0,06 & 3,88 \\
9 & 3,86 & 2,66 & 3,26 & 0,10 & 3,30 \\
10 & 4,52 & 3,33 & 4,00 & 0,08 & 4,00 \\
11 & 3,89 & 2,60 & 3,35 & 0,21 & 3,33 \\
12 & 4,25 & 3,45 & 4,01 & 0,08 & 3,95 \\
13 & 3,55 & 3,07 & 3,11 & 0,04 & 3,21 \\
14 & 4,18 & 3,47 & 3,93 & 0,04 & 3,91 \\
15 & 3,86 & 2,83 & 3,39 & 0,09 & 3,38 \\
16 & 4,46 & 3,64 & 3,97 & 0,06 & 4,01 \\
17 & 3,74 & 3,20 & 3,55 & 0,03 & 3,50 \\
18 & 3,95 & 3,16 & 3,76 & 0,04 & 3,73 \\
19 & 3,50 & 2,89 & 3,22 & 0,09 & 3,20 \\
\hline
\end{tabular}

\subsection{Granulometria}

\subsubsection{Laser}

Os resultados de Sortable Silt calculados a partir da granulometria a laser estão expostos na Figura 7. Uma breve descrição e caracterização com estatística descritiva por estagio encontra-se abaixo e sumarizada (Tabela 3). Vale lembrar que optou-se pela notação em micrometros para a composição do índice de Sortable Silt (SS), pois 
este tem comportamento linear proporcional às velocidades de paleocorrentes expressas por ele.

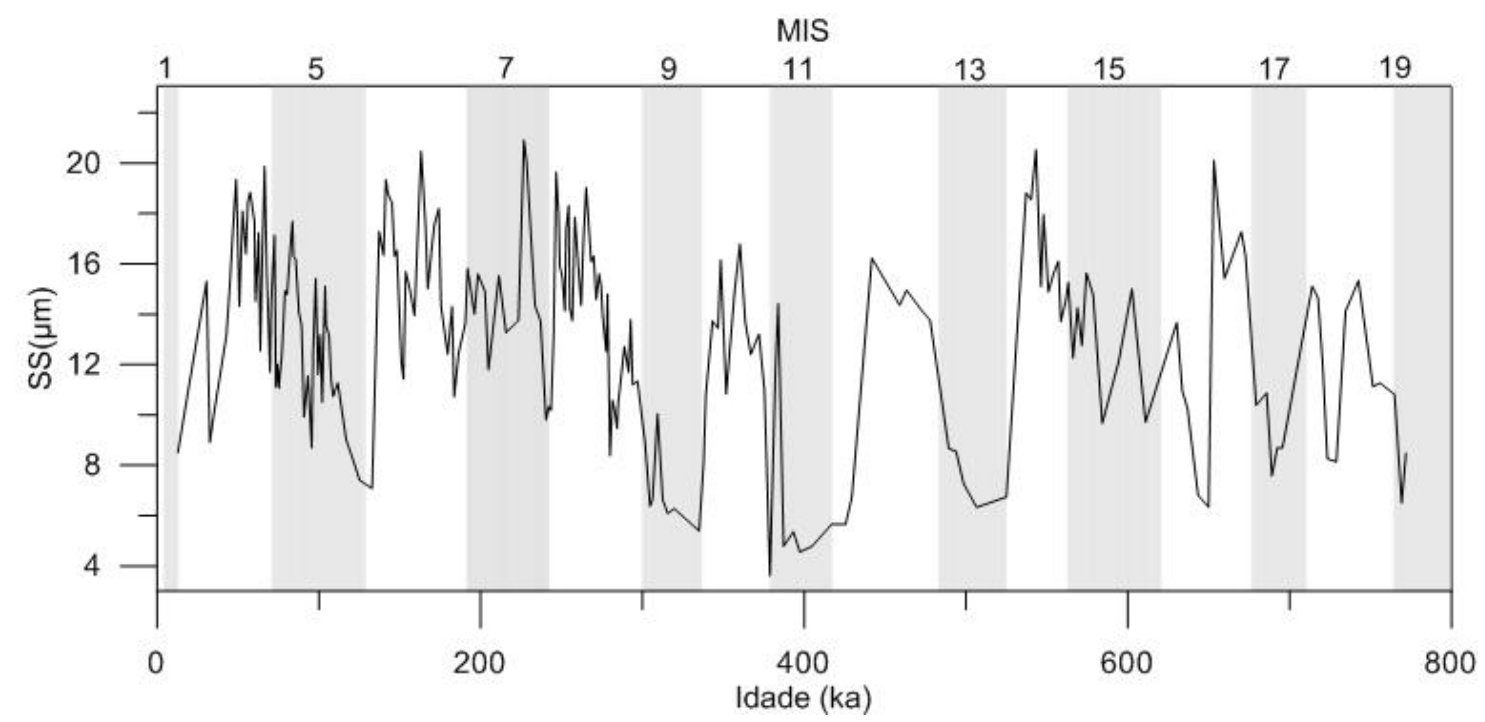

Figura 7: Índice de Sortable Silt a partir da análise a laser. Assinalado em cinza estão os estágios isotópicos interglaciais.

O MIS 19, determinado como período interglacial, apresentou um comportamento de máximo valor de 10,81 $\mu \mathrm{m}$, mínimo de 6,50 $\mu \mathrm{m}$ no início do período, mediana de $8,48 \mu \mathrm{m}$ e uma variância de $4,67 \mu \mathrm{m}$. O período apresentou valores médios de $8,60 \mu \mathrm{m}$, sendo a média abaixo do valor adjacente.

O MIS 18, determinado como período glacial, apresentou um comportamento de máximo valor de 15,34 $\mu \mathrm{m}$ situado no meio do período, mínimo de 8,14 $\mu \mathrm{m}$ no final do período, mediana de 11,95 $\mu \mathrm{m}$ e uma variância de $7,76 \mu \mathrm{m}$. O período apresentou valores médios de 12,22 $\mu \mathrm{m}$, sendo a média acima dos valores adjacentes.

O MIS 17, determinado como período interglacial, apresentou um comportamento de máximo valor de 10,87 um situado próximo ao final do período, mínimo de 7,57 $\mu \mathrm{m}$ no meio do período, mediana de 8,70 $\mu \mathrm{m}$ e uma variância de 1,84 $\mu \mathrm{m}$. O período apresentou valores médios de $9,25 \mu \mathrm{m}$, sendo a média abaixo dos valores adjacentes. 
O MIS 16, determinado como período glacial, apresentou um comportamento de máximo valor de 20,11 um situado próximo ao meio do período, mínimo de 6,34 $\mu \mathrm{m}$ no meio do período, mediana de 13,67 $\mu \mathrm{m}$ e uma variância de $22,56 \mu \mathrm{m}$. O período apresentou valores médios de 13,02 $\mu \mathrm{m}$, acima do período anterior e abaixo do período seguinte, contudo a mediana e variância desse período está acima dos valores adjacentes. Os valores de variância são os maiores ao longo do testemunho.

O MIS 15, determinado como período interglacial, apresentou um comportamento de máximo valor de 15,64 um situado próximo ao final do período, mínimo de 9,67 um no início do período, mediana de 13,50 $\mu \mathrm{m}$ e uma variância de 4,88 $\mu \mathrm{m}$. O período apresentou valores médios de $13,15 \mu \mathrm{m}$, sendo a média abaixo do período seguinte.

O MIS 14, determinado como período glacial, apresentou um comportamento de máximo valor de 20,53 $\mu \mathrm{m}$ situado próximo ao meio do período, mínimo de 13,71 $\mu \mathrm{m}$ no início do período, mediana de 15,85 $\mu \mathrm{m}$ e uma variância de $5,01 \mu \mathrm{m}$. O período apresentou valores médios de $16,58 \mu \mathrm{m}$, média acima dos valores adjacentes. $\mathrm{O}$ período apresentou o maior valor entre os períodos glaciais.

O MIS 13, determinado como período interglacial, apresentou um comportamento de máximo valor de 8,67 $\mu \mathrm{m}$ situado próximo ao final do período, mínimo de 6,33 $\mu \mathrm{m}$ no início do período, mediana de 7,28 $\mu \mathrm{m}$ e uma variância de 1,11 $\mu \mathrm{m}$. O período apresentou valores médios de $7,51 \mu \mathrm{m}$, sendo a média abaixo dos valores adjacentes.

O MIS 12, determinado como período glacial, apresentou um comportamento de máximo valor de 16,22 um situado próximo ao meio do período, mínimo de 5,66 $\mu \mathrm{m}$ no final do período, mediana de $14,19 \mu \mathrm{m}$ e uma variância de $17,91 \mu \mathrm{m}$. O período apresentou valores médios de 12,27 $\mu \mathrm{m}$, média acima dos valores adjacentes. $\mathrm{O}$ período apresentou o menor valor entre os períodos glaciais

O MIS 11, determinado como período interglacial, apresentou um comportamento de máximo valor de 14,42 $\mu \mathrm{m}$ situado próximo ao final do período, mínimo de 3,61 $\mu \mathrm{m}$ no final do período, mediana de 5,08 $\mu \mathrm{m}$ e uma variância de 15,64 
$\mu \mathrm{m}$. O período apresentou valores médios de 6,87 $\mu \mathrm{m}$, sendo média abaixo dos valores adjacentes. O período apresentou o menor valor ao longo do testemunho e a maior variância entre os períodos interglaciais.

O MIS 10, determinado como período glacial, apresentou um comportamento de máximo valor de 16,79 $\mu \mathrm{m}$ situado próximo ao meio do período, mínimo de 8,04 $\mu \mathrm{m}$ no final do período, mediana de $13,33 \mu \mathrm{m}$ e uma variância de 6,13 $\mu \mathrm{m}$. O período apresentou valores médios de 12,91 $\mu \mathrm{m}$, sendo a média acima dos valores adjacentes.

O MIS 9, determinado como período interglacial, apresentou um comportamento de máximo valor de 10,05 $\mu \mathrm{m}$ situado próximo ao final do período, mínimo de 5,39 $\mu \mathrm{m}$ no início do período, mediana de 6,5 $\mu \mathrm{m}$ e uma variância de 2,49 $\mu \mathrm{m}$. O período apresentou valores médios de 7,05 $\mu \mathrm{m}$, sendo média abaixo dos valores adjacentes.

O MIS 8, determinado como período glacial, apresentou um comportamento de máximo valor de 19,65 $\mu \mathrm{m}$ situado próximo ao final do período, mínimo de 8,38 $\mu \mathrm{m}$ no meio do período, mediana de $14,19 \mu \mathrm{m}$ e uma variância de $8,40 \mu \mathrm{m}$. O período apresentou valores médios de 14,18 $\mu \mathrm{m}$, acima do período anterior e abaixo do período seguinte.

O MIS 7, determinado como período interglacial, apresentou um comportamento de máximo valor de $20,91 \mu \mathrm{m}$ situado próximo ao meio do período, mínimo de 9,81 um no início do período, mediana de 14,17 um e uma variância de 9,63 $\mu \mathrm{m}$. O período apresentou valores médios de 14,56 $\mu \mathrm{m}$, média abaixo do período seguinte. O período apresentou o maior valor ao longo do testemunho, sendo as maiores mediana e média entre os períodos interglaciais.

O MIS 6, determinado como período glacial, apresentou um comportamento de máximo valor de 20,47 $\mu \mathrm{m}$ situado próximo ao meio do período, mínimo de 7,08 um no início do período, mediana de $15,7 \mu \mathrm{m}$ e uma variância de 9,59 $\mu \mathrm{m}$. O período apresentou valores médios de 15,27 $\mu \mathrm{m}$, sendo a média acima dos valores adjacentes. 
O MIS 5, determinado como período interglacial, apresentou um comportamento de máximo valor de 17,69 $\mu \mathrm{m}$ situado próximo ao meio do período, mínimo de 7,41 $\mu \mathrm{m}$ no início do período, mediana de 12,40 $\mu \mathrm{m}$ e uma variância de $7,11 \mu \mathrm{m}$. O período apresentou valores médios de 12,66 $\mu \mathrm{m}$, sendo média abaixo dos valores adjacentes.

O MIS 4, determinado como período glacial, apresentou um comportamento de máximo valor de 19,87 $\mu \mathrm{m}$ situado próximo ao final do período, mínimo de 11,7 $\mu \mathrm{m}$ no final do período, mediana de $16,13 \mu \mathrm{m}$ e uma variância de $7,01 \mu \mathrm{m}$. O período apresentou valores médios de 15,91 $\mu \mathrm{m}$, média acima dos valores adjacentes. O período apresentou os maiores valores de mediana e média ao longo do testemunho.

O MIS 3 apresentou um comportamento de máximo valor de 19,34 $\mu \mathrm{m}$ situado próximo ao início do período, mínimo de $8,91 \mu \mathrm{m}$ no final do período, mediana de 15,85 $\mu \mathrm{m}$ e uma variância de 10,64 $\mu \mathrm{m}$. O período apresentou valores médios de $15,31 \mu \mathrm{m}$, sendo a média abaixo a do período anterior e acima do período seguinte. Contudo, o MIS 3, como aqui apresentado anteriormente, tem características peculiares e por isso destoa do padrão determinado.

O MIS 2, determinado como período glacial, apresentou um comportamento de máximo valor de 10,20 $\mu \mathrm{m}$ situado próximo ao final do período, mínimo de 9,30 $\mu \mathrm{m}$ no início do período, mediana de 9,75 $\mu \mathrm{m}$ e uma variância de $0,10 \mu \mathrm{m}$. O período apresentou valores médios de $9,75 \mu \mathrm{m}$, sendo a média acima do período seguinte.

O MIS 1, determinado como período interglacial, apresentou um comportamento de máximo valor de 8,50 $\mu \mathrm{m}$ situado próximo ao início do período, mínimo de 7,9 $\mu \mathrm{m}$ no final do período, mediana de 8,2 $\mu \mathrm{m}$ e uma variância de 0,18 $\mu \mathrm{m}$. O período apresentou valores médios de $8,2 \mu \mathrm{m}$, sendo a média abaixo do valor adjacente. 
Tabela 3: Parâmetros estatísticos extraídos do Sortable Silt a laser.

\begin{tabular}{|cccccc|}
\hline MIS & Máximo & Mínimo & Mediana & Variância & Média \\
1 & 8,50 & 7,90 & 8,20 & 0,18 & 8,20 \\
2 & 10,20 & 9,75 & 9,98 & 0,10 & 9,98 \\
3 & 19,35 & 8,91 & 15,85 & 10,64 & 15,31 \\
4 & 19,87 & 11,70 & 16,13 & 7,01 & 15,91 \\
5 & 17,69 & 7,41 & 12,40 & 7,11 & 12,66 \\
6 & 20,47 & 7,08 & 15,70 & 9,59 & 15,27 \\
7 & 20,91 & 9,81 & 14,17 & 9,63 & 14,56 \\
8 & 19,65 & 8,38 & 14,19 & 8,40 & 14,18 \\
9 & 10,05 & 5,39 & 6,50 & 2,49 & 7,05 \\
10 & 16,79 & 8,04 & 13,33 & 6,13 & 12,91 \\
11 & 14,42 & 3,61 & 5,08 & 15,64 & 6,87 \\
12 & 16,22 & 5,66 & 14,19 & 17,91 & 12,27 \\
13 & 8,67 & 6,33 & 7,28 & 1,11 & 7,51 \\
14 & 20,53 & 13,71 & 15,85 & 5,01 & 16,58 \\
15 & 15,64 & 9,67 & 13,50 & 4,88 & 13,15 \\
16 & 20,11 & 6,34 & 13,67 & 22,56 & 13,02 \\
17 & 10,87 & 7,57 & 8,70 & 1,84 & 9,25 \\
18 & 15,34 & 8,14 & 11,95 & 7,76 & 12,22 \\
19 & 10,81 & 6,50 & 8,48 & 4,67 & 8,60 \\
\hline
\end{tabular}

\subsubsection{Análise Granulométrica através do princípio da velocidade de sedimentação, técnica da pipetagem}

Para resultados de Sortable Silt calculados a partir da granulometria feita pelo princípio da velocidade de deposição, utilizando a técnica da pipetagem (Figura 8), é possível verificar as oscilações no campo da velocidade das correntes de fundo ao longo dos MIS, observando as variações e padrões entre os períodos glaciais e interglaciais, comparativamente, os períodos glaciais obtiveram velocidades mais 
altas do que os períodos interglaciais adjacentes. Uma breve descrição e caracterização com estatística descritiva por estagio encontra-se abaixo e sumarizada (

Tabela 4)

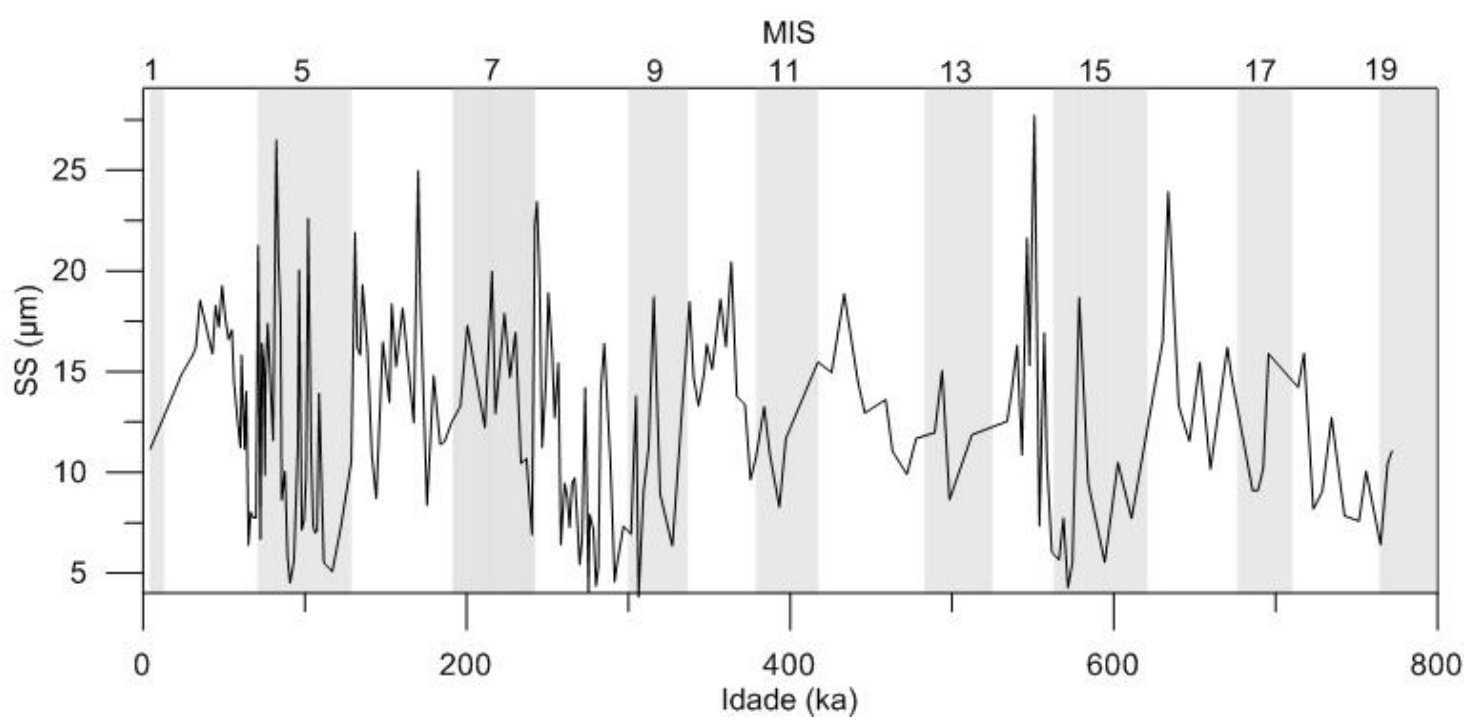

Figura 8: Sortable Silt a partir da análise com o princípio da velocidade de sedimentação, técnica da pipetagem. Assinalado em cinza estão os estágios isotópicos interglaciais.

O MIS 19, determinado como período interglacial, apresentou um comportamento de máximo valor de 11,06 $\mu \mathrm{m}$, mínimo de 6,4 $\mu \mathrm{m}$ no início do período, mediana de 10,45 $\mu \mathrm{m}$ e uma variância de 6,41 $\mu \mathrm{m}$. O período apresentou valores médios de 9,30 $\mu \mathrm{m}$, sendo tal média abaixo do valor adjacente.

O MIS 18, determinado como período glacial, apresentou um comportamento de máximo valor de $15,92 \mu \mathrm{m}$ situado no meio do período, mínimo de $7,58 \mu \mathrm{m}$ no início do período, mediana de 9,57 $\mu \mathrm{m}$ e uma variância de $10,13 \mu \mathrm{m}$. O período apresentou valores médios de 10,70 $\mu \mathrm{m}$, acima do período anterior e abaixo do período seguinte.

O MIS 17, determinado como período interglacial, apresentou um comportamento de máximo valor de 15,89 $\mu \mathrm{m}$ situado próximo ao meio do período,

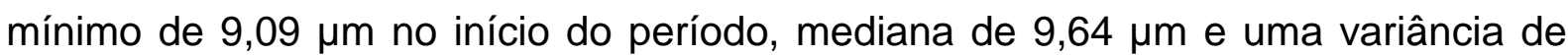


10,62 $\mu \mathrm{m}$. O período apresentou valores médios de 11,07 $\mu \mathrm{m}$, sendo tal média abaixo do valor seguinte.

O MIS 16, determinado como período glacial, apresentou um comportamento de máximo valor de 23,93 $\mu \mathrm{m}$ situado próximo ao meio do período, mínimo de 10,16 $\mu \mathrm{m}$ no fim do período, mediana de $15,11 \mu \mathrm{m}$ e uma variância de $17,36 \mu \mathrm{m}$. O período apresentou valores médios de 15,24 $\mu \mathrm{m}$, sendo tal média acima dos valores adjacentes.

O MIS 15, determinado como período interglacial, apresentou um comportamento de máximo valor de $18,69 \mu \mathrm{m}$ situado próximo ao meio do período, mínimo de 4,27 $\mu \mathrm{m}$ no início do período, mediana de 7,71 $\mu \mathrm{m}$ e uma variância de $19,16 \mu \mathrm{m}$. O período apresentou valores médios de $8,34 \mu \mathrm{m}$, sendo tal média abaixo dos valores adjacentes.

O MIS 14, determinado como período glacial, apresentou um comportamento de máximo valor de 27,72 $\mu \mathrm{m}$ situado próximo ao meio do período, mínimo de 6,04 $\mu \mathrm{m}$ no fim do período, mediana de $14,22 \mu \mathrm{m}$ e uma variância de $38,99 \mu \mathrm{m}$. O período apresentou valores médios de 14,51 $\mu \mathrm{m}$, média acima dos valores adjacentes. Apresentou o maior valor e variância ao longo do testemunho.

O MIS 13, determinado como período interglacial, apresentou um comportamento de máximo valor de 15,05 $\mu \mathrm{m}$ situado próximo ao início do período, mínimo de 8,64 um no meio do período, mediana de 11,92 $\mu \mathrm{m}$ e uma variância de $6,86 \mu \mathrm{m}$. O período apresentou valores médios de $11,88 \mu \mathrm{m}$, sendo tal média abaixo dos valores adjacentes.

O MIS 12, determinado como período glacial, apresentou um comportamento de máximo valor de 18,87 um situado próximo ao início do período, mínimo de 9,90 $\mu \mathrm{m}$ no final do período, mediana de 13,28 $\mu \mathrm{m}$ e uma variância de $7,79 \mu \mathrm{m}$. O período apresentou valores médios de 13,44 $\mu \mathrm{m}$, sendo tal média acima dos valores adjacentes.

O MIS 11, determinado como período interglacial, apresentou um comportamento de máximo valor de 15,48 $\mu \mathrm{m}$ situado próximo ao final do período, mínimo de $8,27 \mu \mathrm{m}$ no meio do período, mediana de $11,32 \mu \mathrm{m}$ e uma variância de 
$5,99 \mu \mathrm{m}$. O período apresentou valores médios de $11,73 \mu \mathrm{m}$, sendo tal média abaixo dos valores adjacentes.

O MIS 10, determinado como período glacial, apresentou um comportamento de máximo valor de 20,45 $\mu$ m situado próximo ao meio do período, mínimo de 9,63 $\mu \mathrm{m}$ no final do período, mediana de $15,01 \mu \mathrm{m}$ e uma variância de $8,37 \mu \mathrm{m}$. O período apresentou valores médios de 15,41 $\mu \mathrm{m}$, sendo tal média acima dos valores adjacentes.

O MIS 9, determinado como período interglacial, apresentou um comportamento de máximo valor de $18,72 \mu \mathrm{m}$ situado próximo ao meio do período, mínimo de 3,82 $\mu \mathrm{m}$ no início do período, mediana de 9,04 $\mu \mathrm{m}$ e uma variância de $22,70 \mu \mathrm{m}$. O período apresentou valores médios de 10,46 $\mu \mathrm{m}$, sendo tal média abaixo dos valores adjacentes. Apresentou o menor valor ao longo do testemunho.

O MIS 8, determinado como período glacial, apresentou um comportamento de máximo valor de 23,45 $\mu$ m situado próximo ao início do período, mínimo de 4,05 $\mu \mathrm{m}$ no meio do período, mediana de $9,46 \mu \mathrm{m}$ e uma variância de $25,56 \mu \mathrm{m}$. O período apresentou valores médios de 10,58 $\mu \mathrm{m}$, sendo tal média abaixo do valor seguinte. Apresentou o menor valor entre os períodos glaciais.

O MIS 7, determinado como período interglacial, apresentou um comportamento de máximo valor de 22,27 $\mu \mathrm{m}$ situado próximo ao final do período, mínimo de 6,91 $\mu \mathrm{m}$ no final do período, mediana de 14,23 $\mu \mathrm{m}$ e uma variância de 17,78 $\mu \mathrm{m}$. O período apresentou valores médios de 14,60 $\mu \mathrm{m}$, sendo tal média abaixo do período seguinte. Apresentou o maior valor de mediana e média entre os períodos interglaciais.

O MIS 6, determinado como período glacial, apresentou um comportamento de máximo valor de 24,98 $\mu \mathrm{m}$ situado próximo ao meio do período, mínimo de 8,36 $\mu \mathrm{m}$ no final do período, mediana de $15,53 \mu \mathrm{m}$ e uma variância de $18,16 \mu \mathrm{m}$. O período apresentou valores médios de 15,26 $\mu \mathrm{m}$, sendo tal média acima dos valores adjacentes.

O MIS 5, determinado como período interglacial, apresentou um comportamento de máximo valor de $26,49 \mu \mathrm{m}$ situado próximo ao início do período, 
mínimo de 4,51 $\mu \mathrm{m}$ no meio do período, mediana de $10,30 \mu \mathrm{m}$ e uma variância de $34,69 \mu \mathrm{m}$. O período apresentou valores médios de $11,88 \mu \mathrm{m}$, sendo tal média acima do valor seguinte. Apresentou o maior valor e variância entre os períodos interglaciais.

O MIS 4, determinado como período glacial, apresentou um comportamento de máximo valor de 15,82 $\mu \mathrm{m}$ situado próximo ao início do período, mínimo de 6,39 $\mu \mathrm{m}$ no final do período, mediana de $11,15 \mu \mathrm{m}$ e uma variância de $10,61 \mu \mathrm{m}$. O período apresentou valores médios de 10,55 $\mu \mathrm{m}$, sendo tal média abaixo dos valores adjacentes.

O MIS 3 apresentou um comportamento de máximo valor de 19,27 $\mu \mathrm{m}$ situado próximo ao final do período, mínimo de $14,56 \mu \mathrm{m}$ no início do período, mediana de $17,08 \mu \mathrm{m}$ e uma variância de 1,91 $\mu \mathrm{m}$. O período apresentou valores médios de 17,01 $\mu \mathrm{m}$, sendo que tal média está acima dos períodos adjacentes. Apresentou o maior valor de média e mediana ao longo do testemunho.

O MIS 2, determinado como período glacial, apresentou um comportamento de máximo valor de 15,20 um situado próximo ao final do período, mínimo de 24,89 $\mu \mathrm{m}$ no início do período, mediana de 15,04 $\mu \mathrm{m}$ e uma variância de $0,05 \mu \mathrm{m}$. O período apresentou valores médios de 15,04 $\mu \mathrm{m}$, sendo tal média acima do período seguinte.

O MIS 1, determinado como período interglacial, apresentou um comportamento de máximo valor de 12,50 um situado próximo ao final do período, mínimo de 11,16 $\mu \mathrm{m}$ no início do período, mediana de 11,83 $\mu \mathrm{m}$ e uma variância de $0,89 \mu \mathrm{m}$. O período apresentou valores médios de $11,83 \mu \mathrm{m}$, sendo tal media abaixo do valor adjacente. 
Tabela 4: Parâmetros estatísticos extraídos do Sortable Silt a com o princípio da velocidade de sedimentação, técnica da pipetagem.

\begin{tabular}{|cccccc|}
\hline MIS & Máximo & Mínimo & Mediana & Variância & media \\
1 & 12,50 & 11,16 & 11,83 & 0,89 & 11,83 \\
2 & 15,20 & 14,89 & 15,04 & 0,05 & 15,04 \\
3 & 19,27 & 14,56 & 17,08 & 1,91 & 17,01 \\
4 & 15,82 & 6,39 & 11,15 & 10,61 & 10,55 \\
5 & 26,49 & 4,51 & 10,30 & 34,69 & 11,88 \\
6 & 24,98 & 8,36 & 15,53 & 18,16 & 15,26 \\
7 & 22,27 & 6,91 & 14,23 & 17,78 & 14,60 \\
8 & 23,45 & 4,05 & 9,46 & 25,56 & 10,58 \\
9 & 18,72 & 3,82 & 9,04 & 22,70 & 10,46 \\
10 & 20,45 & 9,63 & 15,01 & 8,37 & 15,41 \\
11 & 15,48 & 8,27 & 11,32 & 5,99 & 11,73 \\
12 & 18,87 & 9,90 & 13,28 & 7,79 & 13,44 \\
13 & 15,05 & 8,64 & 11,92 & 6,86 & 11,88 \\
14 & 27,72 & 6,04 & 14,22 & 38,99 & 14,51 \\
15 & 18,69 & 4,27 & 7,71 & 19,16 & 8,34 \\
16 & 23,93 & 10,16 & 15,11 & 17,36 & 15,24 \\
17 & 15,89 & 9,09 & 9,64 & 10,62 & 11,07 \\
18 & 15,92 & 7,58 & 9,57 & 10,13 & 10,70 \\
19 & 11,06 & 6,40 & 10,45 & 6,41 & 9,30 \\
\hline
\end{tabular}

\subsubsection{Comparação do Sortable Silt}

Para ambos os índices de Sortable Silt (Figura 9) foi feita uma análise univariada considerando dois cenários: o primeiro ponto a ponto, utilizando a série de dados original, e um segundo utilizando a média por estagio isotópico marinho (MIS). Para ambos foram descartados os MIS 2 e 1 devido à baixa resolução apresentada, - MIS 3 também não foi considerado, uma vez que objetivo é caracterizar as diferenças entre os períodos glaciais e interglaciais, optou-se por descartar o MIS 3 pois apresenta um aspecto misto desse estágio. 


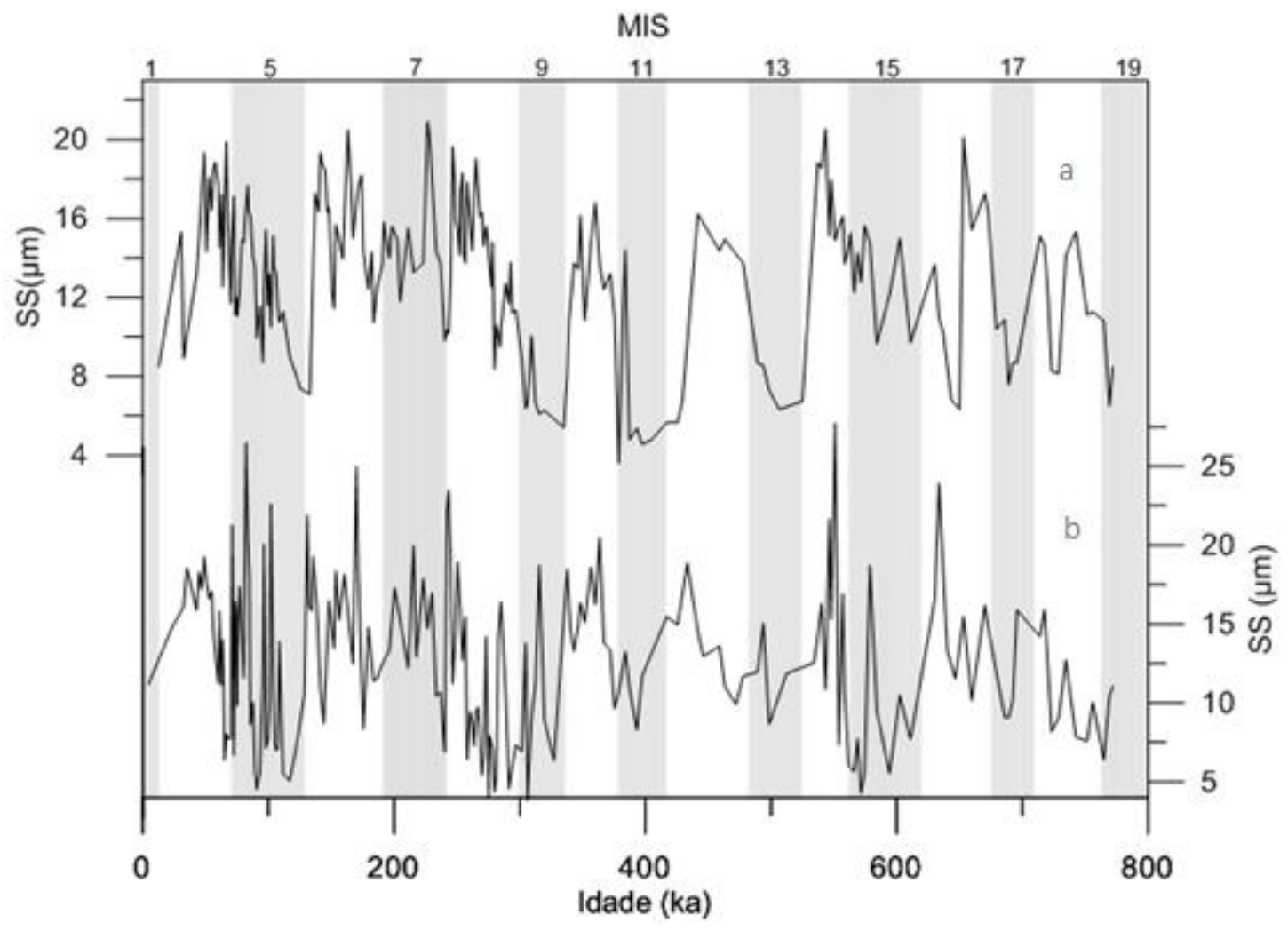

Figura 9: Comparação entre o índice de Sortable Silt a (a) laser e a (b) partir do princípio da velocidade de sedimentação.

Com uma análise univariada (Tabela 5) é possível notar que no índice ponto a ponto, ambas as curvas apresentam uma curtose negativa sendo consideradas platicurticas, apresentando uma distribuição mais achatada em relação a normal, "calda mais leve" e com uma assimetria oposta. No caso do índice construído a partir da análise a laser percebe-se uma assimetria negativa, deslocada para a esquerda. Para o índice a partir da velocidade de sedimentação a assimetria foi positiva deslocada para a direita. 
Tabela 5: Parâmetros estatísticos extraídos da comparação entre os índices de Sortable Silt ponto a ponto e em relação a média, onde SS_M é a análise realizada no Malvern e SS_P é a análise realizada pela técnica da pipetagem.

\begin{tabular}{|cccccccccc|}
\hline & variância & média & des.pad. & Mediana & Min & Max & Assimetria & Curtose & $\begin{array}{c}\text { erro } \\
\text { padrão }\end{array}$ \\
SS_M & 2 & 13,14 & 3,79 & 13,74 & 3,61 & 20,9 & $-0,32$ & $-0,53$ & 0,26 \\
SS_P & 2 & 12,66 & 4,88 & 12,54 & 3,82 & 27,7 & 0,37 & $-0,27$ & 0,35 \\
Média_M & 2 & 11,89 & 3,25 & 12,91 & 6,87 & 16,6 & $-0,27$ & $-1,5$ & 0,79 \\
Média_P & 3 & 12,12 & 2,21 & 11,73 & 8,34 & 15,4 & 0,18 & $-1,34$ & 0,54 \\
\hline
\end{tabular}

A partir dos percentis (Tabela 6) é possível observar que para as séries de média temos uma maior aproximação de valores de corte nos percentis 0.75 e 0.90 enquanto que para a análise ponto a ponto, essa aproximação somente ocorre no percentil 0.75 . A partir dessa análise também é possível observar que a variabilidade de valores é maior nas séries de média, o que pode indicar que considerando ponto a ponto temos uma menor quantidade de pontos discrepantes, ao passo que na análise de média por período, a cada período pode haver algum valor muito discrepante que tenha influencia para sozinho aumentar ou diminuir consideravelmente essa média. 
Tabela 6: Percetis extraídos do Sortable Silt a laser e com o princípio da velocidade de deposição, onde SS_M é a análise realizada no Malvern e SS_P é a análise realizada pela técnica da pipetagem.

\begin{tabular}{|lccccccccccc}
\hline & 0.01 & 0.05 & 0.1 & 0.25 & 0.5 & 0.75 & 0.9 & 0.95 & 0.99 \\
SS_M & 0,78 & 0,34 & 0,49 & 0,73 & 3,74 & 5,70 & 7,77 & 8,83 & 0,41 \\
SS_P & 0,27 & 0,52 & 0,42 & 0,76 & 2,54 & 5,92 & 8,70 & 0,66 & 5,01 \\
Média_M & 0,90 & 0,01 & 0,33 & 0,60 & 2,91 & 4,56 & 5,52 & 6,04 & 6,47 \\
Média_P & 0,50 & 0,11 & 0,00 & 0,58 & 1,73 & 4,51 & 5,25 & 5,29 & 5,38 \\
\hline
\end{tabular}

Para a análise univariada da distribuição considerando a média por período (Tabela 5), e possível observar que ambos os índices apresentam uma curtose negativa, demonstrando o mesmo formato achatado que a série original, com as mesmas direções nos desvios da assimetria, sugerindo que o segundo cenário segue as tendências das series original de dados (Figura 10), inclusive evidenciaram discrepâncias na representação do MIS 4 e 8, onde a análise a laser indica maior velocidade, enquanto pela técnica da pipetagem indica menor velocidade em relação aos estagios adjacentes.

Para a categorização dos períodos glaciais e interglaciais (Tabela 7) foi utilizado "0" caracterizando as médias considerando possuírem valores maiores ou menores que os valores adjacentes e "1" caso ela não apresente essas características. 


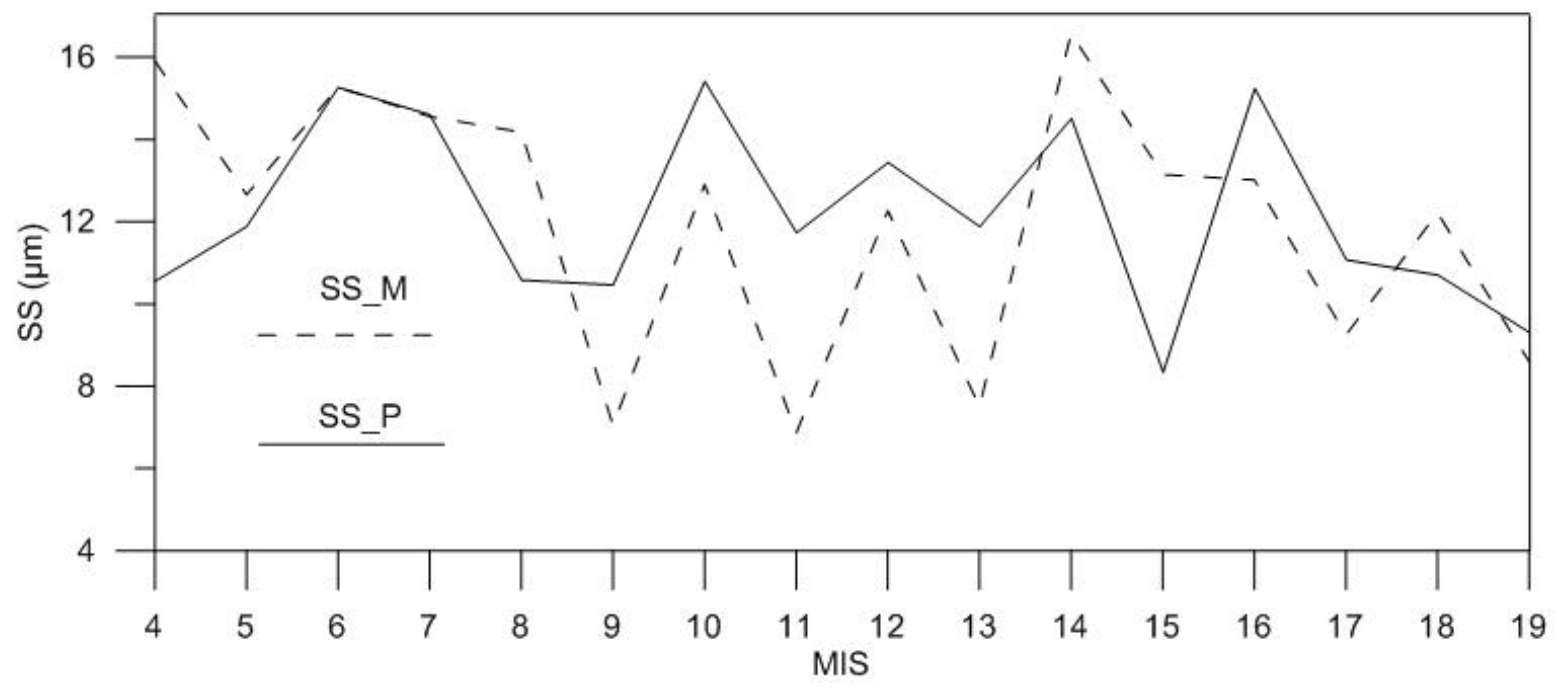

Figura 10:Média por período do Sortable Silt entre os métodos, onde SS_M é a análise realizada no Malvern e SS_P é a análise realizada pela técnica da pipetagem.

Tabela 7: Categorização da média por período.

\begin{tabular}{|ccccc|}
\hline MIS & Média_M & Média_P & Malvern & Pipetagem \\
4 & 15,91 & 10,55 & 0 & 0 \\
5 & 12,66 & 11,88 & 0 & 1 \\
6 & 15,27 & 15,26 & 0 & 0 \\
7 & 14,56 & 14,6 & 1 & 1 \\
8 & 14,18 & 10,58 & 1 & 1 \\
9 & 7,05 & 10,46 & 0 & 0 \\
10 & 12,91 & 15,41 & 0 & 0 \\
11 & 6,87 & 11,73 & 0 & 0 \\
12 & 12,27 & 13,44 & 0 & 0 \\
13 & 7,51 & 11,88 & 0 & 0 \\
14 & 16,58 & 14,51 & 0 & 0 \\
15 & 13,15 & 8,34 & 1 & 0 \\
16 & 13,02 & 15,24 & 1 & 0 \\
17 & 9,25 & 11,07 & 0 & 0 \\
18 & 12,22 & 10,7 & 0 & 1 \\
19 & 8,6 & 9,3 & 0 & 0 \\
\hline
\end{tabular}


Para a elaboração da categorização foi utilizada a média independente da distribuição caudal (apenas um caso foi observado em que a média não foi coerente com a mediana e a variância, ainda sim sendo considerada apenas a média). Para os 16 períodos analisados, obteve-se uma correspondência de 12 períodos, apresentando uma compatibilidade de $75 \%$ entre as categorizações.

\subsection{Isótopos de Carbono}

A partir da curva da razão isotópica do carbono (Figura 11) é possível observar as oscilações registradas em testas de foraminíferos bentônicos entre os MIS, conforme as variações entre os períodos glaciais e interglaciais. Este sinal pode ser interpretado como a assinatura de massas de agua profunda (CURRY; OPPO, 2005). Neste caso, os valores mais positivos dessa curva (Figura 11) indicam uma massa de água de composição mais similar àquelas originadas no hemisfério norte. Por outro lado, os valores mais negativos indicam, proporcionalmente, uma massa de água com maior contribuição de águas de origem no hemisfério sul. Uma breve descrição e caracterização estatística descritiva por estagio encontra-se abaixo sumarizada (Tabela 8). 


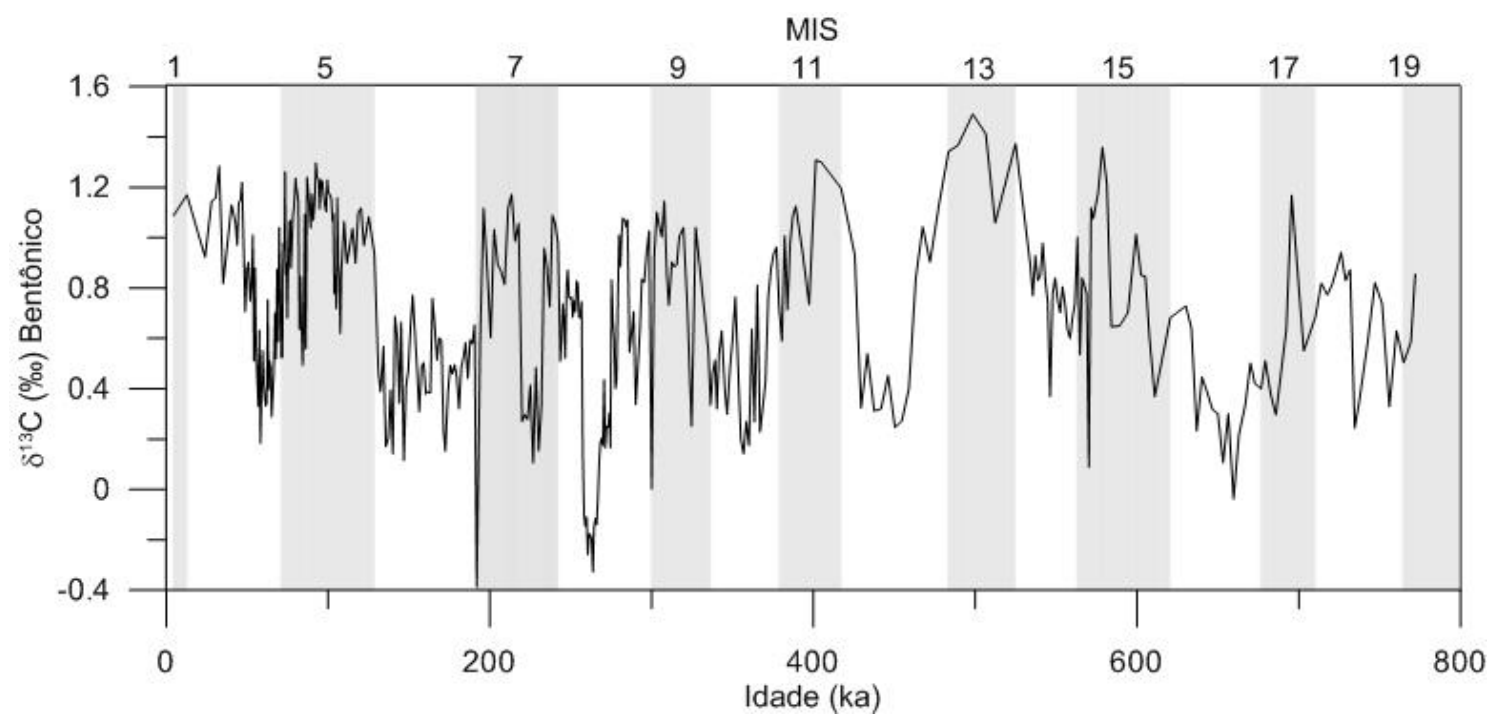

Figura 11: Curva da razão isotópica do carbono em foraminíferos bentônicos do testemunho KF-18. Assinalado em cinza estão os estágios isotópicos interglaciais.

O MIS 19, definido como período interglacial, apresenta a média de 0,65\%o, variância de 0,03\%o, mediana 0,59\%, com um máximo de 0,86\% e um mínimo de $0,50 \%$.

O MIS 18, definido como período glacial, apresenta a média de 0,69\%o, variância de 0,05\%o, mediana 0,79\%, com um máximo de 0,94\%o e um mínimo de $0,24 \%$.

O MIS 17, definido como período interglacial, apresenta a média de 0,58\%o, variância de $0,07 \%$, mediana $0,53 \%$, com um máximo de $1,17 \%$ e um mínimo de $0,30 \%$.

O MIS 16, definido como período glacial, apresenta a média de 0,35\%o, variância de 0,04\%, mediana 0,33\%, com um máximo de 0,73\% e um mínimo de $0,04 \%$.

O MIS 15, definido como período interglacial, apresenta a média de $0,82 \%$, variância de 0,09\%o, mediana 0,82\%o, com um máximo de 1,36\% e um mínimo de 0,09\% . 
O MIS 14, definido como período glacial, apresenta a média de $0,76 \%$, variância de 0,02\%, mediana $0,77 \%$, com um máximo de 0,98\% e um mínimo de $0,37 \%$.

O MIS 13, definido como período interglacial, apresenta a média de 1,34\%, variância de 0,02\%, mediana 1,37\%, com um máximo de 1,49\% e um mínimo de $1,06 \%$. Apresentou o maior valor de máximo, mediana e média ao longo do testemunho.

O MIS 12, definido como período glacial, apresenta a média de 0,59\%, variância de $0,11 \%$, mediana $0,45 \%$, com um máximo de $1,14 \%$ e um mínimo de $0,25 \%$.

O MIS 11, definido como período interglacial, apresenta a média de $0,98 \%$, variância de 0,06\%, mediana 0,99\%, com um máximo de 1,31\%o e um mínimo de $0,59 \%$.

O MIS 10, definido como período glacial, apresenta a média de $0,51 \%$, variância de 0,06\%, mediana 0,48\%, com um máximo de 0,96\% e um mínimo de $0,14 \%$.

O MIS 9, definido como período interglacial, apresenta a média de $0,80 \%$, variância de 0,10\%, mediana 0,90\%, com um máximo de 1,15\% e um mínimo de $0,00 \%$.

O MIS 8, definido como período glacial, apresenta a média de $0,50 \%$, variância de 0,17\%, mediana 0,62\%, com um máximo de 1,08\% e um mínimo de $0,33 \%$. Apresentou a maior variância ao longo do testemunho e o menor valor entre os períodos glaciais.

O MIS 7, definido como período interglacial, apresenta a média de $0,70 \%$, variância de $0,16 \%$, mediana $0,87 \%$, com um máximo de $1,17 \%$ e um mínimo de $0,39 \%$. Apresentou o menor valor ao longo do testemunho e a maior variância entre os períodos interglaciais.

O MIS 6, definido como período glacial, apresenta a média de $0,47 \%$, variância de 0,03\%, mediana 0,48\%, com um máximo de 0,77\% e um mínimo de $0,12 \%$. 
O MIS 5, definido como período interglacial, apresenta a média de 1,00\%, variância de 0,04\%o, mediana 1,07\%o, com um máximo de 1,30\%o e um mínimo de $0,49 \%$.

O MIS 4, definido como período glacial, apresenta a média de 0,53\%o, variância de 0,05\%, mediana 0,50\%, com um máximo de 1,04\%o e um mínimo de $0,18 \%$.

O MIS 3, apresenta a média de 0,91\%o, variância de 0,06\%o, mediana 0,93\%o, com um máximo de $1,28 \%$ e um mínimo de $0,33 \%$.

O MIS 2, definido como período glacial, apresenta a média de 1,03\%o, variância de 0,02\%o, mediana 1,03\%o, com um máximo de 1,14\%o e um mínimo de $0,92 \%$. Apresentou o maior valor de máximo, mediana e média entre os períodos glaciais.

O MIS 1, definido como período interglacial, apresenta a média de 1,13\%o, variância de $0,00 \%$, mediana 1,13\%o, com um máximo de 1,17\%o e um mínimo de $1,09 \%$. 
Tabela 8: Parâmetros estatísticos extraídos da razão isotópica do carbono em foraminíferos bentônicos.

\begin{tabular}{|c|c|c|c|c|c|}
\hline MIS & Máximo & Mínimo & Mediana & Variância & Média \\
\hline 1 & 1,17 & 1,09 & 1,13 & 0 & 1,13 \\
\hline 2 & 1,14 & 0,92 & 1,03 & 0,02 & 1,03 \\
\hline 3 & 1,28 & 0,33 & 0,93 & 0,06 & 0,91 \\
\hline 4 & 1,04 & 0,18 & 0,5 & 0,05 & 0,53 \\
\hline 5 & 1,3 & 0,49 & 1,07 & 0,04 & 1 \\
\hline 6 & 0,77 & 0,12 & 0,48 & 0,03 & 0,47 \\
\hline 7 & 1,17 & $-0,39$ & 0,87 & 0,16 & 0,7 \\
\hline 8 & 1,08 & $-0,33$ & 0,62 & 0,17 & 0,5 \\
\hline 9 & 1,15 & 0 & 0,9 & 0,1 & 0,8 \\
\hline 10 & 0,96 & 0,14 & 0,48 & 0,06 & 0,51 \\
\hline 11 & 1,31 & 0,59 & 0,99 & 0,06 & 0,98 \\
\hline 12 & 1,14 & 0,25 & 0,45 & 0,11 & 0,59 \\
\hline 13 & 1,49 & 1,06 & 1,37 & 0,02 & 1,34 \\
\hline 14 & 0,98 & 0,37 & 0,77 & 0,02 & 0,76 \\
\hline 15 & 1,36 & 0,09 & 0,82 & 0,09 & 0,82 \\
\hline 16 & 0,73 & $-0,04$ & 0,33 & 0,04 & 0,35 \\
\hline 17 & 1,17 & 0,3 & 0,53 & 0,07 & 0,58 \\
\hline 18 & 0,94 & 0,24 & 0,79 & 0,05 & 0,69 \\
\hline 19 & 0,86 & 0,5 & 0,59 & 0,03 & 0,65 \\
\hline
\end{tabular}

\subsection{Susceptibilidade Magnética}

A partir da curva da suscetibilidade magnética (Figura 12) é possível observar as oscilações registradas no sedimento pela variação no campo magnético da Terra entre os MIS, conforme as variações entre os períodos glaciais e interglaciais. Uma breve descrição e caracterização estatística descritiva por estagio encontra-se abaixo sumarizada (Tabela 9). 


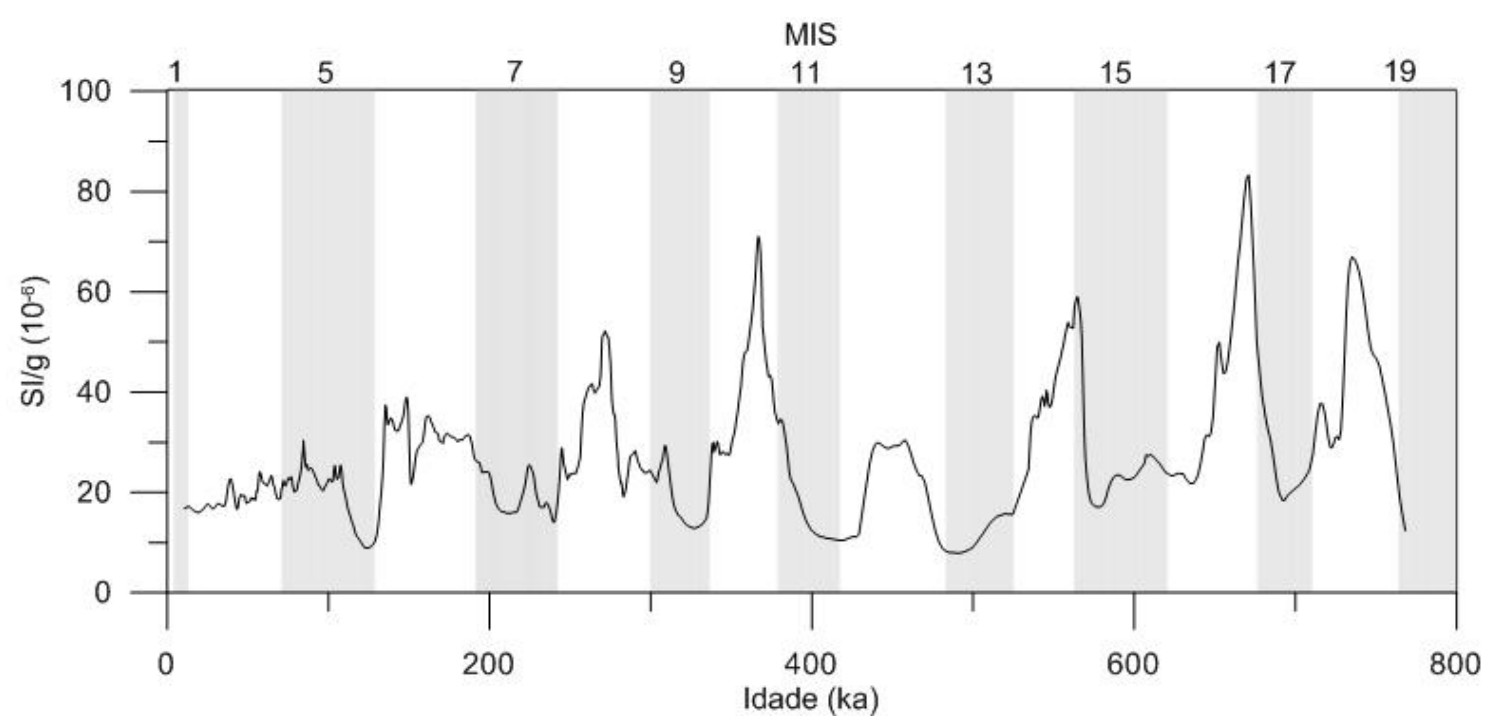

Figura 12: Susceptibilidade magnética ao longo do período. Assinalado em cinza estão os estágios isotópicos interglaciais.

Para o MIS 19 a susceptibilidade magnética corrigida apresentou em seu único ponto amostrado um valor de $18,77 \mathrm{SI} 10^{-5}$.

Para o MIS 18 a susceptibilidade magnética corrigida apresentou no período

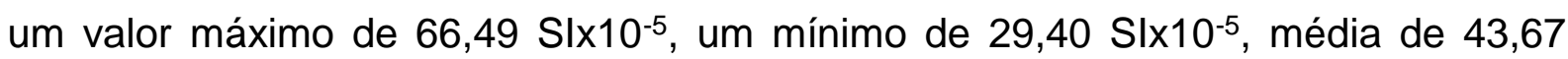
SIx10-5, variância de 178,45 SIX10 $^{-5}$ e uma mediana de 37,95 SIx10

Para o MIS 17 a susceptibilidade magnética corrigida apresentou no período um valor máximo de 39,43 SIX10-5, um mínimo de 18,42 SIX10-5, média de 26,01

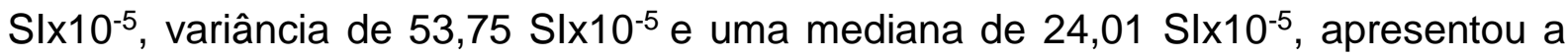
maior mediana entre os períodos interglaciais.

Para o MIS 16 a susceptibilidade magnética corrigida apresentou no período

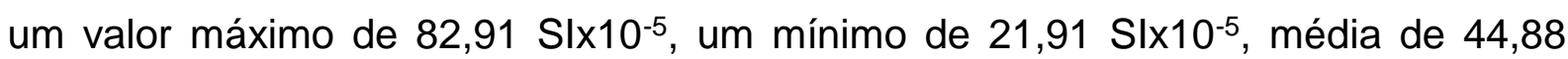

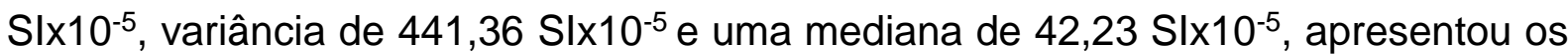
maiores valores de suceptibilidade magnética, medinana, variância e média ao longo de todo o testemunho. 
Para o MIS 15 a susceptibilidade magnética corrigida apresentou no período

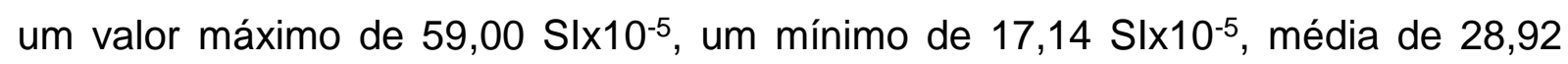
SIX10-5, variância de $194,86 \mathrm{SI}^{-10^{-5}}$ e uma mediana de $23,81 \mathrm{SI}^{-10^{-5}}$, apresentou 0 maior valor, média e variância entre os períodos interglaciais.

Para o MIS 14 a susceptibilidade magnética corrigida apresentou no período

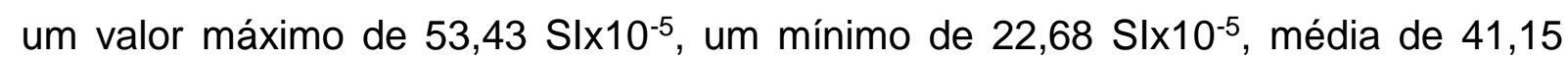

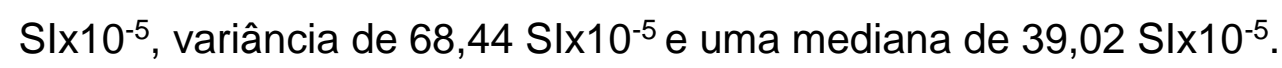

Para o MIS 13 a susceptibilidade magnética corrigida apresentou no período

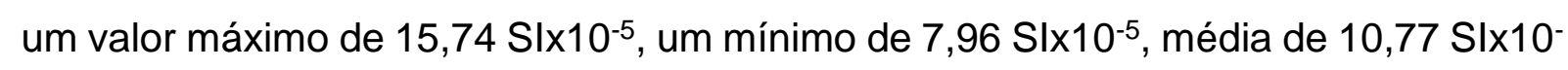
5 , variância de 11,16 SIX10 $10^{-5}$ e uma mediana de 8,74 SIX10 $10^{-5}$, apresentou o menor valor ao longo de todo testemunho.

Para o MIS 12 a susceptibilidade magnética corrigida apresentou no período

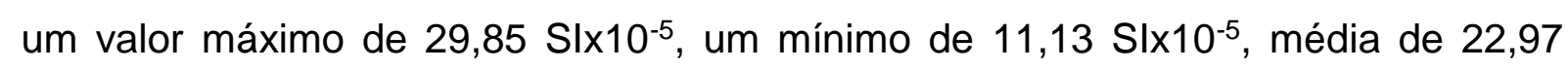
SIX10-5, variância de 55,32 $\mathrm{SI}^{-1} 10^{-5}$ e uma mediana de $25,78 \mathrm{SI} \times 10^{-5}$, apresentou o menor valor entre os períodos glaciais.

Para o MIS 11 a susceptibilidade magnética corrigida apresentou no período

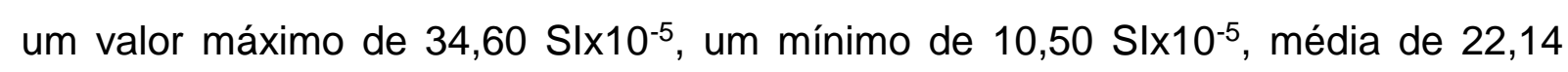

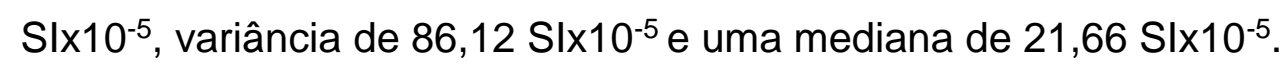

Para o MIS 10 a susceptibilidade magnética corrigida apresentou no período um valor máximo de 70,86 SIX10-5, um mínimo de 27,44 SIX10-5, média de 41,11 SIX10 $0^{-5}$, variância de 173,55 SIX10 $^{-5}$ e uma mediana de 39,14 SIX10 $0^{-5}$.

Para o MIS 9 a susceptibilidade magnética corrigida apresentou no período um

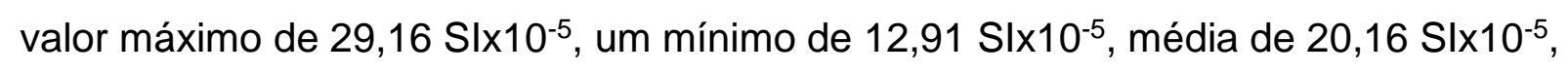
variância de 28,48 SIX10 $10^{-5}$ e uma mediana de 21,06 SIX10-5.

Para o MIS 8 a susceptibilidade magnética corrigida apresentou no período um

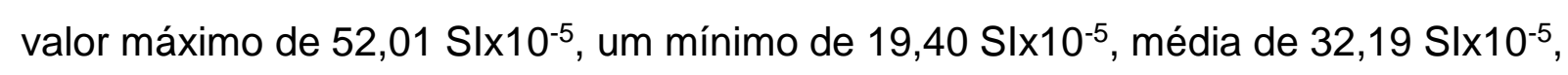
variância de 95,39 SIx10-5 e uma mediana de 27,64 SIx10-5.

Para o MIS 7 a susceptibilidade magnética corrigida apresentou no período um

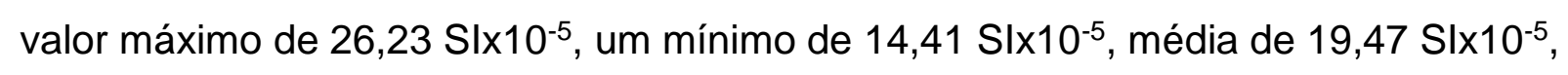
variância de $13,95 \mathrm{SI} 10^{-5}$ e uma mediana de 17,95 SIX10-5. 
Para o MIS 6 a susceptibilidade magnética corrigida apresentou no período um

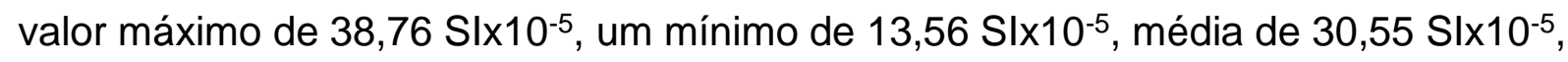
variância de $23,13 \mathrm{SI} 10^{-5}$ e uma mediana de $31,24 \mathrm{SI} \times 10^{-5}$.

Para o MIS 5 a susceptibilidade magnética corrigida apresentou no período um

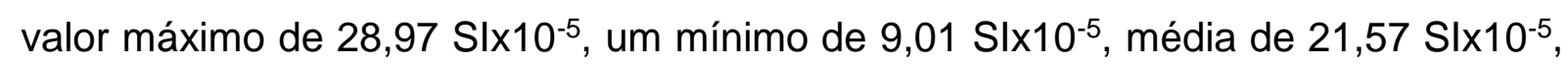
variância de $17,53 \mathrm{SI} 10^{-5}$ e uma mediana de $22,41 \mathrm{SI} \times 10^{-5}$.

Para o MIS 4 a susceptibilidade magnética corrigida apresentou no período um

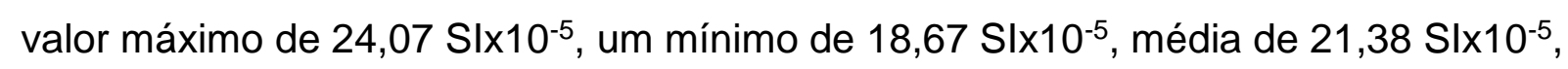
variância de 2,68 SIX10-5 e uma mediana de 21,67 SIX10-5.

Para o MIS 3 a susceptibilidade magnética corrigida apresentou no período um

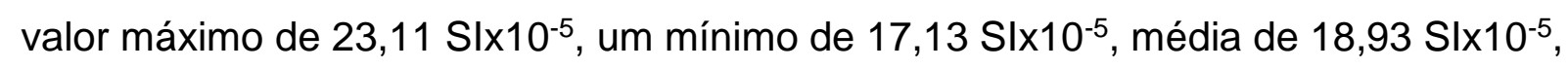
variância de 2,27 SIX10 $^{-5}$ e uma mediana de 18,73 SIX10-5.

Para o MIS 2 a susceptibilidade magnética corrigida apresentou no período um

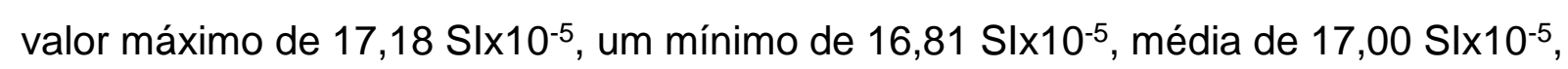
variância de 0,07 SIx10-5 e uma mediana de 17,00 SIx10-5.

Para o MIS 1 a susceptibilidade magnética corrigida apresentou em seu único ponto amostrado um valor de 11,13 SIX10-5 
Tabela 9: Parâmetros estatísticos extraídos da susceptibilidade magnética.

\begin{tabular}{|cccccc|}
\hline MIS & Máximo & Mínimo & Mediana & Variância & Média \\
1 & 17,13 & 17,13 & 17,13 & 0,00 & 17,13 \\
2 & 17,18 & 16,81 & 17,00 & 0,07 & 17,00 \\
3 & 23,11 & 17,13 & 18,73 & 2,27 & 18,93 \\
4 & 24,07 & 18,67 & 21,67 & 2,68 & 21,38 \\
5 & 28,97 & 9,01 & 22,41 & 17,53 & 21,57 \\
6 & 38,76 & 13,56 & 31,24 & 23,13 & 30,55 \\
7 & 26,23 & 14,41 & 17,95 & 13,95 & 19,47 \\
8 & 52,01 & 19,40 & 27,64 & 95,39 & 32,19 \\
9 & 29,16 & 12,91 & 21,06 & 28,48 & 20,16 \\
10 & 70,86 & 27,44 & 39,14 & 173,55 & 41,11 \\
11 & 34,60 & 10,50 & 21,66 & 86,12 & 22,14 \\
12 & 29,85 & 11,13 & 25,78 & 55,32 & 22,97 \\
13 & 15,74 & 7,96 & 8,74 & 11,16 & 10,77 \\
14 & 53,43 & 22,68 & 39,02 & 68,44 & 41,15 \\
15 & 59,00 & 17,14 & 23,81 & 194,86 & 28,92 \\
16 & 82,91 & 21,91 & 42,23 & 441,36 & 44,88 \\
17 & 39,43 & 18,42 & 24,01 & 53,75 & 26,01 \\
18 & 66,49 & 29,40 & 37,95 & 178,45 & 43,67 \\
19 & 18,77 & 18,77 & 18,77 & 0,00 & 18,77 \\
\hline
\end{tabular}

\subsection{Taxa de sedimentação}

A partir das profundidades coletadas em conjunto com o modelo de idade foi possível calcular as taxas de sedimentação lineares para cada MIS (Figura 13). Abaixo encontra-se uma breve descrição da variação da taxa entre os períodos glaciais e interglaciais, além uma sumarização completa de todo o período (Tabela 10). 


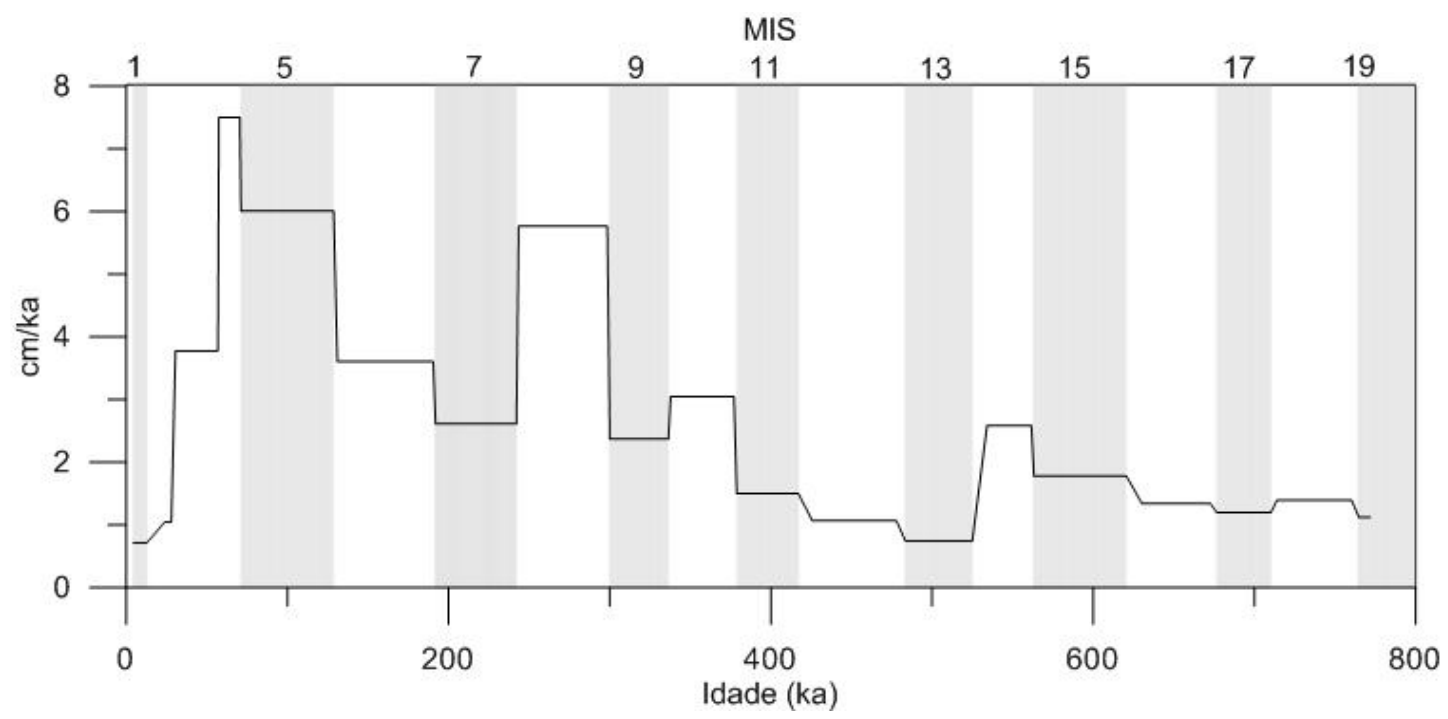

Figura 13: Taxa de sedimentação linear. Assinalado em cinza estão os estágios isotópicos interglaciais.

A maior taxa de sedimentação linear encontrada ao longo de todo o período foi de $7,5 \mathrm{~cm} / \mathrm{ka}$ no MIS 4, sendo que desde o MIS 7 é observado um crescimento nas taxas de deposição até o MIS 4, quando voltou a baixar até atingir o menor valor do período de $0,72 \mathrm{~cm} / \mathrm{ka}$ no MIS 1 .

O MIS 2 apresentou a menor taxa de sedimentação entre os períodos glaciais $(1,05 \mathrm{~cm} / \mathrm{ka})$, enquanto o MIS 5 apresentou a maior taxa de sedimentação entre os períodos interglaciais de $6,01 \mathrm{~cm} / \mathrm{ka}$.

É possível observar que a taxa de sedimentação pode ser dividida em 2 intervalos: o primeiro (MIS 19 - 8), apresentando uma menor variação, enquanto o segundo (MIS 8 - 1) apresenta uma maior variação. 
Tabela 10: Taxa de sedimentação linear em $\mathrm{cm} / \mathrm{ka}$.

\begin{tabular}{|cc|}
\hline MIS & $\begin{array}{c}\text { Taxa de } \\
\text { Sedimentação }\end{array}$ \\
1 & 0,72 \\
2 & 1,05 \\
3 & 3,78 \\
4 & 7,5 \\
5 & 6,01 \\
6 & 3,61 \\
7 & 2,62 \\
8 & 5,77 \\
9 & 2,37 \\
10 & 3,05 \\
11 & 1,5 \\
12 & 1,07 \\
13 & 0,74 \\
14 & 2,59 \\
15 & 1,78 \\
16 & 1,34 \\
17 & 1,2 \\
18 & 1,4 \\
19 & 1,12 \\
\hline
\end{tabular}

\subsection{Teor de carbonato}

A partir da curva do Teor de Carbonato (Figura 14) é possível observar distinções nos valores de carbonato entre os MIS, ou seja, entre períodos glaciais e interglaciais. A partir desta curva, é possível determinar que na profundidade do testemunho estudado $(2200 \mathrm{~m})$ a estratigrafia do carbonato é do tipo-Atlântico, com a maior deposição de carbonatos durante períodos interglaciais (TOLEDO et al., 2016). Os pontos escolhidos para análise foram os mesmos utilizados nas análises isotópicas 
do oxigênio. Segue abaixo uma breve descrição por estagio e uma sumarização completa de todo o período (Tabela 11):

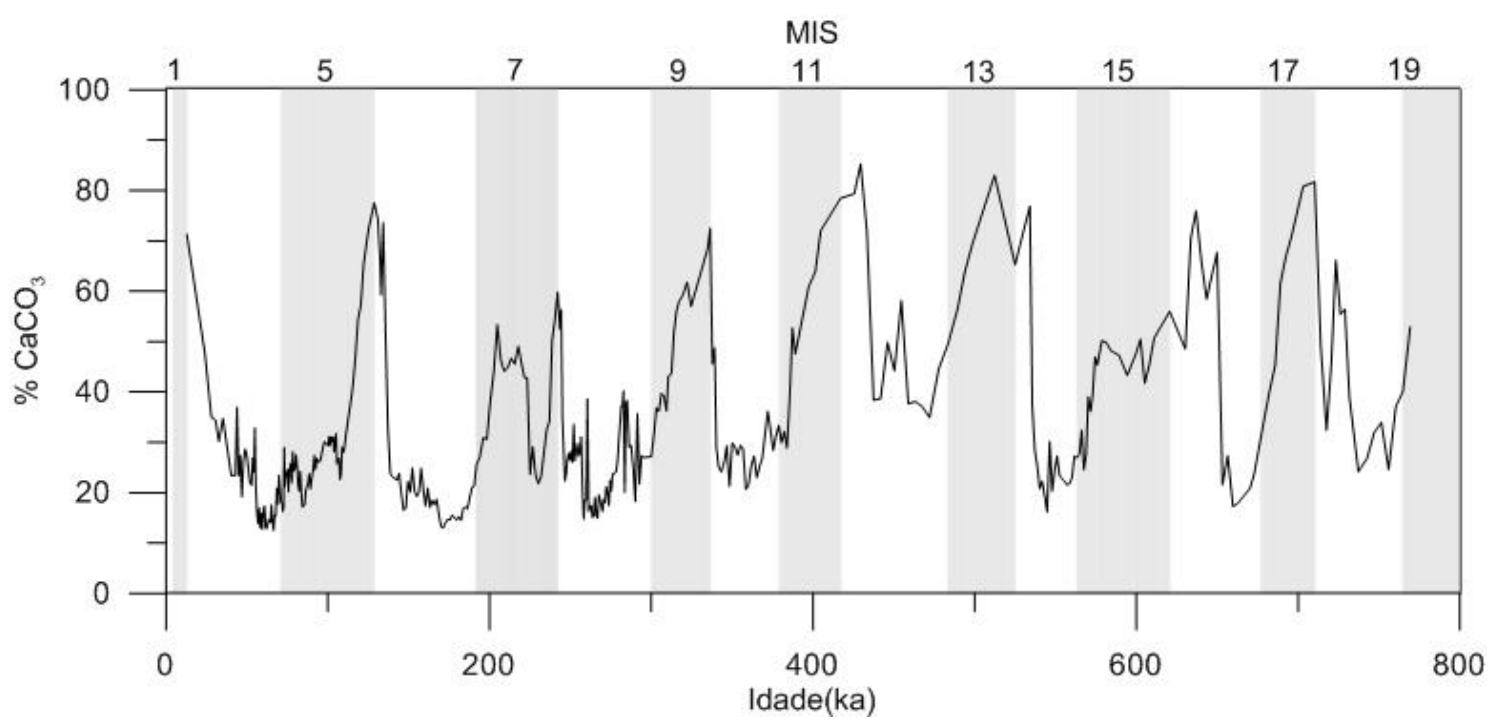

Figura 14: Teor de Carbonato. Assinalado em cinza estão os estágios isotópicos interglaciais.

No MIS 19 a litofácie presente nesse intervalo aponta características de lama pobre em carbonato. O conteúdo de carbonato apresentou uma média de 46,52, mediana de $46,52 \%$, variância de $81,32 \%$ com um máximo de $52,90 \%$ e um mínimo de $40,15 \%$.

No MIS 18 a litofácie presente nesse intervalo aponta características de lama pobre em carbonato no segmento entre 2025 e $1995 \mathrm{~cm}$, lama rica em carbonato entre 1990 e $1965 \mathrm{~cm}$ e lama marga em $1960 \mathrm{~cm}$ do testemunho. O conteúdo de carbonato apresentou uma média de 40,21, mediana de $37,04 \%$, variância de $178,19 \%$ com um máximo de $66,17 \%$ e um mínimo de $24,18 \%$.

No MIS 17 a litofácie presente nesse intervalo aponta características de lama marga em carbonato no segmento entre 1955 e $1940 \mathrm{~cm}$, lama pobre entre 1935 e $1916 \mathrm{~cm}$ do testemunho. O conteúdo de carbonato apresentou uma média de 60,30, mediana de $64,21 \%$, variância de $325,63 \%$ com um máximo de $81,71 \%$ e um mínimo de $35,10 \%$. Apresentou a maior variância entre os períodos interglaciais. 
No MIS 16 a litofácie presente nesse intervalo aponta características de lama pobre em carbonato no segmento entre 1910 e $1880 \mathrm{~cm}$, lama marga entre 1875 e $1845 \mathrm{~cm}$ do testemunho. O conteúdo de carbonato apresentou uma média de $44,54 \%$, mediana de 48,54\%, variância de 540,86\% com um máximo de 76,00\% e um mínimo de $16,27 \%$. Apresentou a maior variância alo longo de todo testemunho. Apresentou a maior mediana entre os períodos glaciais.

No MIS 15 a litofácie presente nesse intervalo aponta características de lama marga em carbonato no segmento entre 1840 e $1765 \mathrm{~cm}$, lama pobre entre 1760 e $1740 \mathrm{~cm}$ do testemunho. O conteúdo de carbonato apresentou uma média de $41,73 \%$, mediana de $45,08 \%$, variância de $84,95 \%$ com um máximo de $56,00 \%$ e um mínimo de $24,56 \%$.

No MIS 14 a litofácie presente nesse intervalo aponta características de lama pobre em carbonato no segmento entre 1735 e $1685 \mathrm{~cm}$, lama rica entre 1680 e 1645 centímetro do testemunho. O conteúdo de carbonato apresentou uma média de $26,89 \%$, mediana de $22,95 \%$, variância de $168,18 \%$ com um máximo de $76,92 \%$ e um mínimo de $16,15 \%$.

No MIS 13 a litofácie presente nesse intervalo aponta características de lama rica em carbonato no segmento entre 1640 e $1635 \mathrm{~cm}$, lama marga entre 1630 e 1610 centímetro do testemunho. O conteúdo de carbonato apresentou uma média de $64,57 \%$, mediana de $64,53 \%$, variância de $131,25 \%$ com um máximo de $83,04 \%$ e um mínimo de $49,62 \%$. Apresenotu o maior valor entre os períodos interglaciais.

No MIS 12 a litofácie presente nesse intervalo aponta características de lama marga em carbonato no segmento em $1605 \mathrm{~cm}$, lama rica entre 1600 e $1560 \mathrm{~cm}$, lama marga entre 1555 e $1545 \mathrm{~cm}$ do testemunho. O conteúdo de carbonato apresentou uma média de $50,63 \%$, mediana de $44,21 \%$, variância de $304,88 \%$ com um máximo de $85,28 \%$ e um mínimo de $34,91 \%$. Apresentando o maior valor de teor de carbonato ao longo do testemunho e a maior média entre os períodos glaciais.

No MIS 11 a litofácie presente nesse intervalo aponta características de lama marga em carbonato no segmento entre 1540 e $1510 \mathrm{~cm}$, lama pobre entre 1505 e $1485 \mathrm{~cm}$ do testemunho. O conteúdo de carbonato apresentou uma média de 49,41\%, 
mediana de 50,13\%, variância de 291,24\% com um máximo de 78,45\% e um mínimo de $28,83 \%$.

No MIS 10 a litofácie presente nesse intervalo aponta características de lama pobre em carbonato no segmento entre 1480 e 1435 cm, lama rica entre 1430 e 1366 $\mathrm{cm}$, lama marga em $1361 \mathrm{~cm}$ do testemunho. O conteúdo de carbonato apresentou uma média de $28,84 \%$, mediana de $27,90 \%$, variância de $45,12 \%$ com um máximo de 48,72\% e um mínimo de $20,67 \%$.

No MIS 9 a litofácie presente nesse intervalo aponta características de lama marga em carbonato no segmento entre 1356 e $1316 \mathrm{~cm}$, lama pobre entre 1311 e $1271 \mathrm{~cm}$ do testemunho. O conteúdo de carbonato apresentou uma média de 48,13\%, mediana de 43,62\%, variância de $182,15 \%$ com um máximo de $72,51 \%$ e um mínimo de $27,14 \%$.

No MIS 8 a litofácie presente nesse intervalo aponta características de lama pobre em carbonato no segmento entre 1266 e $1246 \mathrm{~cm}$, lama rica entre 1241 e 1191 cm, lama pobre entre 1186 e $1051 \mathrm{~cm}$, lama rica entre 1046 e $946 \mathrm{~cm}$ do testemunho. O conteúdo de carbonato apresentou uma média de $25,72 \%$, mediana de $24,20 \%$, variância de 74,94\% com um máximo de 56,32\% e um mínimo de 14,76\%.

No MIS 7 a litofácie presente nesse intervalo aponta características de lama marga em carbonato no segmento entre 941 e $936 \mathrm{~cm}$, lama pobre entre 931 e 891 cm, lama marga entre 886 e $836 \mathrm{~cm}$, lama pobre entre 831 e $811 \mathrm{~cm}$ do testemunho. O conteúdo de carbonato apresentou uma média de $38,42 \%$, mediana de $42,77 \%$, variância de 122,24\% com um máximo de 59,83\% e um mínimo de 21,81\%.

No MIS 6 a litofácie presente nesse intervalo aponta características de lama pobre em carbonato no segmento entre 806 e $791 \mathrm{~cm}$, lama rica entre 786 e $616 \mathrm{~cm}$, lama marga entre 611 e $588 \mathrm{~cm}$ do testemunho. O conteúdo de carbonato apresentou uma média de $24,10 \%$, mediana de $19,16 \%$, variância de $243,66 \%$ com um máximo de $74,29 \%$ e um mínimo de $13,01 \%$.

No MIS 5 a litofácie presente nesse intervalo aponta características de lama marga em carbonato no segmento entre 583 e $573 \mathrm{~cm}$, lama pobre entre 568 e 368 cm, lama rica entre 363 e $238 \mathrm{~cm}$ do testemunho. O conteúdo de carbonato 
apresentou uma média de 28,61\%, mediana de 25,84\%, variância de $146,50 \%$ com um máximo de $77,58 \%$ e um mínimo de $16,29 \%$. Apresentou o menor valor de teor de carbonato entre os períodos interglaciais.

No MIS 4 a litofácie presente nesse intervalo aponta características de lama rica em carbonato. O conteúdo de carbonato apresentou uma média de 15,94\%, mediana de 15,46\%, variância de 9,23\% com um máximo de 23,48\% e um mínimo de $12,49 \%$. Apresentando o menor valor de teor de carbonato ao longo de todo o testemunho.

No MIS 3 a litofácie presente nesse intervalo aponta características de lama rica em carbonato ao longo do segmento entre 131 e $51 \mathrm{~cm}$, lama marga entre $46 \mathrm{e}$ $27 \mathrm{~cm}$ do testemunho. O conteúdo de carbonato apresentou uma média de $25,74 \%$, mediana de $25,19 \%$, variância de $37,35 \%$ com um máximo de $36,92 \%$ e um mínimo de $13,89 \%$.

No MIS 2, o conteúdo de carbonato apresentou uma média de 41,39\%, mediana de $41,39 \%$, variância de $81,79 \%$ com um máximo de $47,79 \%$ e um mínimo de $35,00 \%$.

No MIS 1, representado por uma única amostra de teor de carbonato de $71,34 \%$, sendo o maior valor ao longo de todo o testemunho. 
Tabela 11: Parâmetros estatísticos extraídos do teor de carbonato.

\begin{tabular}{|cccccc|}
\hline MIS & Máximo & Mínimo & Mediana & Variância & Media \\
1 & 71,34 & 71,34 & 71,34 & 0,00 & 71,34 \\
2 & 47,79 & 35,00 & 41,39 & 81,76 & 41,39 \\
3 & 36,92 & 13,89 & 25,19 & 37,35 & 25,74 \\
4 & 23,48 & 12,49 & 15,46 & 9,23 & 15,94 \\
5 & 77,58 & 16,29 & 25,84 & 146,50 & 28,61 \\
6 & 74,29 & 13,01 & 19,16 & 243,66 & 24,10 \\
7 & 59,83 & 21,81 & 42,77 & 122,24 & 38,42 \\
8 & 56,32 & 14,76 & 24,20 & 74,94 & 25,72 \\
9 & 72,51 & 27,14 & 43,62 & 182,15 & 48,13 \\
10 & 48,72 & 20,67 & 27,90 & 45,12 & 28,84 \\
11 & 78,45 & 28,83 & 50,13 & 291,24 & 49,41 \\
12 & 85,28 & 34,91 & 44,21 & 304,88 & 50,63 \\
13 & 83,04 & 49,62 & 64,53 & 131,25 & 64,57 \\
14 & 76,92 & 16,15 & 22,95 & 168,18 & 26,89 \\
15 & 56,00 & 24,56 & 45,08 & 84,95 & 41,73 \\
16 & 76,00 & 17,26 & 48,54 & 540,86 & 44,54 \\
17 & 81,71 & 35,10 & 64,21 & 325,63 & 60,30 \\
18 & 66,17 & 24,18 & 37,04 & 178,19 & 40,21 \\
19 & 52,90 & 40,15 & 46,52 & 81,32 & 46,52 \\
\hline
\end{tabular}

\subsection{Análise espectral}

Para melhor caracterizara influência das variações astronômicas foram escolhidas as curvas da razão isotópica do oxigênio em foraminíferos bentônicos e os dados de susceptibilidade magnética (Figura 15). 


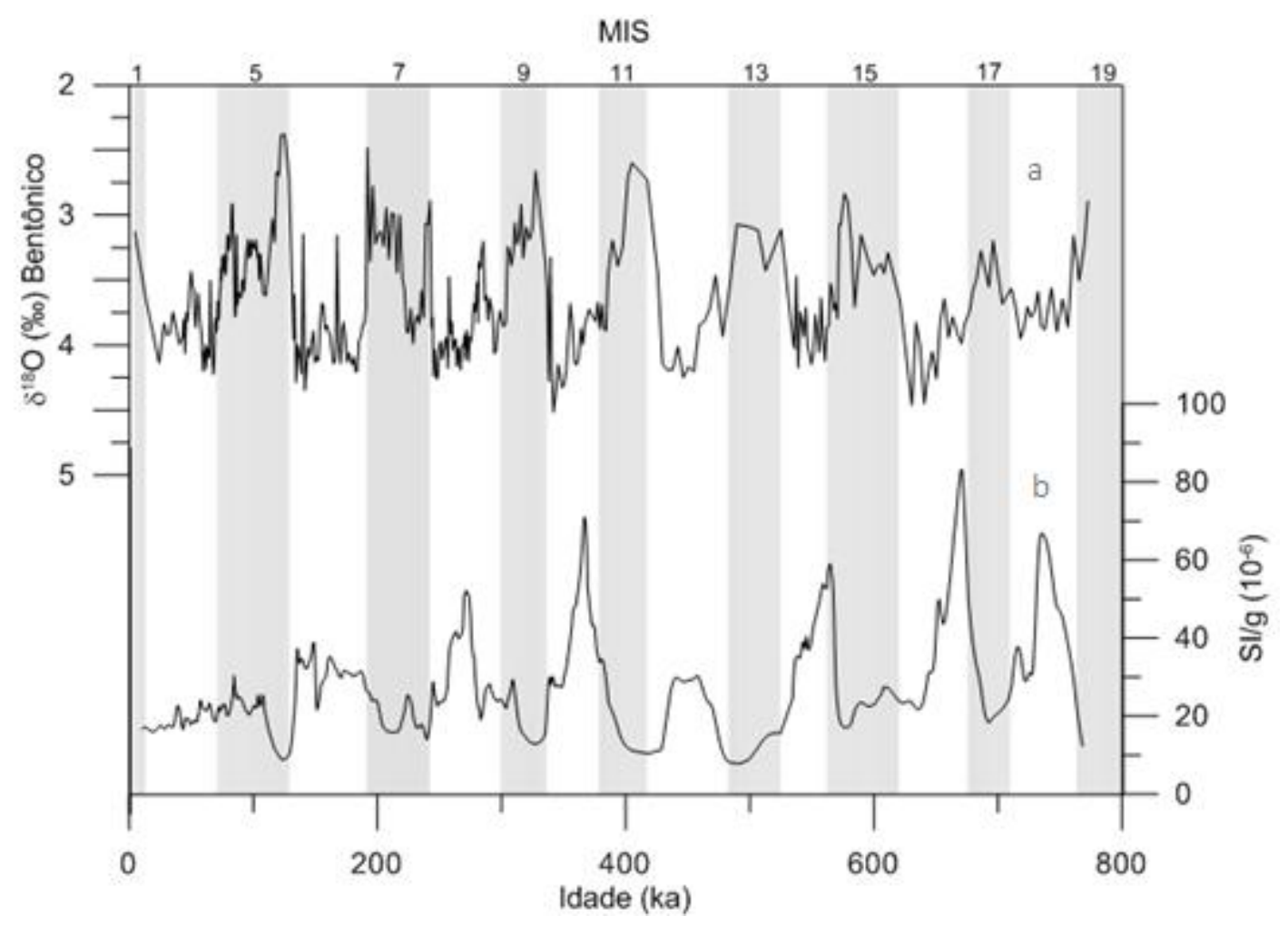

Figura 15: (a) Curva da razão isotopica do oxigeno e (b) susceptibilidade magnetica. Assinalado em cinza estão os estágios isotópicos interglaciais.

Neste estudo as frequências próximas a 0,01 anos-1 representam os ciclos de 100 mil anos, enquanto as frequências de 0,025 anos ${ }^{-1}$ estão associadas aos ciclos

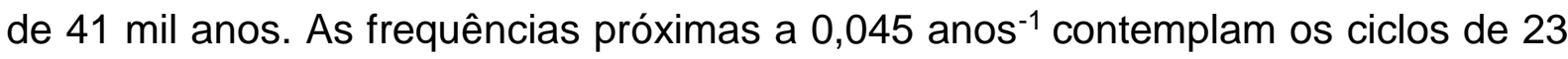
mil anos.

Foram calculadas as frequências de influência ao longo do período, sendo possível observar que para a razão isotópica de oxigênio, apareceram 3 períodos distintos (Figura 16). O sinal forte apresentando 73,41 foi associado a ciclos com período de 100 mil anos, o segundo sinal apresenta uma força de 18,64 e está relacionado com períodos de 41 mil anos. O último sinal apresentado, com uma força de 13,38, está relacionado a ciclos com períodos de 23 mil anos. 


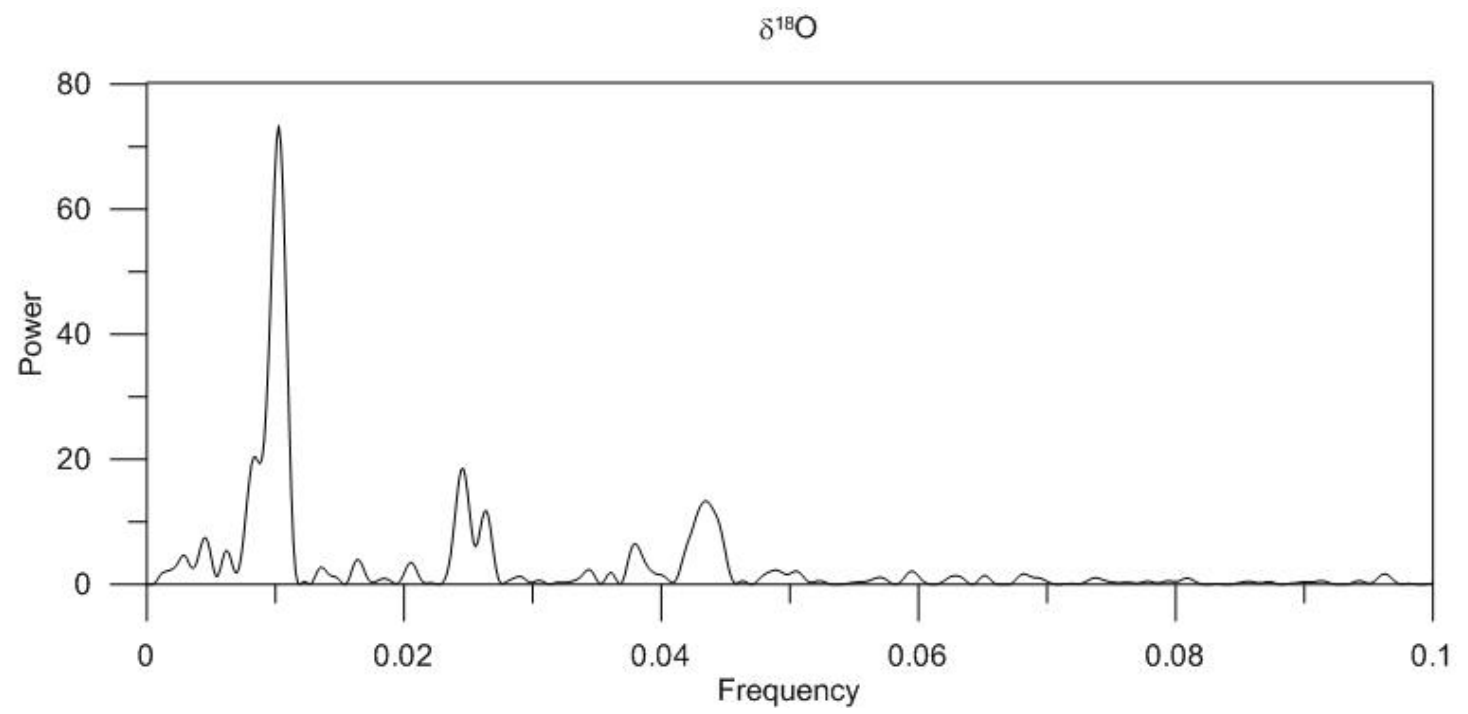

Figura 16: Frequência dos isotopos de oxigênio.

Para a susceptibilidade magnética, as frequências calculadas (Figura 17), apresentam um píco bem definido, de força 132,63, que representa os ciclos com períodos de 100 mil anos.

Susceptibilidade Magnética

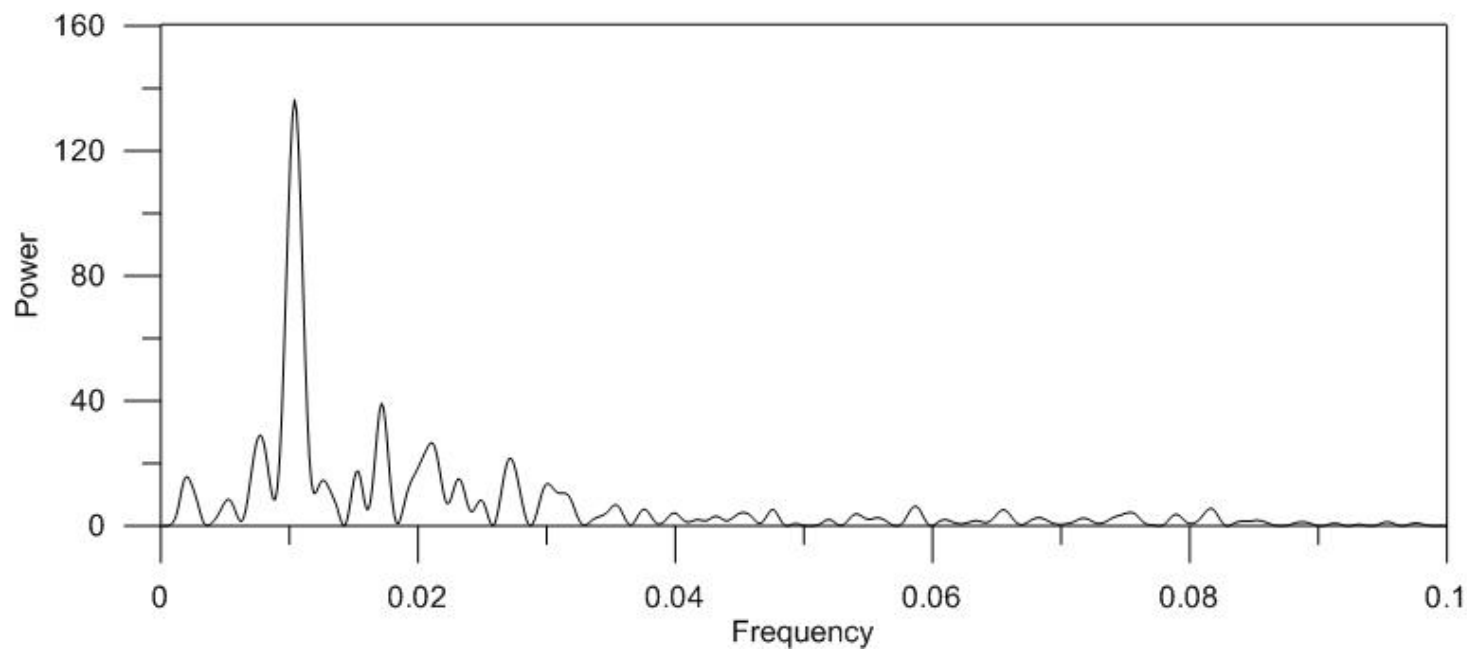

Figura 17: Frequência da susceptibilidade magnética.

A análise de frequência para os dados de Sortable Silt apresentou uma frequência bem definida para os períodos de 100 mil anos (Figura 18), apresentando 
uma força de 28,36 . Seguido por um pico mal definido de força 6,45 que está relacionado a ciclos com períodos de 41 mil anos.

Sortable Silt

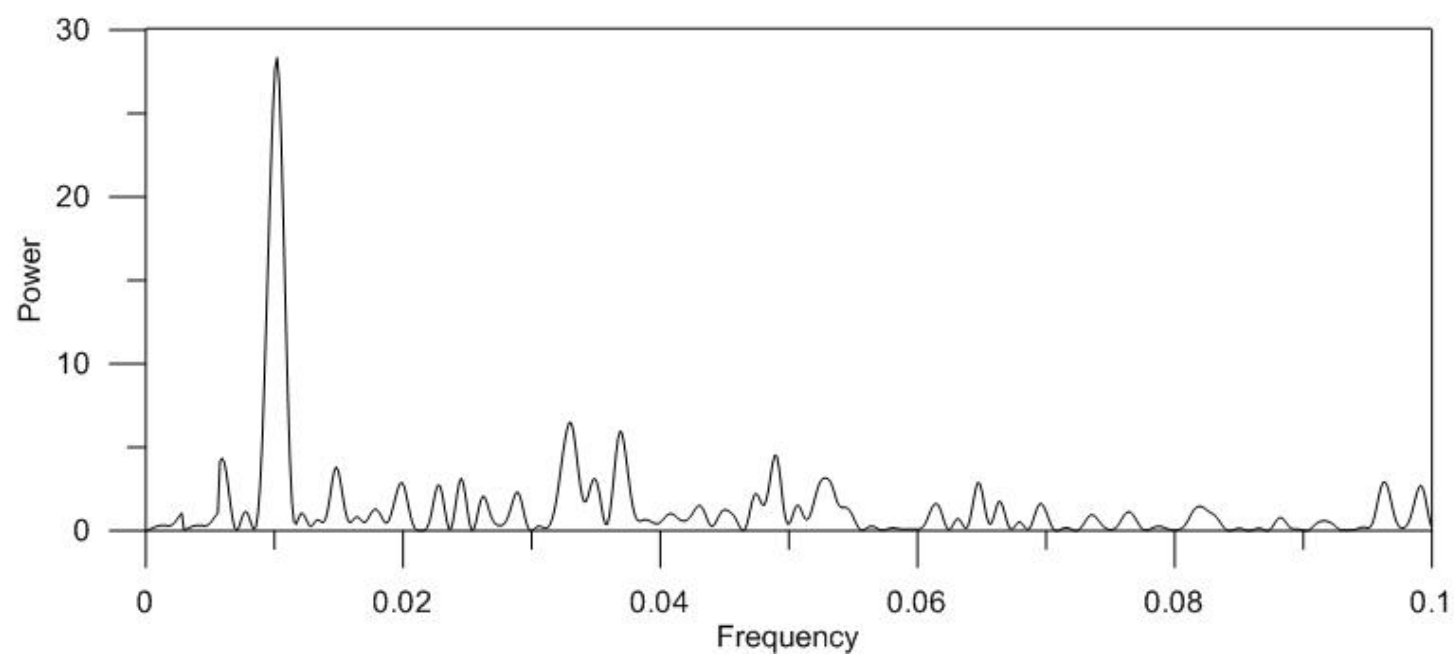

Figura 18: Frequência do Sortable Silt a laser.

\subsection{Fluxo de Massa}

A partir da incidência de raios gama em conjunto com o teor de carbonato e a taxa de sedimentação linear foi possível calcular o fluxo de massa para o KF18 ao longo do período analisado.

O fluxo de massa pode ser subdividido em: total, não-carbonatados e carbonatados.

\subsubsection{Fluxo Total}

O fluxo total representa o acumulo de sedimento total expresso, em massa, na região para cada MIS (Figura 19). Abaixo uma breve descrição simplificada da 
variação do fluxo entre os períodos e uma sumarização completa de todo o período (Tabela 12).

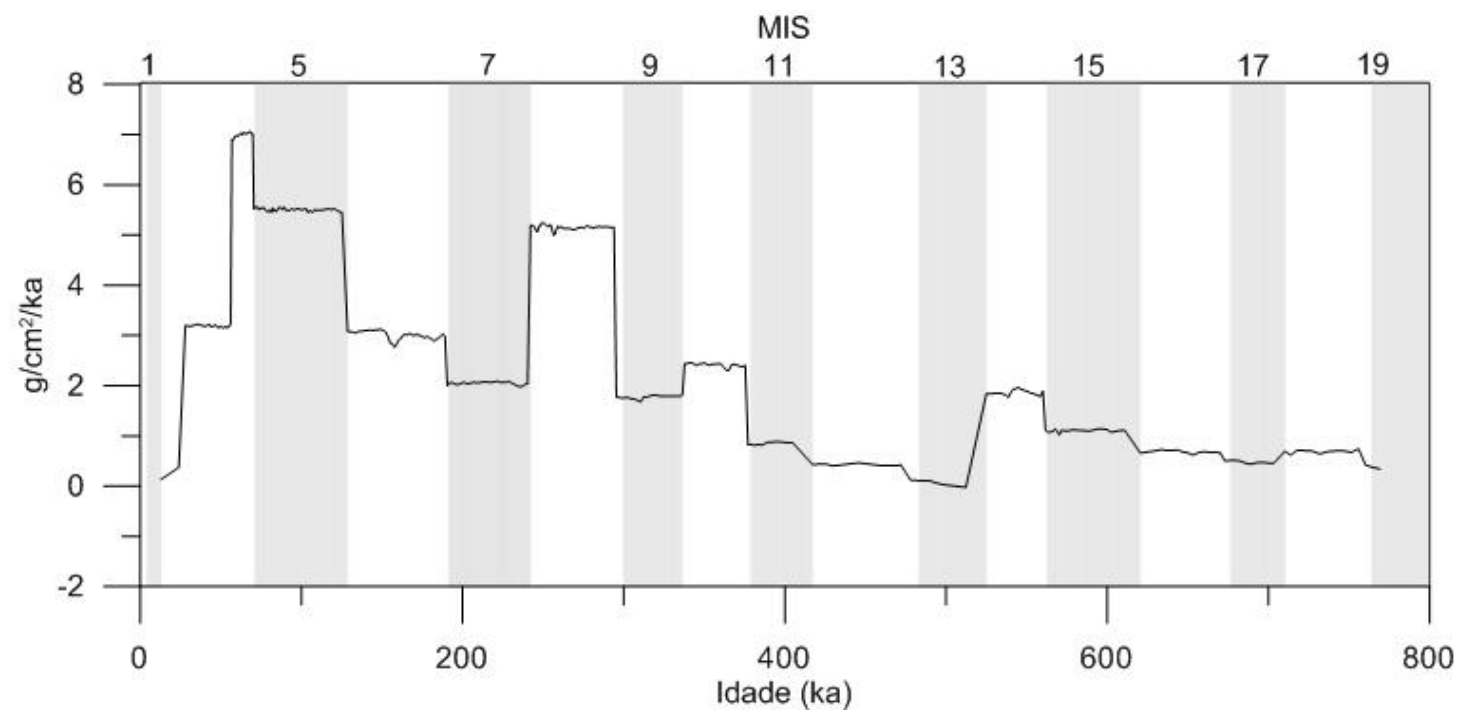

Figura 19: Fluxo de massa total. Assinalado em cinza estão os estágios isotópicos interglaciais.

O maior fluxo médio encontrada ao longo de todo o período analisado foi de 6,93 g/cm2/ka no MIS 4, sendo que, desde o MIS 7, foi observado um crescimento no fluxo total médio de massa até o MIS 4, quando retornou a baixar, ate atingir o menor valor médio do período de 0,13 g/cm2/ka no MIS 1.

O MIS 2 apresentou o menor fluxo médio entre os períodos glaciais de 1,79 $\mathrm{g} / \mathrm{cm} 2 / \mathrm{ka}$, enquanto o MIS 5 apresentou o maior fluxo médio de massa entre os períodos interglaciais de $5,47 \mathrm{~g} / \mathrm{cm} 2 / \mathrm{ka}$. 
Tabela 12: Fluxo total médio em g/cm1/ka.

\begin{tabular}{|cc|}
\hline MIS & $\begin{array}{c}\text { Fluxo } \\
\text { médio } \\
\text { Total }\end{array}$ \\
1 & 0,13 \\
2 & 3,2 \\
3 & 6,91 \\
4 & 7,06 \\
5 & 5,58 \\
6 & 3,12 \\
7 & 5,19 \\
8 & 5,24 \\
9 & 1,82 \\
10 & 2,46 \\
11 & 0,88 \\
12 & 0,47 \\
13 & 1,84 \\
14 & 1,97 \\
15 & 1,14 \\
16 & 0,73 \\
17 & 0,7 \\
18 & 0,75 \\
19 & 0,37 \\
\hline
\end{tabular}

\subsubsection{Fluxo de não carbonatados}

Representa o acúmulo de sedimento não carbonatados, podendo-se considerar como o fluxo de terrígenos, expresso em massa na região para cada MIS (Figura 20). Abaixo temos uma breve descrição simplificada da variação do fluxo entre os períodos e uma sumarização completa de todo o período (Tabela 13). 


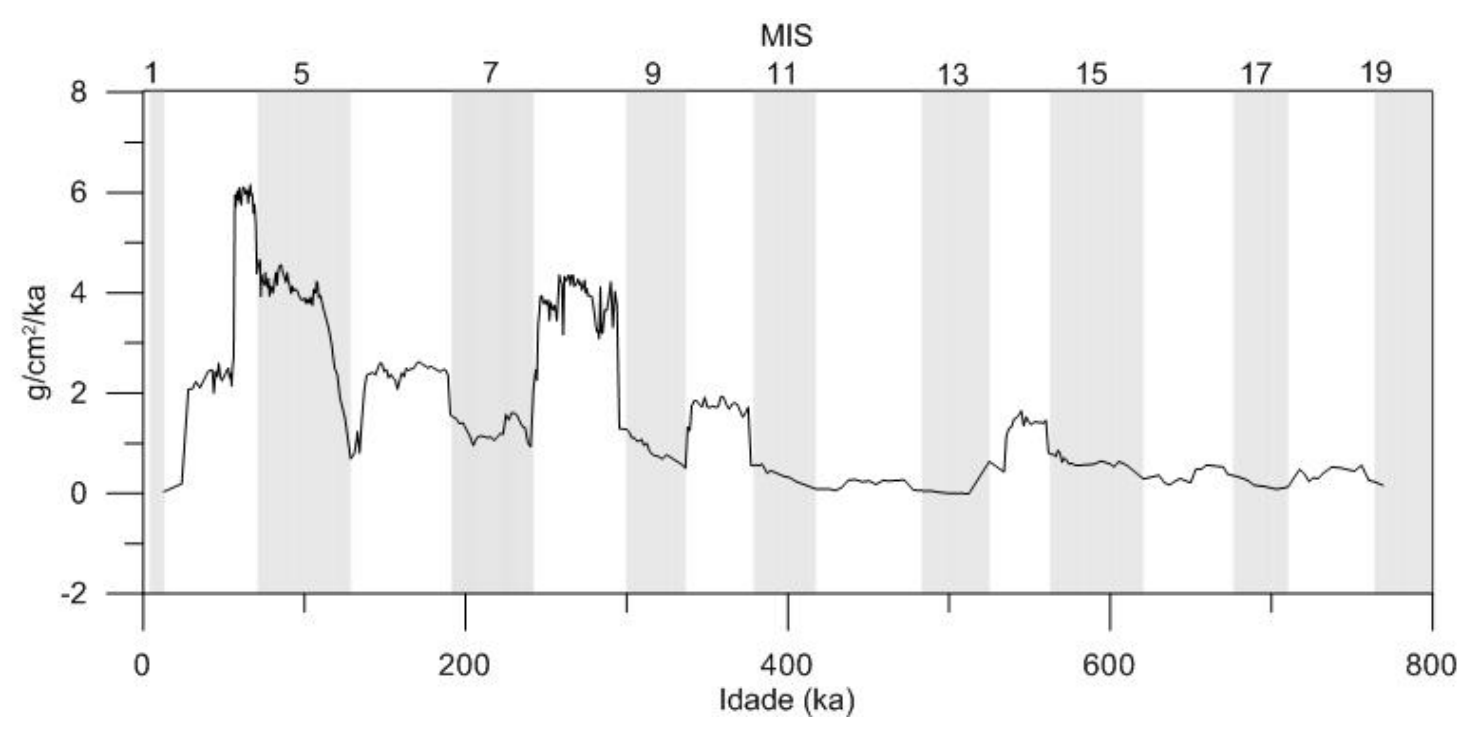

Figura 20: Fluxo de sedimento terrigeno em g/cm2/ka.Assinalado em cinza estão os estágios isotópicos interglaciais.

O maior fluxo médio de terrígenos encontrado ao longo de todo o período foi de $5,83 \mathrm{~g} / \mathrm{cm} 2 / \mathrm{ka}$ no MIS 4, sendo que o menor valor médio do período foi de $0,0,04$ $\mathrm{g} / \mathrm{cm} 2 / \mathrm{ka}$ no MIS 1.O MIS 2 apresentou o menor fluxo médio de terrígenos entre os períodos glaciais de $1,14 \mathrm{~g} / \mathrm{cm} 2 / \mathrm{ka}$, enquanto o MIS 5 apresentou o maior fluxo médio de terrígenos em massa entre os períodos interglaciais de 3,92 $\mathrm{g} / \mathrm{cm} 2 / \mathrm{ka}$. As tendências apresentadas anteriormente para os fluxos totais foram observadas igualmente para o fluxo médio de terrígenos. 
Tabela 13: Fluxo médio de não carbonatados (terrígeno).

\begin{tabular}{|c|c|}
\hline MIS & $\begin{array}{l}\text { Fluxo médio de não } \\
\text { carbonatados }\end{array}$ \\
\hline 1 & 0,04 \\
\hline 2 & 1,14 \\
\hline 3 & 2,53 \\
\hline 4 & 5,83 \\
\hline 5 & 3,92 \\
\hline 6 & 2,26 \\
\hline 7 & 1,31 \\
\hline 8 & 3,78 \\
\hline 9 & 0,91 \\
\hline 10 & 1,67 \\
\hline 11 & 0,42 \\
\hline 12 & 0,2 \\
\hline 13 & 0,13 \\
\hline 14 & 1,34 \\
\hline 15 & 0,63 \\
\hline 16 & 0,37 \\
\hline 17 & 0,19 \\
\hline 18 & 0,4 \\
\hline 19 & 0,19 \\
\hline
\end{tabular}

\subsubsection{Fluxo de carbonato}

Representa o acúmulo de sedimento carbonatado, expresso em massa na região para cada MIS (Figura 21) apresentando uma distribuição bem mais complexa que os demais fluxos. Abaixo, uma breve descrição da variação do fluxo entre os períodos e uma sumarização completa de todo o período (Tabela 14). 


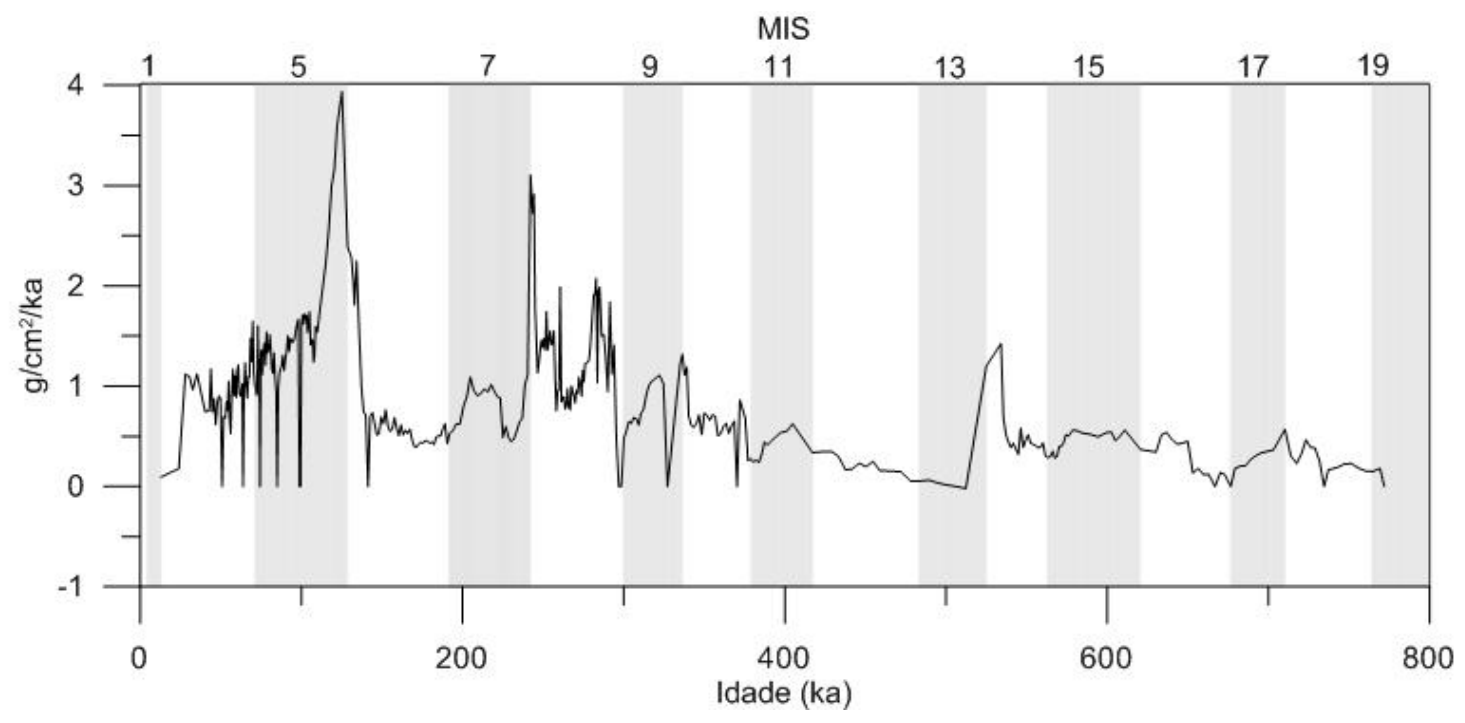

Figura 21: Fluxo de carbonato em $\mathrm{g} / \mathrm{cm}^{2} / \mathrm{ka}$.Assinalado em cinza estão os estágios isotópicos interglaciais.

Para o MIS 19 obtivemos um fluxo de carbonatos médio de $0,11 \mathrm{~g} / \mathrm{cm}^{2} / \mathrm{ka}$, variância de $0,01 \mathrm{~g} / \mathrm{cm}^{2} / \mathrm{ka}$, um máximo de $0,18 \mathrm{~g} / \mathrm{cm}^{2} / \mathrm{ka}$ e mínimo de $0 \mathrm{~g} / \mathrm{cm}^{2} / \mathrm{ka} \mathrm{com}$ uma mediana de $0,15 \mathrm{~g} / \mathrm{cm}^{2} / \mathrm{ka}$.

Para o MIS 18 obtivemos um fluxo de carbonatos médio de $0,25 \mathrm{~g} / \mathrm{cm}^{2} / \mathrm{ka}$,

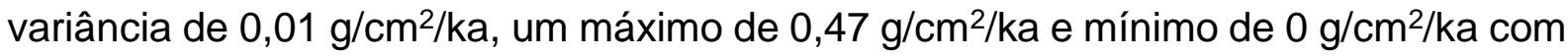
uma mediana de $0,23 \mathrm{~g} / \mathrm{cm}^{2} / \mathrm{ka}$.

Para o MIS 17 temos um fluxo de carbonatos médio de $0,27 \mathrm{~g} / \mathrm{cm}^{2} / \mathrm{ka}$, variância de $0,02 \mathrm{~g} / \mathrm{cm}^{2} / \mathrm{ka}$, um máximo de $0,57 \mathrm{~g} / \mathrm{cm}^{2} / \mathrm{ka}$ e mínimo de $0 \mathrm{~g} / \mathrm{cm}^{2} / \mathrm{ka}$ com uma mediana de $0,27 \mathrm{~g} / \mathrm{cm}^{2} / \mathrm{ka}$.

Para o MIS 16 obtivemos um fluxo de carbonatos médio de $0,28 \mathrm{~g} / \mathrm{cm}^{2} / \mathrm{ka}$, variância de $0,03 \mathrm{~g} / \mathrm{cm}^{2} / \mathrm{ka}$, um máximo de $0,54 \mathrm{~g} / \mathrm{cm}^{2} / \mathrm{ka}$ e mínimo de $0 \mathrm{~g} / \mathrm{cm}^{2} / \mathrm{ka} \mathrm{com}$ uma mediana de $0,26 \mathrm{~g} / \mathrm{cm}^{2} / \mathrm{ka}$.

Para o MIS 15 obtivemos um fluxo de carbonatos médio de $0,45 \mathrm{~g} / \mathrm{cm}^{2} / \mathrm{ka}$, variância de $0,01 \mathrm{~g} / \mathrm{cm}^{2} / \mathrm{ka}$, um máximo de $0,56 \mathrm{~g} / \mathrm{cm}^{2} / \mathrm{ka}$ e mínimo de $0,28 \mathrm{~g} / \mathrm{cm}^{2} / \mathrm{ka}$ com uma mediana de $0,50 \mathrm{~g} / \mathrm{cm}^{2} / \mathrm{ka}$. 
Para o MIS 14 obtivemos um fluxo de carbonatos médio de 0,49 g/ $\mathrm{cm}^{2} / \mathrm{ka}$, variância de 0,06 g/cm²/ka, um máximo de 1,43 g/ $\mathrm{cm}^{2} / \mathrm{ka}$ e mínimo de 0,3 g/cm²/ka com uma mediana de $0,43 \mathrm{~g} / \mathrm{cm}^{2} / \mathrm{ka}$.

Para o MIS 13 obtivemos um fluxo de carbonatos médio de 0,2 g/cm²/ka, variância de 0,20 g/cm²/ka, um máximo de $1,20 \mathrm{~g} / \mathrm{cm}^{2} / \mathrm{ka}$ e mínimo de $0 \mathrm{~g} / \mathrm{cm}^{2} / \mathrm{ka} \mathrm{com}$ uma mediana de $0,04 \mathrm{~g} / \mathrm{cm}^{2} / \mathrm{ka}$.

Para o MIS 12 obtivemos um fluxo de carbonatos médio de 0,21 g/cm²/ka, variância de 0,01 g/cm²/ka, um máximo de 0,35 g/cm²/ka e mínimo de 0,06 g/cm²/ka com uma mediana de $0,17 \mathrm{~g} / \mathrm{cm}^{2} / \mathrm{ka}$. Com exceção dos períodos que tiveram valores nulos, apresentou o menor valor ao longo de todo o período.

Para o MIS 11 obtivemos um fluxo de carbonatos médio de 0,39 g/. $\mathrm{cm}^{2} / \mathrm{ka}$, variância de 0,02 g/cm²/ka, um máximo de 0,63 g/ $\mathrm{cm}^{2} / \mathrm{ka}$ e mínimo de 0,24 g/cm²/ka com uma mediana de $0,38 \mathrm{~g} / \mathrm{cm}^{2} / \mathrm{ka}$.

Para o MIS 10 obtivemos um fluxo de carbonatos médio de 0,65 g/ $/ \mathrm{cm}^{2} / \mathrm{ka}$, variância de 0,05 g/cm²/ka, um máximo de $1,19 \mathrm{~g} / \mathrm{cm}^{2} / \mathrm{ka}$ e mínimo de $0 \mathrm{~g} / \mathrm{cm}^{2} / \mathrm{ka} \mathrm{com}$ uma mediana de $0,65 \mathrm{~g} / \mathrm{cm}^{2} / \mathrm{ka}$.

Para o MIS 9 obtivemos um fluxo de carbonatos médio de 0,81 g/cm²/ka, variância de $0,10 \mathrm{~g} / \mathrm{cm}^{2} / \mathrm{ka}$, um máximo de $1,32 \mathrm{~g} / \mathrm{cm}^{2} / \mathrm{ka}$ e mínimo de $0 \mathrm{~g} / \mathrm{cm}^{2} / \mathrm{ka} \mathrm{com}$ uma mediana de $0,75 \mathrm{~g} / \mathrm{cm}^{2} / \mathrm{ka}$.

Para o MIS 8 obtivemos um fluxo de carbonatos médio de 1,27 g/. $\mathrm{cm}^{2} / \mathrm{ka}$, variância de 0,26 g/cm²/ka, um máximo de $2,91 \mathrm{~g} / \mathrm{cm}^{2} / \mathrm{ka}$ e mínimo de $0 \mathrm{~g} / \mathrm{cm}^{2} / \mathrm{ka} \mathrm{com}$ uma mediana de 1,24 g/cm²/ka. Apresentou o maior valor de fluxo, mediana e média entre os períodos glaciais.

Para o MIS 7 obtivemos um fluxo de carbonatos médio de 0,86 g/. $\mathrm{cm}^{2} / \mathrm{ka}$, variância de 0,25 g/cm²/ka, um máximo de 3,11 g/cm²/ka e mínimo de 0,45 g/cm²/ka com uma mediana de $0,88 \mathrm{~g} / \mathrm{cm}^{2} / \mathrm{ka}$.

Para o MIS 6 obtivemos um fluxo de carbonatos médio de 0,71 g/cm²/ka, variância de 0,24 g/cm²/ka, um máximo de $2,28 \mathrm{~g} / \mathrm{cm}^{2} / \mathrm{ka}$ e mínimo de $0 \mathrm{~g} / \mathrm{cm}^{2} / \mathrm{ka} \mathrm{com}$ uma mediana de $0,56 \mathrm{~g} / \mathrm{cm}^{2} / \mathrm{ka}$. 
Para o MIS 5 obtivemos um fluxo de carbonatos médio de $1,46 \mathrm{~g} / \mathrm{cm}^{2} / \mathrm{ka}$, variância de $0,45 \mathrm{~g} / \mathrm{cm}^{2} / \mathrm{ka}$, um máximo de $3,94 \mathrm{~g} / \mathrm{cm}^{2} / \mathrm{ka}$ e mínimo de $0 \mathrm{~g} / \mathrm{cm}^{2} / \mathrm{ka}$ com uma mediana de $1,38 \mathrm{~g} / \mathrm{cm}^{2} / \mathrm{ka}$. apresentou o maior valor de fluxo, media, variância e mediana ao longo de todo o período.

Para o MIS 4 obtivemos um fluxo de carbonatos médio de $1,05 \mathrm{~g} / \mathrm{cm}^{2} / \mathrm{ka}$, variância de $0,10 \mathrm{~g} / \mathrm{cm}^{2} / \mathrm{ka}$, um máximo de $1,65 \mathrm{~g} / \mathrm{cm}^{2} / \mathrm{ka}$ e mínimo de $0 \mathrm{~g} / \mathrm{cm}^{2} / \mathrm{ka}$ com uma mediana de $1,08 \mathrm{~g} / \mathrm{cm}^{2} / \mathrm{ka}$.

Para o MIS 3 obtivemos um fluxo de carbonatos médio de $0,81 \mathrm{~g} / \mathrm{cm}^{2} / \mathrm{ka}$, variância de $0,06 \mathrm{~g} / \mathrm{cm}^{2} / \mathrm{ka}$, um máximo de $1,17 \mathrm{~g} / \mathrm{cm}^{2} / \mathrm{ka}$ e mínimo de $0 \mathrm{~g} / \mathrm{cm}^{2} / \mathrm{ka}$ com uma mediana de $0,83 \mathrm{~g} / \mathrm{cm}^{2} / \mathrm{ka}$.

Para o MIS 2 obtivemos um fluxo de carbonatos médio de $0,65 \mathrm{~g} / \mathrm{cm}^{2} / \mathrm{ka}$,

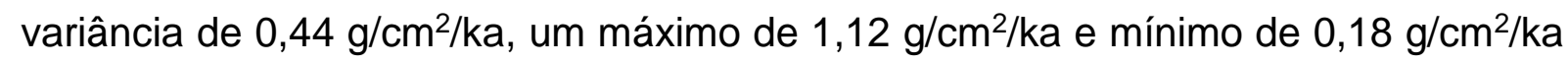
com uma mediana de $0,65 \mathrm{~g} / \mathrm{cm}^{2} / \mathrm{ka}$. Apresentou a maior variância entre os períodos glaciais.

Para o MIS 1 obtivemos um fluxo de carbonatos médio de $0,09 \mathrm{~g} / \mathrm{cm}^{2} / \mathrm{ka}$,

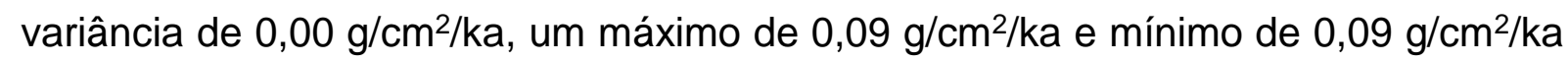
com uma mediana de $0,09 \mathrm{~g} / \mathrm{cm}^{2} / \mathrm{ka}$. Com exceção dos períodos que tiveram valores nulos, apresentou o menor valor de fluxo entre os períodos interglaciais. 
Tabela 14: Parâmetros estatísticos extraídos do fluxo de carbonato.

\begin{tabular}{|cccccc|}
\hline MIS & Máximo & Mínimo & Mediana & Variância & Média \\
1 & 0,09 & 0,09 & 0,09 & 0,00 & 0,09 \\
2 & 1,12 & 0,18 & 0,65 & 0,44 & 0,65 \\
3 & 1,17 & 0,00 & 0,83 & 0,06 & 0,81 \\
4 & 1,65 & 0,00 & 1,08 & 0,10 & 1,05 \\
5 & 3,94 & 0,00 & 1,38 & 0,45 & 1,46 \\
6 & 2,28 & 0,00 & 0,56 & 0,24 & 0,71 \\
7 & 3,11 & 0,45 & 0,88 & 0,25 & 0,86 \\
8 & 2,91 & 0,00 & 1,24 & 0,26 & 1,27 \\
9 & 1,32 & 0,00 & 0,75 & 0,10 & 0,81 \\
10 & 1,19 & 0,00 & 0,65 & 0,05 & 0,65 \\
11 & 0,63 & 0,24 & 0,38 & 0,02 & 0,39 \\
12 & 0,35 & 0,06 & 0,17 & 0,01 & 0,21 \\
13 & 1,20 & $-0,02$ & 0,04 & 0,20 & 0,19 \\
14 & 1,43 & 0,30 & 0,43 & 0,06 & 0,49 \\
15 & 0,56 & 0,28 & 0,50 & 0,01 & 0,45 \\
16 & 0,54 & 0,00 & 0,26 & 0,03 & 0,28 \\
17 & 0,57 & 0,00 & 0,27 & 0,02 & 0,27 \\
18 & 0,47 & 0,00 & 0,23 & 0,01 & 0,25 \\
19 & 0,18 & 0,00 & 0,15 & 0,01 & 0,11 \\
\hline
\end{tabular}




\section{Discussão}

O presente trabalho utilizou diferentes análises granulométricas a fim de caracterizar a região alvo e avaliar a utilização do índice de Sortable Silt proveniente da composição granulométrica do sedimento, para avaliar seu potencial e sua sensibilidade em diferenciar os ciclos glaciais e interglaciais, juntamente com eventos importantes durante o período amostrado.

No presente estudo foram utilizados dois métodos granulométricos distintos: um através da análise da granulometria baseada no princípio da velocidade da sedimentação, no caso a pipetagem que fornece indiretamente o tamanho do grão, $\mathrm{e}$ outro através da granulometria a laser, que determina o tamanho do grão diretamente, afim de comparar e determinar a amplitude da diferença entre os métodos, sugerindo uma melhor aplicação de cada método para o emprego na reconstituição paleoceanografica. Inicialmente será apresentada uma breve discussão e análise sobre as vantagens e desvantagem desse índice, relativamente novo e ainda pouco explorado.

\subsection{Sortable Silt}

O primeiro estudo significativo para a quantificação da fração fina foi desenvolvido por LEDBETTER em 1986, no qual ele desenvolve um índice para determinar a velocidade das correntes a partir da granulometria do sedimento fino, correlacionando a velocidade das correntes com o tamanho do sedimento (Figura 22). Apesar de ser um dos primeiros estudos e ter uma importância considerável, a partir dele não houveram muitos avanços na calibração do proxy, tornando-o uma caracterização qualitativa das velocidades de corrente de fundo. Devido a isso, o presente estudo optou por não utilizar a forma transformada em $\mathrm{cm} / \mathrm{s}$ e sim pelo índice de $\mu \mathrm{m}$ para ambas análises, a laser e pelo princípio da velocidade de deposição, uma vez que esse índice é diretamente proporcional a velocidade e comumente encontrado na literatura. 


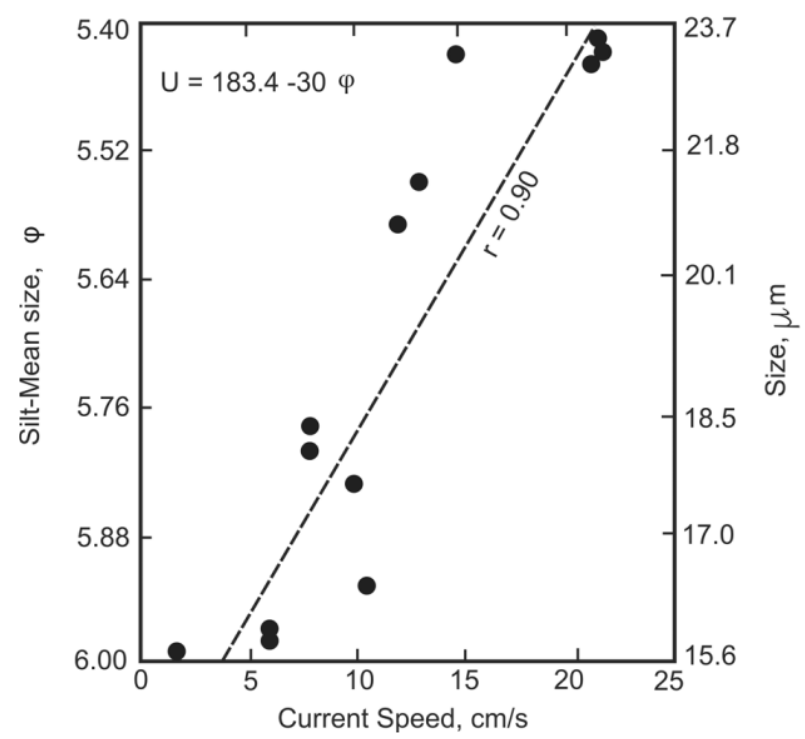

Figura 22: Índice para a potência das correntes a partir do sedimento fino desenvolvido por Ledbetter em 1986, relacionando a velocidade das correntes de fundo com o Sortable Silt nas escalas (esquerda) phi ( $\Phi)$ e (direita) $\mu \mathrm{m}$.

Devido a resposta sensível na alteração da composição das frações granulométrica no sedimento, não somente pela contribuição das alterações nas correntes de fundo, mas também com o efeito da floculação ocasionada pela diferença de cargas entre as partículas do sedimento, pode possívelmente ocasionar em um resultado subestimado das velocidades das correntes de fundo (TEGZES; JANSEN; TELFORD, 2015). Esse efeito faz com que as partículas menores se agreguem e depositem-se seguindo o comportamento hidrodinâmico de grãos maiores, apresentando velocidades de sedimentação semelhantes.

Uma discussão mais ampla e comparativa ocorre quanto ao método analítico para a composição do índice, uma vez que o traçador se baseia na velocidade de sedimentação. Ainda que os métodos de análise que se baseiam por esse princípio pareçam ser os mais indicados, fornecem de forma indireta o tamanho das partículas e no caso desse estudo, apresentam um agravante devido ao método utilizado (pipetagem), que apresenta pouca capacidade de caracterizar as diferentes classes do sedimento fino, deixando a traçador menos sensível (sem considerar a alta carga horaria exigida pelo método) 
Para as medições a laser os principais pontos favoráveis são a otimização da velocidade de análise do material e a capacidade de uma melhor caracterização das classes de tamanho presentes no sedimento, tornando-a assim mais sensível a pequenas variações quando comparado com o método da pipetagem. Porém, devido a presença de minerais em forma de placas, o tamanho aferido a esses grãos pode ser sobrestimado devido à posição no momento da medição, sugerindo que esses grãos possuem uma velocidade de deposição similares a grãos maiores.

O efeito da fonte do sedimento pode ser considerado como um possível interferente para o Sortable Silt, pois alguns autores acreditam que a origem do sedimento e a sua proximidade com a fonte exerce significativamente uma influência sobre a dominância do tamanho do grão. Para o caso de sedimentos maiores, que é o caso das areias, esse efeito é relativamente importante como observado em alguns trabalhos, ocorrendo uma má classificação do sedimento em rios devido à proximidade da rocha fonte, como apontado por Gibbs em 1967. Entretanto, a região estudada não apresenta um aporte fluvial significativamente capaz de transportar esse sedimento mais grosso até o ponto amostrado.

Analisando os dois métodos é possível observar que ambos caracterizam os períodos glaciais e interglaciais, apresentando velocidades medias superiores nos períodos glaciais e inferiores nos períodos interglaciais (gráfico das médias). Assim como observada na Tabela 7, ambos os métodos apresentam o mesmo número de vales e picos. O índice obtido a partir da análise a laser apresenta períodos médios de máximos e mínimos melhor definidos.

O índice obtido através da análise a laser apresenta um maior potencial para descrever eventos de menor magnitude devido a sua maior sensibilidade, tanto em sua construção, por apresentar uma melhor caracterização das classes de tamanho, quanto na variabilidade e melhor definição dos eventos maiores como a variação cíclica entre períodos glaciais e interglaciais.

\subsection{Contexto Oceanográfico}


O Oceano Atlântico moderno apresenta um fluxo de água quente na superfície fluindo para sul que, é contrabalanceado por um fluxo de água fria profunda em direção a norte (Rintoul,1991). Durantes períodos glaciais, estudos de modelagem da circulação sugerem que fluxo de águas superficiais e profundas foram reduzidos, ocasionados pela presença da formação de gelo em altas latitudes no Atlântico Norte interferindo na formação de água profunda (KELLOGG, 1980; DUPLESSY et al., 1988)).

Os dados de $\delta^{18} \mathrm{O}$ assim como as variações magnéticas no sedimento, apresentaram um importante papel na detecção das variações orbitais responsáveis pelas induções nas variações climáticas. Acredita-se que essas influencias astronômicas são as principais causas externas das intercalações entre períodos glaciais e interglaciais. (HAYS et al.,1976; IMBRIE et al., 1984).

Os resultados de Sortable Silt apresentaram claramente três padrões diferentes de comportamento e podemos dividi-las em três intervalos (Figura 23), no primeiro intervalo compreendido entre 800 até 550 mil anos (MIS 19-14), os valores dos fluxos de sedimentos não carbonatados demonstra um aporte menor, uma maior variação da susceptibilidade magnética e os valores do índice de Sortable Silt demonstram que as velocidades das correntes de fundo apresentaram os maiores nos períodos glaciais e velocidades não tão baixas nos interglaciais. A região apontou condições de turbulência e mistura superiores ao resto do período estudado, segundo a assinatura isotópica isso provavelmente foi ocasionado pela maior influência de massas de águas originadas no Norte (CURRY; OPPO, 2005). Atualmente a NADW apresenta características similares e ocupa esta profundidade. 


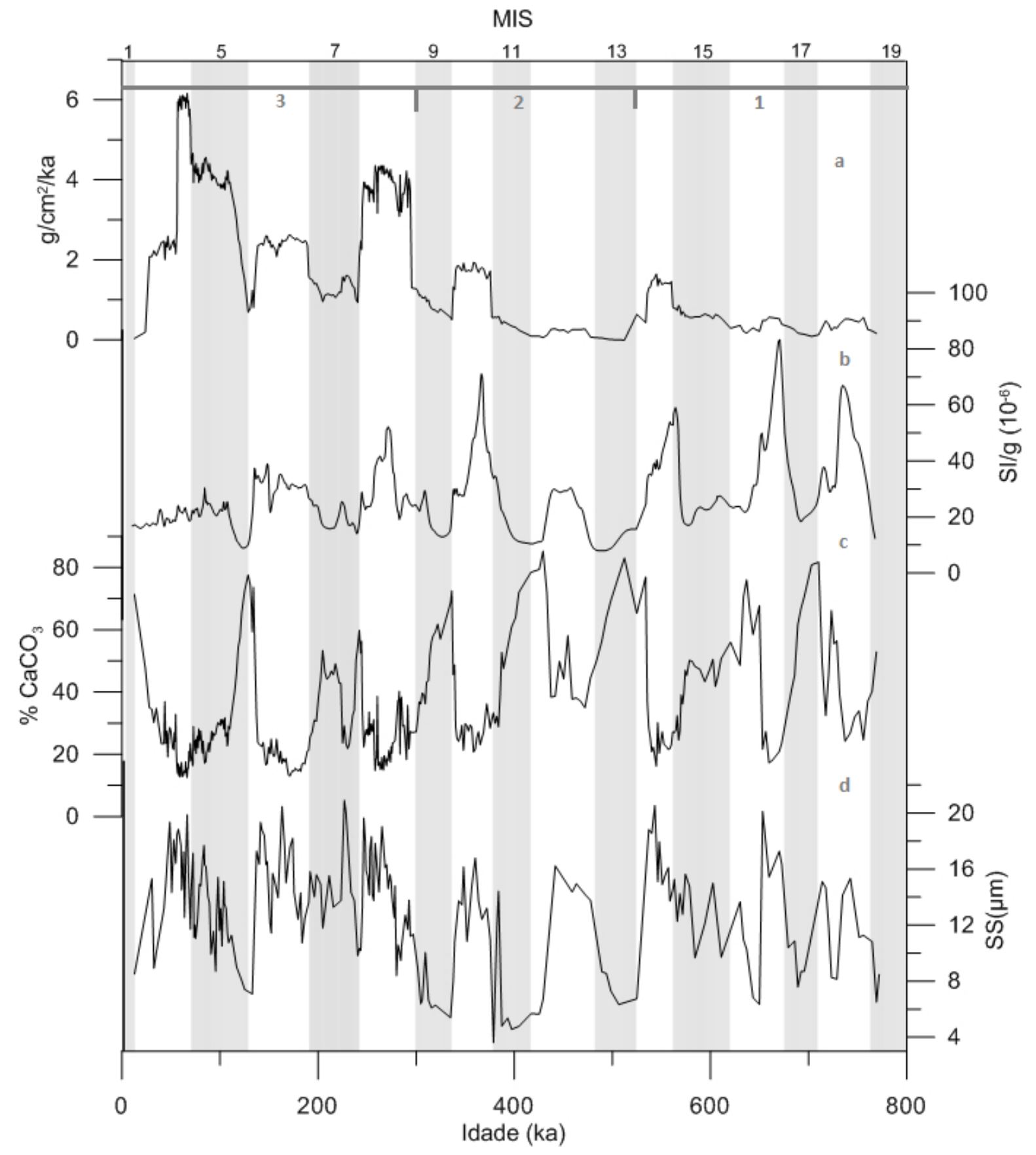

Figura 23: (a) Fluxo de não carbonatados; (b) Susceptibilidade Magnética;(c) teor de carbonato; (d) Sortable Silt a laser. Assinalado em cinza estão os estágios isotópicos interglaciais. A linha numerada identifica os intervalos indicados no texto.

O segundo intervalo compreendido entre 550-300 mil anos (MIS 13-9) apresentou menores velocidades médias entre os intervalos interglaciais, ocasionados pela menor turbulência e mistura na região durante o período, com relação ao teor de carbonato acumulado apresentou a melhor definição entre os 
períodos glaciais e interglaciais, enquanto as componentes magnéticas apresentaram alteração no comportamento entre os peridos glaciais e interglaciais.

O terceiro intervalo compreendido entre 300 mil anos ao atual, apresentou menor variação das velocidades das correntes de fundo entre os períodos glaciais e interglaciais, apresentando um maior fluxo de material não carbonatado em ambos os períodos e uma menor variação da susceptibilidade magnética.

WAELBROECK e colaboradores (2002), realizaram estudos sobre a relação entre a variação dos paleonível do mar e os isótopos de oxigênio em foraminíferos bentônicos no Atlantico Norte e Pacifico equatorial, demonstraram, através de uma serie de regressões, que o comportamento do nível do mar e a curva dos isótopos de oxigênio são semelhantes (Figura 24). Assim sendo, no presente estudo as inferências do nível do mar alto/baixo serão baseadas nos dados de isótopos de oxigênio do testemunho KF-18.

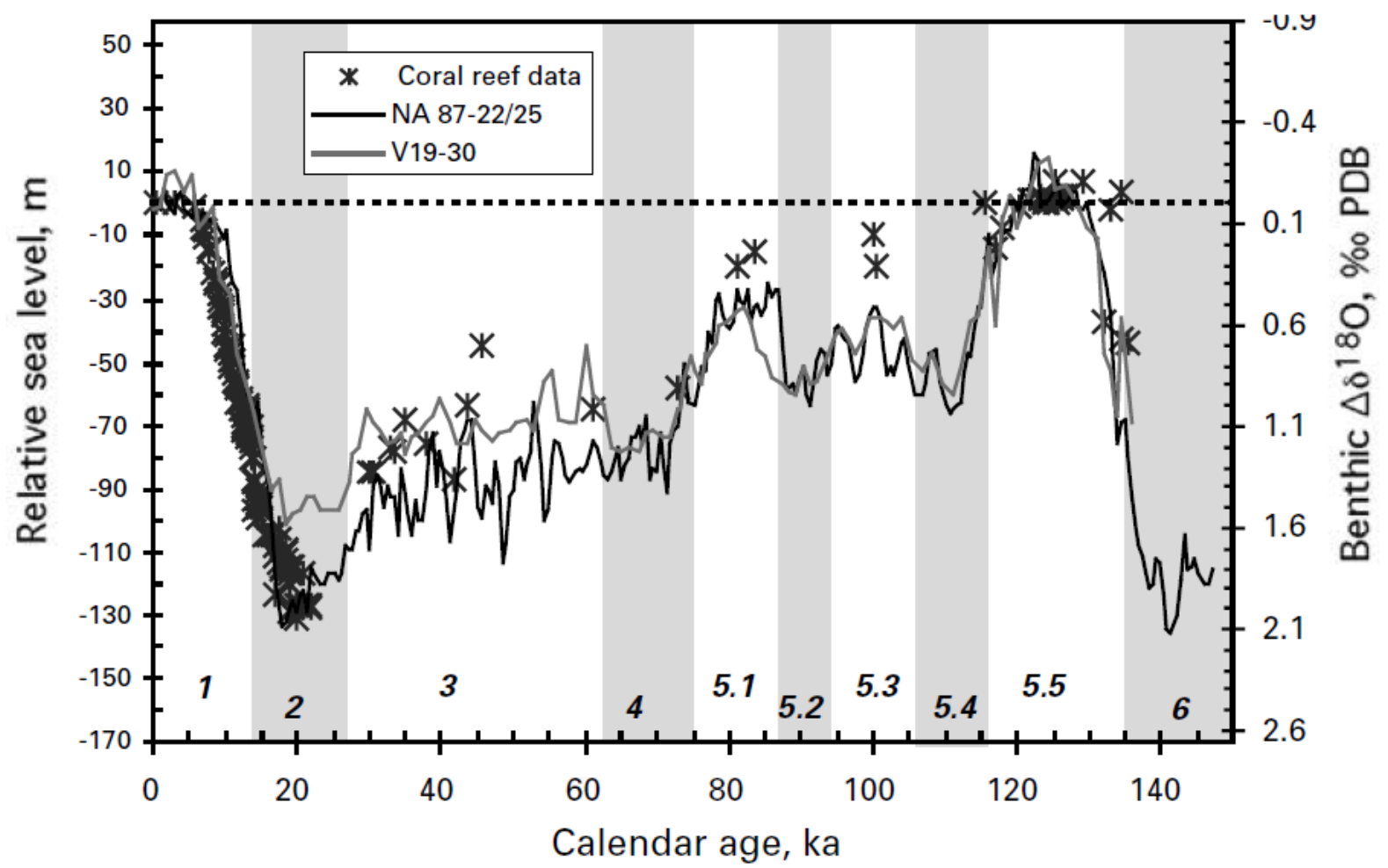

Figura 24: Relação entre Isotopos de Oxigênio em foraminiferos bentonicos e a variação relativa do nivel do mar obtida por WAELBROECK et al.(2002). 
O baixo nível do mar possibilitou aos sedimentos de origem terrígena atingir mais facilmente o talude e as bacias marginais, devido a exposição da plataforma continental, podendo ter ocasionado assim um sinal equivocado apresentando maiores velocidades médias nesse no MIS 8 (Figura 25). Como a composição do Sortable Silt não distingue o material transportado pelas correntes de fundo e aqueles provenientes de eventos extremos que podem atingir as altas profundidades, nesses casos o Sortable Silt apresentará um sinal maior que o real (TEGZES; JANSEN; TELFORD, 2015). Durante períodos glaciais, de acentuado rebaixamento do nível do mar, os dados de Sortable Silt possam não expressar diretamente as velocidades das paleocorrentes de fundo, devido a possibilidade de material de maior granulometria ter sido depositado na região, facilitado pelo rebaixamento do nível do mar e consequente exposição da plataforma continental e maior proximidade das desembocaduras dos rios e o talude continental.

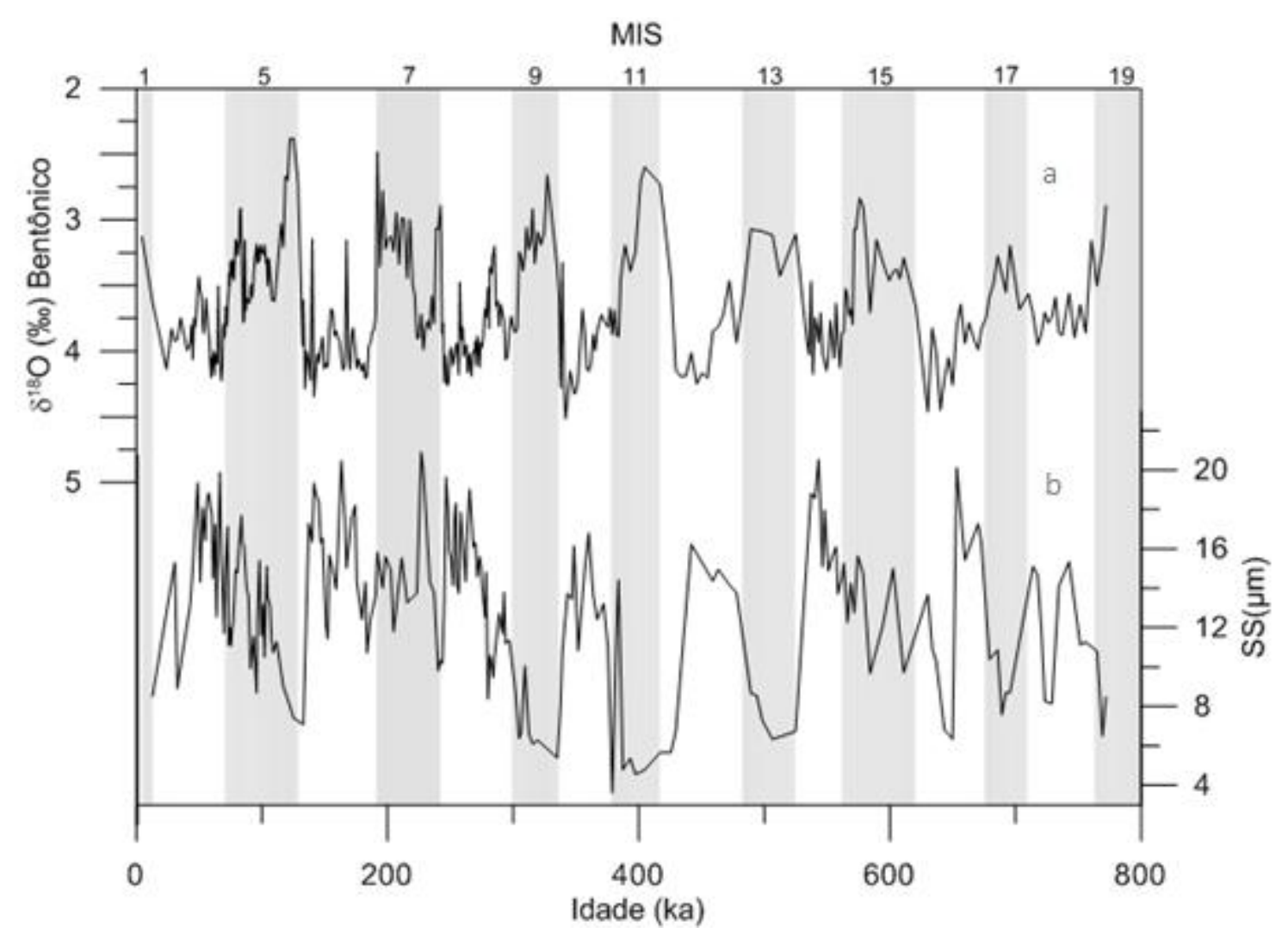

Figura 25: Comparação entre a (a) isótopos de oxigênio e o (b) Sortable Silt a laser. Assinalado em cinza estão os estágios isotópicos interglaciais. 
Anaisando a figura 25, a curva isotópica do oxigênio indica que o rebaixamento médio do nível do mar teria atingido os menores níveis durante os MIS 16, 12 e 10, no entanto, mesmo apresentando picos bem evidentes nas velocidades das correntes de fundo nestes estágios, pode-se observar que são também as menores velocidades registradas em períodos glaciais. Observando o fluxo de material terrígeno (Figura 20), estes apresentaram valores nos MIS 16, 12 e 10 bem inferiores quando comparados com o MIS 8. Portanto, estes dois indícios sugerem que não ocorreu uma interferência no índice com a variação do nível médio do mar, descartando aparente interferência do sedimento proveniente do continente com a exposição da plataforma continental, não comprometendo a composição do índice de Sortable Silt.

De acordo com a distribuição dos valores da razão dos isótopos de carbono em foraminíferos bentônicos, estes sugerem alterações na circulação profunda diferentes da atual (OPPO e FAIRBANKS, 1987; CURRY et al., 1988; BOYLE, 1988, CURRY e OPPO, 2005). A águas eram empobrecidas em $\delta^{13} \mathrm{C}$, características do Oceano Austral nos períodos glaciais (BOYLE, 1988; BOYLE, 1992; IMBRIE et al., 1992).

Curry e Lohman (1982) examinaram as variações durante os intervalos glaciais em termos de circulação de águas profundas. Puderam concluir que uma maior proporção de águas de fundo originadas ao sul entrara na porção oeste do Atlântico Sul durante o último máximo glacial, em resposta a um declínio da componente norte.

Os dados da razão dos isótopos de carbono em foraminíferos bentônicos (Figura 26) mostraram valores baixos na composição da água, coincidindo com o aumento das velocidades nas correntes de fundo, sugerindo maiores velocidades de paleocorrentes profundas, concomitante à penetração e domínio das águas provenientes da componente sul durante os períodos glaciais. 


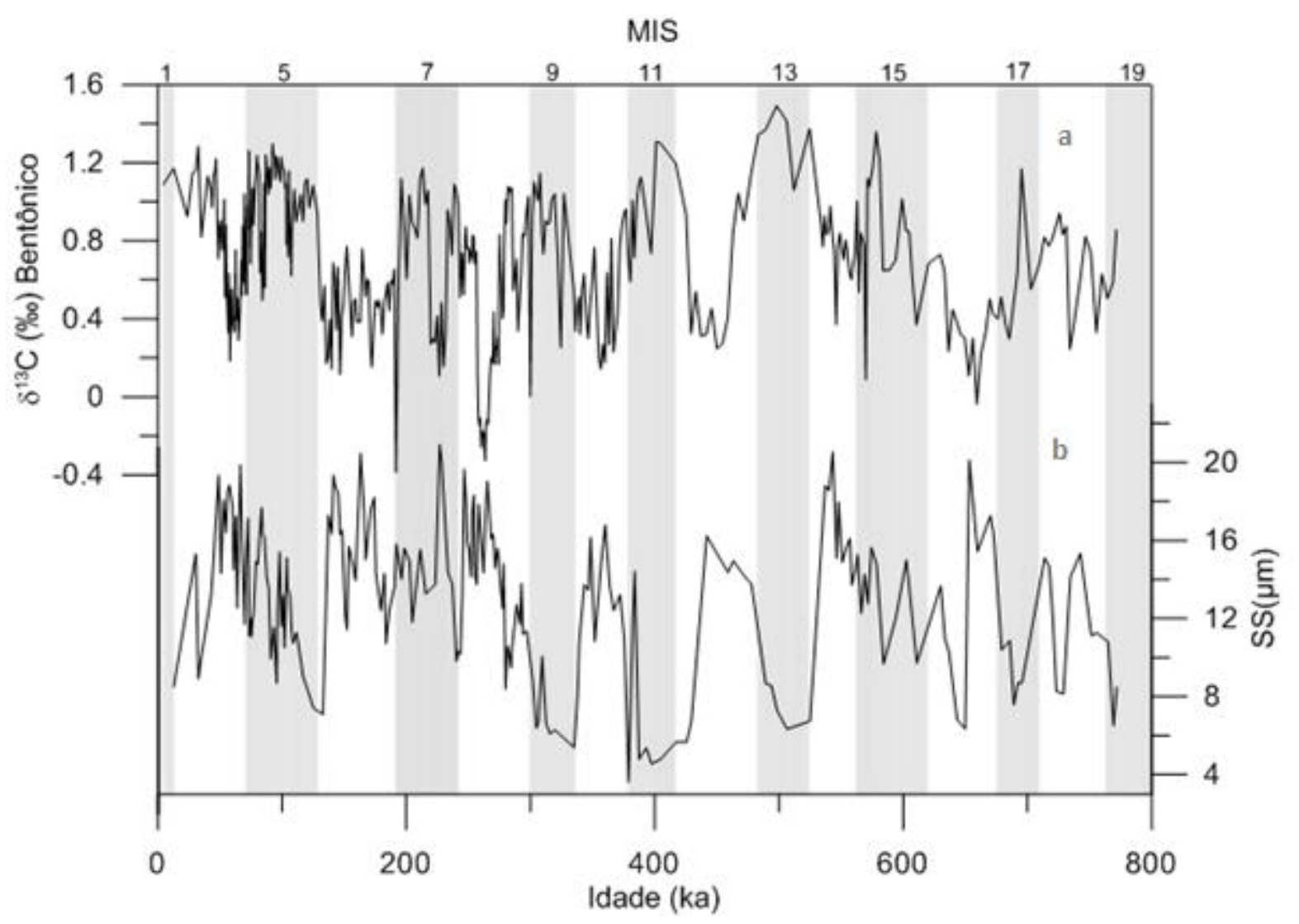

Figura 26: Comparação entre a (a) razão dos isótopos de carbono com o (b) Sortable Silt a laser. Assinalado em cinza estão os estágios isotópicos interglaciais.

Nos intervalos glaciais a partir do MIS 8, ocorrem episódio em que a massa de água de fundo apresenta teores valores de isótopos de carbono menores, sugerindo uma contribuição maior da componente sul, junto à retomada das maiores velocidades de paleocorrentes.

O conteúdo de carbonato foi maior nas terminações glaciais apresentando picos evidentes, contudo o conteúdo de carbonato nos interglaciais é maior quando comparado aos glaciais (Figura 27). A velocidade média das correntes de fundo apresentou um comportamento mais intenso durante os períodos glaciais com exceção do MIS 7, período interglacial. Mesmo período que apresentou menor conteúdo de carbonato. Parte do MIS 7 foi marcado por um rápido retorno de dominância na composição de águas da componente sul (Figura 26) mesmo em um período interglacial, responsável pela corrosão de parte do material carbonático (GONZALES et al., 2017). 


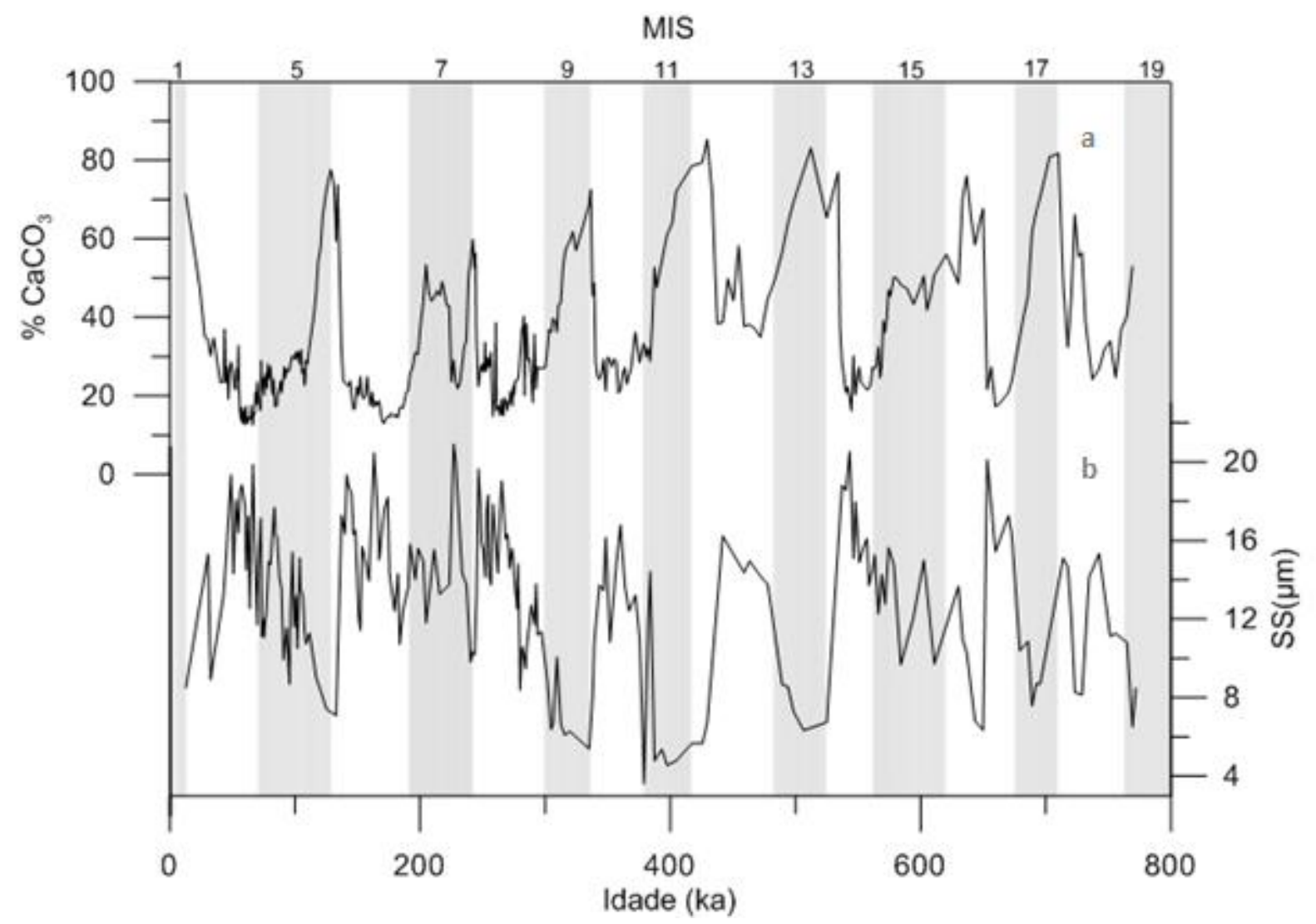

Figura 27: Curva do (a) Teor de carbonato e (b) do Sortable Silt. Assinalado em cinza estão os estágios isotópicos interglaciais.

\subsection{Componentes Orbitais}

O testemunho estudado contempla o final da transição do Pleistoceno Médio (MPT, sigla em inglês para Mid Plistocene Transition), 1250-700 ka, refere-se a mudança do regimento e influência dos ciclos astronômicos, onde a componente dominante deixa de ser de 41 mil anos do Plioceno superior e Pleistoceno inferior e passa a ser regido por ciclos de 100 mil anos, nos últimos 700-650 mil anos. O MPT e a Transição do Pleistoceno tardio (LPT, Late Pleistocene Transition) designa os estágios finais de uma transição de 50 milhões de anos desde o ótimo climático do Eoceno para os períodos glaciais mais frios do Cenozoico, onde os ciclos eram mais 
curtos, com períodos em torno de 41 mil anos (IMBRIE et al., 1984). A partir dos últimos 700 mil anos e observado um distinto prolongamento entre os ciclos glaciais e interglaciais, iniciando se os ciclos de 100 mil anos, possibilitando a existência de três estágios distintos, condições interglaciais completas, condições glaciais leves (MIS 3) e condições glaciais máximas (MIS 2).

Nas análises de frequências aplicadas nos isótopos de oxigênio, susceptibilidade magnética e no Sortable Silt (Figura 28) evidenciam tal comportamento, dessa nova era regida pelos ciclos de aproximadamente 100 mil anos. Observado um sinal forte e bem definido representando o ciclo em torno de 100 mil anos para as três análises, e dois picos de menor intensidade e não tão bem definidos associado a ciclos de $41 \mathrm{mil}$ anos e 23 mil anos para as frequências dos isótopos de oxigênio. Entretanto as alterações no regime de ciclicidade de um período regido por ciclos de 41 mil anos (Obliquidade) para os períodos regidos por ciclos de 100 mil anos (Excentricidade) não foram evidenciados no Sortable Silt e na susceptibilidade magnética. As frequências do Sortable Silt apresentaram uma forte representatividade para eventos de maior magnitude. 


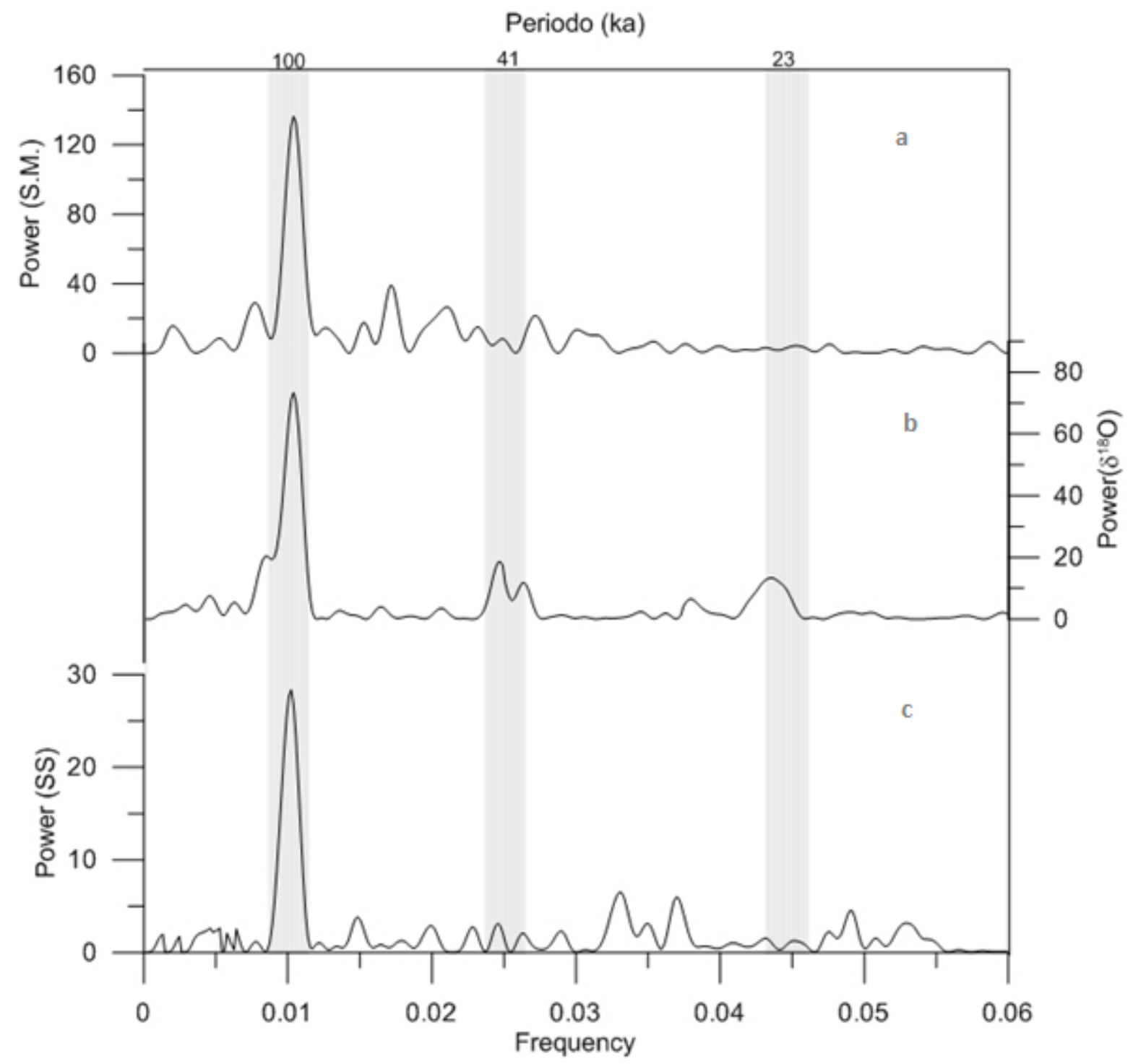

Figura 28: Análise de frequências para: (a) Susceptibilidade magnética, (b) isótopos de oxigênio e (c) Sortable Silt a laser. Os períodos marcados em cinza correspondem a 100, 41 e 23 mil anos da esquerda para a direita.

Os MIS 11 e 9 apresentaram os menores valores para a velocidade das correntes de fundo (Figura 27), que corresponde ao Evento Brunhes Medio (Mis Brunhes Event, MBE), que está centrado em torno de 400 mil anos, correspondendo ao intervalo entre o MIS 11 e 9, que coincide com o aumento global da produção de carbonato dos sedimentos.

A partir de estudos de sedimentos pelágicos (FARIDUDDIN; LOUBERE, 1997; SCHMIEDL; MACKENSEN, 1997; HAYASHI et al., 2013) é possível aferir que o MIS 8 foi um marco local para as alterações da sedimentação pelágica em escala 
planetária, a partir desse estagio foi possível observar mudanças significativas nas composições dos depósitos, resultado de um rearranjo ecológico em virtude de alterações no padrões físicos e químicos da água, devido a alterações em composições de massas de água ao longo de toda a coluna. Entre o MIS 7 e 6 ocorreu a redução gradativa da paleoprodutividade primaria superficial pela primeira vez desde o MIS 15, onde a temperatura do mar foi relativamente mais elevada considerando a média entre um estágio interglacial e outro glacial (EMILIANI, 1955), tais eventos não foram observados no registro de velocidade sugerindo que não são sensíveis para o Sortable Silt. 


\section{Conclusão}

Com base no registro sedimentar do testemunho KF18 da Bacia de Santos, foi possível avaliar o comportamento da velocidade das correntes de fundo ao longo dos últimos 800 mil anos, proporcionando informações paleoceanograficas que devem complementar o registro evolutivo oceanográfico da região.

As interpretações utilizando o Sortable Silt possibilitaram monitorar a variação das velocidades das correntes de fundo entre os períodos glaciais e interglaciais, estipulando um padrão de velocidades maiores paras os períodos glaciais e menores para os períodos interglaciais.

O núcleo da NADW seria menos profundo que atualmente, portanto a base da componente norte estaria mais próxima da profundidade dos testemunhos, caracterizando assim uma maior mistura entre águas da componente norte e sul. Utilizando o modelo conceitual da velocidade resultante, no qual dois fluxos de velocidades diferentes em sentidos opostos apresentam uma resultante inferior as componentes da velocidade e considerando os estágios interglaciais como sendo o ponto de equilíbrio, no qual apresenta tanto a componente norte e sul na resultante da velocidade, podendo se teorizar sobre o fato de que que a componente norte é de maior intensidade, sendo desacelerada pela componente sul.

Durante os períodos interglaciais a componente norte apresenta dominância na composição das águas profunda da região de acordo com a assinatura isotópica de carbono (Figura 26). No cenário glacial, no qual a componente norte é enfraquecida decorrente do enfraquecimento da AMOC, ocasionando uma dominância da componente sul, apresentando assim velocidades maiores, podendo ser devido a diminuição do efeito da desaceleração. Comparativamente podemos inferir que a velocidade da componente norte é maior que a da componente sul, porém para uma maior certeza é necessário um estudo mais aprofundado considerando a direção de deposição dos grãos. 
No caso de eventos de menor duração entre os ciclos glaciais e interglaciais o traçador determinado a partir da análise a laser, apresentou sinais que possivelmente estão associados a eventos importantes ao longo do período como: o MBE entre os MIS 11 e 9, indicando as menores velocidades médias; apresentou uma boa resposta com um pico de velocidade à um evento dominado por águas da componente sul durante o período interglacial equivalente ao MIS 7; e o evento anteriormente mencionado no MIS 5.Em resumo, a partir da contrução do índice do Sortable Silt com uma maior resolução, análise a laser, alterações em eventos de menor duração são perceptíveis. No caso de baixas resoluções na contrução do índice, técnica da pipetagem, devem ser restritos apenas a eventos de grande magnitude.

Para as interferências, são necessários mais estudos para determinar a magnitude no Sortable Silt. Por mais que tais interferências não tenham sido detalhadas nesse presente estudo, a quantificação seria de suma importância para a melhoria da proxy, que até o dado momento não se encontra perfeitamente calibrado.

O Sortable Silt evidenciou o comportamento induzido pelas variações astronômicas, permitindo evidenciar a influência dos períodos de 100 mil anos (Excentricidade) na região.

Em termos gerais, o Sortable Silt demonstrou uma boa eficiência no auxílio para a reconstrução paleoceanografica em conjunto com os demais traçadores, com mais estudos relacionados a empregabilidade do Sortable Silt e uma calibração mais precisa é possível prever um futuro promissor para o uso da proxy, abrindo um leque de opções. 


\section{Referências bibliográficas}

AUFFRET, G.; ZARAGOSI, S.; DENNIELOU, B.; CORTIJO, E.; ROOIJ, V.; D., G.; F., P.; C., E.; F., S.; M. Terrigenous uxes at the Celtic margin during the last glacial cycle. Marine Geology, v. 3121, p. 1-30, 2002.

BROECKER, W. S. Chaotic Climate. Scientific American - SCI AMER, v. 273, p. 6268, 1995.

BROECKER, W. S.; DENTON, G. H. The role of ocean-atmosphere reorganizations in glacial cycles. Quaternary Science Reviews, v. 9, n. 4, p. 305-341, 1990.

BROECKER, W. S.; TAKAHASHI, T.; TAKAHASHI, T. Sources and flow patterns of deep-ocean waters as deduced from potential temperature, salinity, and initial phosphate concentration. Journal of Geophysical Research, v. 90, n. C4, p. 69256939, 1985.

CAMPOS, E. J. D.; LENTINI, C. A. D.; MILLER, J. L.; PIOLA, A. R. Interannual variability of the sea surface temperature in the South Brazil Bight. Geophysical Research Letters, v. 26, n. 14, p. 2061-2064, 1999.

CARVALHO, C. V. D. A. Simulação de transporte e deposição de sedimentos siliciclásticos em ambientes de plataforma, talude e bacia. 2002. PUC-RIO PONTIFÍCIA UNIVERSIDADE CATÓLICA DO RIO DE JANEIRO, 2002.

CIRANO, M.; MATA, M. M.; CAMPOS, E. J. D.; DEIRÓ, N. F. R. A circulação oceânica de larga-escala na região oeste do Atlântico Sul com base no modelo de circulação global occam. Revista Brasileira de Geofisica, v. 24, n. 2, p. 209-230, 2006.

CONTI, L. A.; FURTADO, V. V. Geomorfologia da plataforma continental do Estado 
de São Paulo. Revista Brasileira de Geociências, v. 36, n. 2, p. 305-312, 2006.

CURRY, W. B.; OPPO, D. W. Glacial water mass geometry and the distribution of ?? 13C of ??CO2 in the western Atlantic Ocean. Paleoceanography, v. 20, n. 1, p. 1-12, 2005.

DE ALMEIDA, F. K.; DE MELLO, R. M.; COSTA, K. B.; TOLEDO, F. A. L. The response of deep-water benthic foraminiferal assemblages to changes in paleoproductivity during the Pleistocene (last 769.2kyr), western South Atlantic Ocean. Palaeogeography, Palaeoclimatology, Palaeoecology, v. 440, p. 201-212, 2015.

DUARTE, C. S. L.; VIANA, a. R. Santos Drift System: stratigraphic organization and implications for late Cenozoic palaeocirculation in the Santos Basin, SW Atlantic Ocean. Geological Society, London, Special Publications, v. 276, p. 171-198, 2007.

EMILIANI, C. Pleistocene Temperatures. The Journal of Geology, v. 63, n. 6, p. 538578, 1955.

FARIDUDDIN, M.; LOUBERE, P. The surface ocean productivity response of deeper water benthic foraminifera in the Atlantic Ocean. Marine Micropaleontology, v. 32, n. 3-4, p. 289-310, 1997.

FRENZ, M.; HOPPNER, R.; STUUT, J.-B. W.; WAGNER, T.; HENRICH, R. Surface sediment bulk geochemistry and grain-size composition related to the oceanic circulation along the South American continental margin in the southwest Atlantic. [s.l: s.n.]

GHIL, M. Advanced spectral methods for climatic time series. Reviews of Geophysics, v. 40, n. 1, p. 1003, 2002. 
GONZALES, M. V.; DE ALMEIDA, F. K.; COSTA, K. B.; SANTAROSA, A. C. A.; CAMILLO, E.; DE QUADROS, J. P.; TOLEDO, F. A. L. HOEGLUNDINA ELEGANS PRESERVATION FOR MARINE SEDIMENTS IN THE WESTERN SOUTH ATLANTIC. The Journal of Foraminiferal Research, v. 47, n. 1, p. 56-69, 2017.

GORDON, A. L. Interocean exchange of thermocline water. Journal of Geophysical Research, v. 91, n. C4, p. 5037, 1986.

HALL, I. R.; MCCAVE, I. N.; ZAHN, R.; CARTER, L.; KNUTZ, P. C.; WEEDON, G. P. Paleocurrent reconstruction of the deep Pacific inflow during the middle Miocene: Reflections of East Antarctic Ice Sheet growth. Paleoceanography, v. 18, n. 2, p. n/an/a, 2003.

HAYASHI, H.; IDEMITSU, K.; WADE, B. S.; IDEHARA, Y.; KIMOTO, K.; NISHI, H.; MATSUI, H. Middle miocene to pleistocene planktonic foraminiferal biostratigraphy in the eastern equatorial Pacific Ocean. Paleontological Research, v. 17, n. Figure I, p. 91-109, 2013.

HENDERSON, G. M.; ANDERSON, R. F. The U-series toolbox for paleoceanography. Reviews in Mineralogy and Geochemistry, v. 52, n. 1, p. 493-531, 2003. IMBRIE, J.; HAYS, J. D.; MARTINSON, D. G.; MCINTYRE, A.; MIX, A. C.; MORLEY, J. J.; PISIAS, N. G.; PRELL, W. L.; SHACKLETON, N. J. The orbital theory of Pleistocene climete:support from a revised chronolgy of the marine $\delta 180$ record. Milankovitch and Climate (Part 1), p. 269-305, 1984.

KOWSMANN, R.; COSTA, M. Sedimentação quaternária da margem continental brasileira e das áreas oceânicas adjacentes. - In: Projeto REMAC - Reconhecimento Global da Margem Continental Brasileira. Rio de Janeiro, Petrobrás, Cenpes, 
Dintep, v. 8, p. 1-55, 1 jan. 1979.

KRISSEK, L. A. Essentials of oceanography. 12. ed. [s.l: s.n.]v. 57

LIMA, R. M. F.; LUZ, J. A. M. da. Análise granulométrica por técnicas que se baseiam na sedimentação gravitacional: Lei de Stokes. Rem: Revista Escola de Minas, v. 54, n. 2, p. 155-159, jun. 2001.

LISIECKI, L. E.; RAYMO, M. E. A Pliocene-Pleistocene stack of 57 globally distributed benthic ?? 180 records. Paleoceanography, v. 20, n. 1, p. 1-17, 2005.

LÜTHI, D.; LE FLOCH, M.; BEREITER, B.; BLUNIER, T.; BARNOLA, J.-M.; SIEGENTHALER, U.; RAYNAUD, D.; JOUZEL, J.; FISCHER, H.; KAWAMURA, K.; STOCKER, T. F. High-resolution carbon dioxide concentration record 650,000800,000 years before present. Nature, v. 453, n. 7193, p. 379-382, 2008.

MAHIQUES, M. M.; DA SILVEIRA, I. C. A.; DE MELLO E SOUSA, S. H.; RODRIGUES, M. Post-LGM sedimentation on the outer shelf-upper slope of the northernmost part of the São Paulo Bight, southeastern Brazil. Marine Geology, v. 181, n. 4, p. 387-400, 2002.

MAHIQUES, M. M.; TESSLER, M. G.; MARIA CIOTTI, A.; DA SILVEIRA, I. C. A.; E SOUSA, S. H. D. M.; FIGUEIRA, R. C. L.; TASSINARI, C. C. G.; FURTADO, V. V.; PASSOS, R. F. Hydrodynamically driven patterns of recent sedimentation in the shelf and upper slope off Southeast Brazil. Continental Shelf Research, v. 24, n. 15, p. 1685-1697, 2004.

MAHIQUES, M. M. de; TASSINARI, C. C. G.; MARCOLINI, S.; VIOLANTE, R. A.; FIGUEIRA, R. C. L.; DA SILVEIRA, I. C. A.; BURONE, L.; DE MELLO E SOUSA, S. $\mathrm{H}$. Nd and $\mathrm{Pb}$ isotope signatures on the Southeastern South American upper margin: 
Implications for sediment transport and source rocks. Marine Geology, v. 250, n. 12, p. 51-63, 2008.

MILLIMAN, J. D. Morphology and Structure of Upper Continental Margin Off Southern Brazil. AAPG Bulletin (American Association of Petroleum Geologists), v. 62, p. 1029-1048, 1978.

MOLYNEUX, E. G.; HALL, I. R.; ZAHN, R.; DIZ, P. Deep water variability on the southern Agulhas Plateau: Interhemispheric links over the past $170 \mathrm{ka}$. Paleoceanography, v. 22, n. 4, p. 1-14, 2007.

NAGAI, R. H.; FERREIRA, P. A. L.; MULKHERJEE, S.; MARTINS, M. V.; FIGUEIRA, R. C. L.; SOUSA, S. H. M.; MAHIQUES, M. M. Hydrodynamic controls on the distribution of surface sediments from the southeast South American continental shelf between $23^{\circ} \mathrm{S}$ and $38^{\circ} \mathrm{S}$. Continental Shelf Research, v. 89, p. 51-60, 2014.

PETERSON, R. G.; STRAMMA, L. Upper-level circulation in the South Atlantic Ocean. Progress in Oceanography, v. 26, n. 1, p. 1-73, 1991.

PIMENTA, F.; CAMPOS, E.; L. MILLER, J.; PIOLA, A. Numerical study of the Plata River plume along the southeastern South American continental shelf. [s.I: s.n.]v. 53

PIOLA, A. R.; E, C.; DONNERS, JOHN GORDON, A. L.; NOF, D. The South Atlantic contribution to the global thermohaline circulation. p. 30-38, 2003.

PIOLA, A. R.; MATANO, R. P.; PALMA, E. D.; MÖLLER, O. O.; CAMPOS, E. J. D. The influence of the Plata River discharge on the western South Atlantic shelf. Geophysical Research Letters, v. 32, n. 1, p. 1-4, 2005.

RAWLE, A.; LIMITED, M. I.; PARK, E. B.; ROAD, G. Basic Principles of Particle. 
Surface Coatings International Part A Coatings Journal, v. 44, n. 0, p. 1-8, 2003. RAZIK, S.; GOVIN, A.; CHIESSI, C. M.; VON DOBENECK, T. Depositional provinces, dispersal, and origin of terrigenous sediments along the SE South American continental margin. Marine Geology, v. 363, p. 261-272, 2015.

RINTOUL, S. R. South Atlantic Interbasin Exchange. J. Geophys. Res., v. 96, p. 2675-2692, 1991.

SCHMIEDL, G.; MACKENSEN, A. Late Quaternary paleoproductivity and deep water circulation in the eastern South Atlantic Ocean: Evidence from benthic foraminifera. Palaeogeography, Palaeoclimatology, Palaeoecology, v. 130 , n. $1-4$, p. $43-80$, 1997.

SCHULZ, M.; STATTEGGER, K. Spectrum: spectral analysis of unevenly spaced paleoclimatic time series. Computers \& Geosciences, v. 23, n. 9, p. 929-945, 1997. SHILLABEER, N.; HART, B.; RIDDLE, A. M. The use of a mathematical model to compare particle size data derived by dry-sieving and laser analysis. Estuarine, Coastal and Shelf Science, v. 35, n. 1, p. 105-111, 1992.

SILVEIRA, I. C. A. da; SCHMIDT, A. C. K.; CAMPOS, E. J. D.; GODOI, S. S. de; IKEDA, Y. A corrente do Brasil ao largo da costa leste brasileira. Brazilian Journal of Oceanography, v. 48, n. 2, 2000.

STRAMMA, L. The Brazil current transport south of $23^{\circ} \mathrm{S}$. Deep Sea Research Part A, Oceanographic Research Papers, v. 36, n. 4, p. 639-646, 1989.

STRAMMA, L.; IKEDA, Y.; PETERSON, R. G. Geostrophic transport in the Brazil current region north of $20^{\circ}$ S. Deep Sea Research Part A, Oceanographic Research Papers, v. 37, n. 12, p. 1875-1886, 1990. 
SUGUIO, K. Introdução à sedimentologia. São Paulo, Edgar Blucher / EDUSP, p. $317,1973$.

TEGZES, A. D.; JANSEN, E.; TELFORD, R. J. Which is the better proxy for paleocurrent strength: Sortable-silt mean size (S S ??) or sortable-silt mean grain diameter (dSS)? A case study from the Nordic Seas. Geochemistry, Geophysics, Geosystems, v. 16, n. 10, p. 3456-3471, 2015.

TEIXEIRA, W. .; TOLEDO, M. C. M. D.; FAIRCHILD, T. R. .; TAIOLI, F. Decifrando a TerraDecifrando a Terra, 2000. .

TOLEDO, F. A. L.; QUADROS, J. P.; CAMILLO, E.; SANTAROSA, A. C. A.; FLORES, J. A.; COSTA, K. B. Plankton biochronology for the last 772,000??years from the western South Atlantic Ocean. Marine Micropaleontology, v. 127, p. 50-62, 2016.

TOMCZAK, M.; GODFREY, J. S. Regional Oceanography: An Introduction. 2. ed. Delhi: Daya Publishing House, 2005.

WAELBROECK, C.; LABEYRIE, L.; MICHEL, E.; DUPLESSY, J. C.; MCMANUS, J. F. Sea-level and deep water temperature changes derived from benthic foraminifera isotopic records. v. 21, p. 295-305, 2002.

WALLACE, J. M.; HOBBS, P. V. Atmospheric Science: An Introductory Survey. [s.l: s.n.]v. 92 
